\title{
WestVirginiaUniversity
}

THE RESEARCH REPOSITORY @ WVU

Graduate Theses, Dissertations, and Problem Reports

2019

\section{Three Essays in Applied Econometrics}

Collin Dean Hodges

West Virginia University, cdhodges@mix.wvu.edu

Follow this and additional works at: https://researchrepository.wvu.edu/etd

Part of the Health Economics Commons, Public Economics Commons, and the Regional Economics

Commons

\section{Recommended Citation}

Hodges, Collin Dean, "Three Essays in Applied Econometrics" (2019). Graduate Theses, Dissertations, and Problem Reports. 4067.

https://researchrepository.wvu.edu/etd/4067

This Dissertation is protected by copyright and/or related rights. It has been brought to you by the The Research Repository @ WVU with permission from the rights-holder(s). You are free to use this Dissertation in any way that is permitted by the copyright and related rights legislation that applies to your use. For other uses you must obtain permission from the rights-holder(s) directly, unless additional rights are indicated by a Creative Commons license in the record and/ or on the work itself. This Dissertation has been accepted for inclusion in WVU Graduate Theses, Dissertations, and Problem Reports collection by an authorized administrator of The Research Repository @ WVU.

For more information, please contact researchrepository@mail.wvu.edu. 


\title{
Three Essays in Applied Econometrics
}

\author{
Collin Dean Hodges
}

Dissertation submitted to the Davis College of Agriculture, Natural Resources and Design at West Virginia University

in partial fulfillment of the requirements for the degree of Doctor of Philosophy in the Division of Resource Economics and Management

\author{
Heather Stephens, Ph.D., Chair \\ Joshua Hall, Ph.D. \\ Daniel Grossman, Ph.D. \\ Xiaoli Etienne, Ph.D. \\ Department of Resource Economics and Management
}

Morgantown, West Virginia

2019

Keywords: health economics, public economics, obesity, opioids, municipal incorporation Copyright 2019 Collin Hodges 


\section{Abstract \\ Three Essays in Applied Econometrics \\ Collin Dean Hodges}

The body of work presented here consists of a collection of research projects developed during my time as a graduate student at West Virginia University. As will soon become apparent, this collection of research topics is quite eclectic. This is, in part, due to the to the nature of the research process itself--where one often begins by asking one question and ends by answering a completely different one--but also due to the fact that my time at West Virginia University has provided me the opportunity to gain insight into a wide variety of economic fields as well as work on a variety of interesting and exciting projects. In any case, it is my hope that the diversity of topics will not overly impair the reader's enjoyment of what I believe to be otherwise interesting explorations of timely research questions.

Chapter 1 presents research examining the connection between socioeconomic status and obesity in the United States. Though this relationship has been firmly established in the literature, little attention has been paid to what effect a change in socioeconomic status has on obesity prevalence. As part of the "American Dream" is socioeconomic mobility, it remains an interesting and, to date, little examined research question: what impact does a change in socioeconomic status have on an individual's obesity? Analysis conducted utilizing a confidential, geo-coded and nationallyrepresentative sample of individuals from the National Longitudinal Survey of Youth suggest that individuals who move from a lower to a higher socioeconomic group are less likely to be obese. This suggests that upward socioeconomic movement has multiple, positive effects that manifest in better health outcomes.

In Chapter 2 we shift away from health outcomes research and instead examine a public economics question related to municipal government formation and property values, namely: what impact does municipal incorporation - that is, new city formation - have on residential property values? Though the literature contains several examples of research examining the effect of special municipal districts on property values - such as home owner's associations and school districtsvery little research exists examining the effect of new city formation on property values. Analysis 
conducted on four new cities in Riverside County, California using fifteen years of housing transactions data suggests that, in contrast to previous research, municipal incorporation did not result in an increase in housing values. The chapter concludes with a discussion of the potential regional factors contributing to this interesting result.

Chapter 3 circles back to health economics research by examining another ongoing public health crisis in the United States: the opioid epidemic. The State of West Virginia has the highest rate of drug overdose deaths in the nation, with opioid overdose deaths accounting for the overwhelming majority of overdose deaths in the state. Thus, it is unsurprising that West Virginia and the greater Appalachian area in general, are generally considered to be "ground zero" of the national opioid epidemic. That said, previous research examining this complex issue has utilized aggregated death certificate data that inherently precludes an individual-level component to any econometric analysis. The analysis presented in this chapter, however, is based on confidential, individual-level death certificate data obtained from the state of West Virginia and represents the first analysis conducted at the individual level. This micro-level data allows for the examination of both the individual and sub-county local characteristics associated with opioid overdose deaths across the state. Analysis of these West Virginian death certificates suggests that individual employment in certain industries - such as coal mining and construction - is associated with a higher risk of opioid overdose death. Results also suggest that medication diversion across several different medical professions is potentially contributing to opioid deaths in those industries. Further, a spatial analysis of the effect of industry-specific employment growth across zip codes generates results suggesting that the effect of local employment growth on opioid overdose deaths varies both across industries and space. The chapter concludes with some brief comments and discussion of potential policy implications. 


\section{Acknowledgements}

First and foremost, thank you to the members of my dissertation committee, Heather Stephens, Joshua Hall, Daniel Grossman and Xiaoli Etienne for their research feedback and guidance navigating the academic job market. The pay was zero and the work non-zero, but for your willingness to serve as members of my committee, I will remain always grateful.

Heather, thank you for your assistance in obtaining what, at times, seemed to be impossible to obtain datasets and for always being generous with your time. To Josh, thank you for your frequent guidance, the numerous opportunities to gain valuable academic experiences, and your support throughout my graduate career. There is no question that I would not be here today without your support. To Dan, thank you for the part you played in introducing me to the field of health economics. I consider myself very fortunate to have been a part of the initial offering of these fascinating field courses at West Virginia University. To Xiaoli, thank you for your constructive comments and feedback, as well as for setting the bar high with regard to article reading. I have not quite reached your level of one article a day.

I would also like to thank my undergraduate professors, Pete Calcagno, Malavika Nair and Doug Walker, for their initial suggestion that I look further into this whole "graduate school" thing. Your amazing classes at the College of Charleston are why I am where I am today. Pete, thank you for your friendship, guidance, the great work you continue to do with the Center for Public Choice and Market Process and the numerous opportunities you provide for undergraduate students to engage with economics ideas outside of the classroom. To Mal, thank you for being the first to encourage me to pursue a graduate degree. It was certainly something that, at the time, seemed well beyond my reach. To Doug, thank you for your friendship and advice over the years. I look forward to catching up with you and Pete in Charleston very soon.

I also must, of course, thank my occasional office-mates and friends, Elham Erfanian and Caleb

Stair. Elham, I am exceedingly grateful that you possess a healthy and, apparently, inexhaustible sense of humor. Thank you for sharing your eternal optimism with me and for always having a 
smile on your face. Caleb, you are a character. If your adventures in wildlife economics do not lead to your being consumed by sharks or alligators, then I hope you will continue to entertain me with your stories in the future. Thank you both for your friendship, your confidence and for all the laughs.

Thank you also to my Charleston friends, who always welcomed me home as if we had never been apart. You will never know how much your friendships have meant, and continue to mean, to me. I could not ask for a better group of people to call my friends. I look forward to having many more visits and adventures with you all in the near future.

Finally, to my parents, Michael and Sarah Hodges, thank you for providing me the opportunity to learn, grow and pursue a variety of different interests over the course of my life. Any child would consider themselves fortunate to have been raised as your son, but I am thankful that I was the one to enjoy such a privilege. To my mother, one final note: I look forward to making your eyes roll when I insist that you refer to me as, "Dr. Hodges." 


\section{Table of Contents}

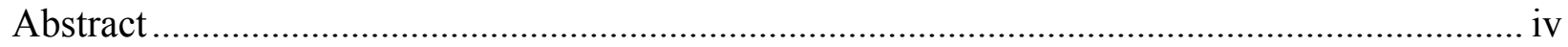

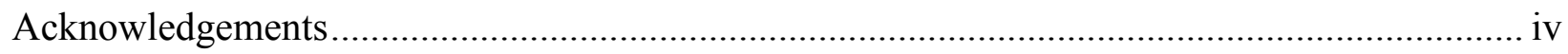

1.1 The Impact of Changes in Socioeconomic Status on Obesity Prevalence: Introduction .......... 1

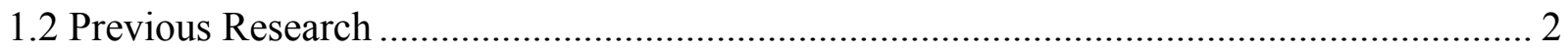

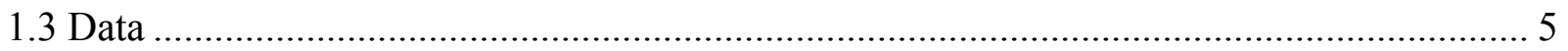

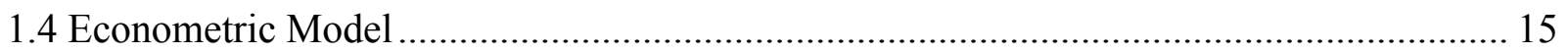

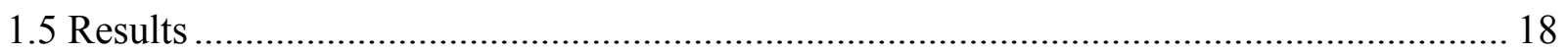

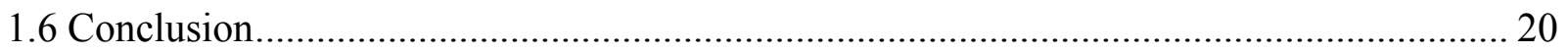

2.1 The Impact of Municipal Incorporation on Property Values: Introduction............................. 21

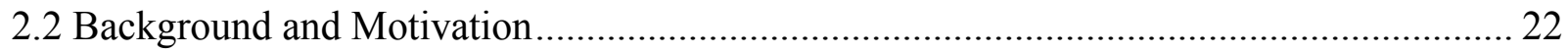

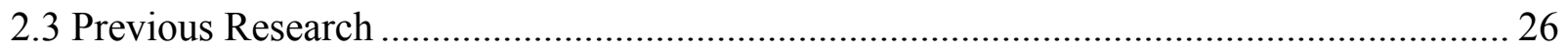

2.4 Process of Municipal Incorporation in California......................................................... 28

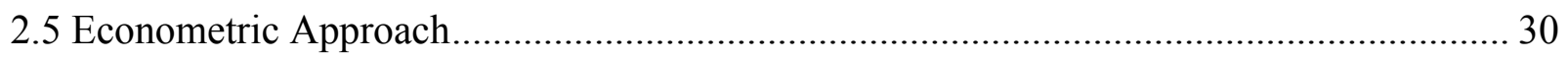

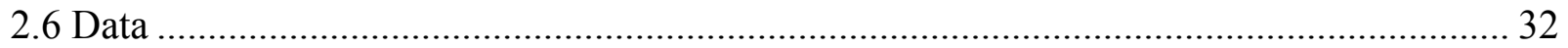

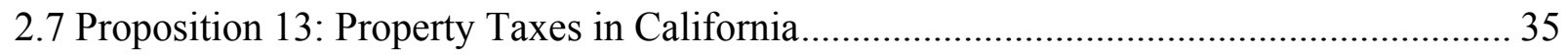

2.8 Coarsened Exact Matching (CEM) and Counterfactual Sales ............................................ 40

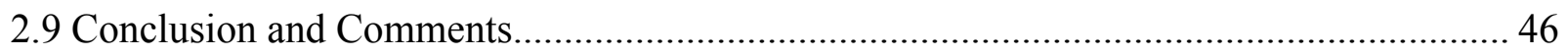

3.1 West Virginia Death Certificate Analysis; Coal Country and the Opioid Crisis: Introduction

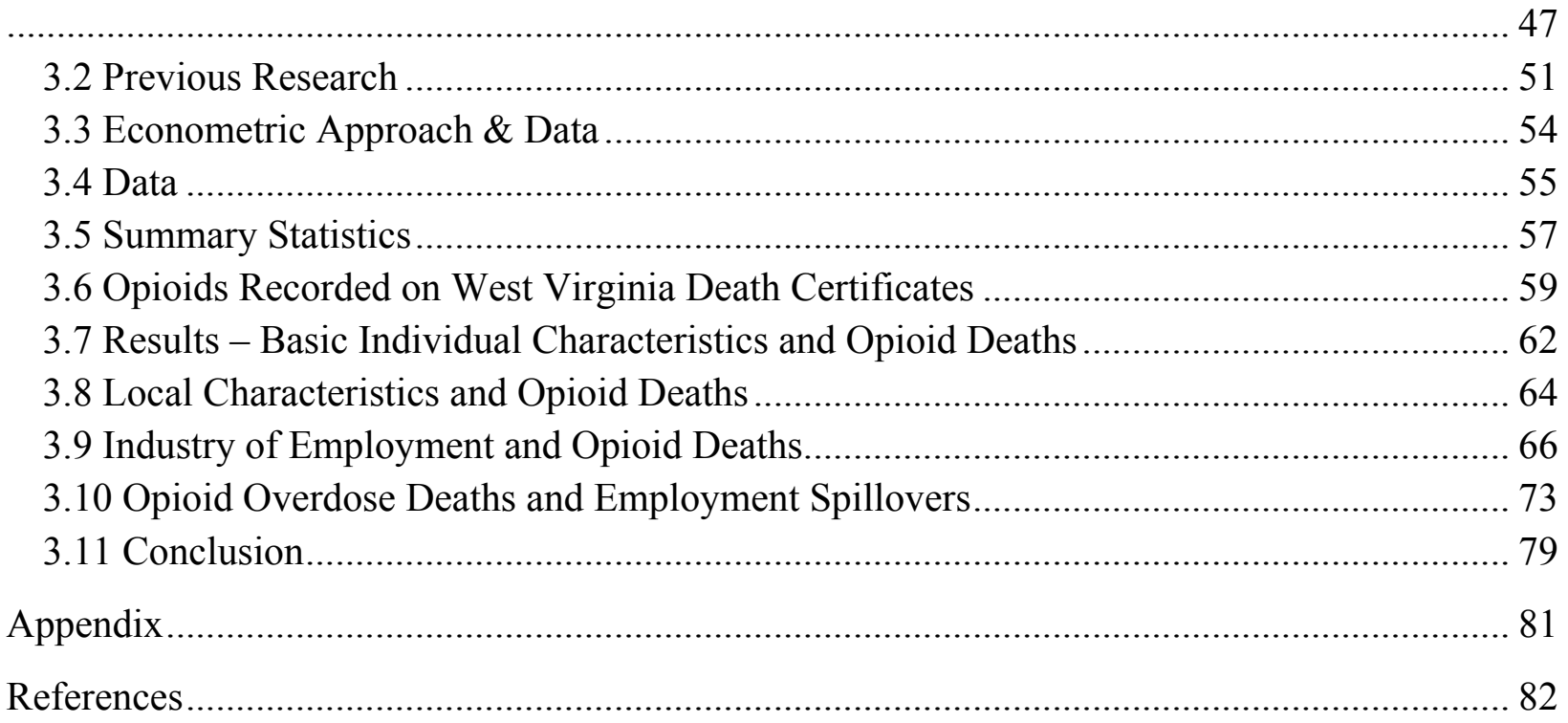




\subsection{The Impact of Changes in Socioeconomic Status on Obesity Prevalence: Introduction}

The prevalence of obesity in the U.S. remains a serious public health concern. In 1994, approximately $30 \%$ of U.S. adults ages 20 or older and $10 \%$ of U.S. youths ages 2-19 were obese. By 2014 , that number had risen to nearly $40 \%$ for U.S. adults and $17 \%$ for U.S. youth. ${ }^{1}$ Obesity related health conditions, which include type 2 diabetes, heart disease, stroke, and certain kinds of cancer are among the leading causes of preventable death in the United States. Indeed, obese individuals 40 years of age may experience shorter lifespans compared to those of normal weight, with estimates ranging from 3 to 13 years less (Kinge and Morris, 2014). In 2014, the estimated annual medical cost of U.S. obesity was almost $\$ 150$ billion, with individual annual medical costs for those with obesity over $\$ 1400$ higher than those of normal weight. ${ }^{2}$ Additionally, the overall economy suffers due to lost productivity caused by employee absenteeism and premature death (Goettler et al. 2017). Estimates of the national costs to employers due to obesity related health issues range from $\$ 5.5$ billion to $\$ 11.3$ billion annually (Cawley et al. $2007 \& 2008$, Andreyeva et al. 2014, Asay et al. 2016). Obesity has also been shown to increase the risk of personal bankruptcy (Guettabi and Munasib, 2015).

Previous research has shown that obesity affects some groups more than others and that different socioeconomic groups exhibit different rates of obesity (Ogden et al. 2010). As a result, the health and financial costs of obesity are borne by some groups more than others, with low socioeconomic status (SES) associated with higher rates of adult obesity.

In the U.S. and in other countries, parents often work hard to give their children a better life than they had. This is especially true among the working poor, who face challenges unique to their socioeconomic status during their pursuit of the "American Dream." This paper contributes to the literature by examining if achieving the "American Dream" - that is, improving one's individual socioeconomic status - translates into better health outcomes.

${ }^{1}$ Center for Disease Control: Prevalence of Overweight, Obesity, and Extreme Obesity Among Adults: United States, Trends 1960-1962 Through 2007-2008.

${ }^{2}$ Center for Disease Control, Adult Obesity Facts. 
Utilizing confidential data from the 1979 cohort of the National Longitudinal Survey of Youth, this paper investigates what, if any, differences in obesity exist between individuals who change SES groups and those who do not. ${ }^{3}$ The highest grade completed by the individual's mother is utilized as a proxy for childhood SES and the highest grade completed by the individual is utilized as a proxy for adult SES. ${ }^{4}$ The results suggest that individuals who move from a lower to a higher socioeconomic group are less likely to be obese. Further, the results vary by region, with larger effects being observed among individuals who were born in southern states.

\subsection{Previous Research}

A wealth of previous research has examined the connection between SES and health outcomes, including obesity. Baum and Ruhm (2009) utilize the highest grade completed by an individual's mother as a proxy for childhood SES and then investigate whether or not childhood SES is correlated with adult body weight, finding an inverse relationship. They also provide evidence that children of low SES are more likely than their counterparts to be obese in adulthood. Case et al. (2002) investigate whether or not the income gradients observed in adult health are connected to childhood circumstances. They conclude that one mechanism impacting a child's health status is the ability of that child's parents to address (via their specific SES characteristics) the onset of chronic conditions. This conclusion suggests that children from lower SES households are likely to enter adulthood in both a lower SES and with poorer health.

Marmot et al. (1991), studying a group of over 10,000 British civil servants, investigate possible correlations between social class and mortality from a variety of diseases by using grade of employment as a proxy for social class. They observe an inverse relationship between employment

\footnotetext{
${ }^{3}$ The U.S. Bureau of Labor Statistics offers data on several cohorts of survey subjects. The 1979 survey cohort was chosen due to it containing the longest continuous timeline of data collection.

${ }^{4}$ The use of maternal education as a proxy for childhood SES was previously utilized by Baum and Ruhm (2009).
} 
grade and the prevalence of angina, ischemia ${ }^{5}$, and symptoms of chronic bronchitis. Van den Berg et al. (2006) analyze the effects of early life economic conditions on historical individual mortality rates in the Netherlands by using exogenous macroeconomic conditions as an instrument for early life SES conditions. Their results suggest that the state of the business cycle at birth affects mortality later in life, with individuals born during a recession exhibiting increased mortality rates. These results are in line with other previous research that has documented a connection between early life SES and health and mortality in adulthood.

Disparities in health outcomes among U.S. adults of varying levels of educational attainment have also been well documented. Mokdad et al. (2001), referencing data collected by a random survey conducted by the Centers for Disease Control (CDC), find an inverse relationship between obesity and education, with $26 \%$ of high school dropouts being obese compared to $22 \%$ of high school graduates. Individuals in the survey identified as having completed either some college or having completed a college degree or higher show even lower levels of obesity: $20 \%$ and 15\% respectively. These trends carried over to more recent versions of the surveys conducted by the CDC as well. Cutler et al. (2010) also investigate the relationship between education and health behaviors, commonly referred to as the education gradient. They present evidence that approximately $30 \%$ of the gradient can be explained by income, insurance and family background, and $30 \%$ can be explained by individual knowledge and cognitive ability, with increased cognitive ability being correlated with positive health behaviors and outcomes.

However, little research has been conducted that examines how a change in socioeconomic status affects health outcomes. That said, research by Powell-Wiley et al. (2015) and Ludwig et al. (2011) provide some useful insights, although their samples are geographically and representatively limited. Powell-Wiley et al. (2015) construct a neighborhood level deprivation index (NDI) to examine the effect that moving to a more socioeconomically deprived neighborhood has on an

\footnotetext{
${ }^{5}$ Ischemia is the restriction of blood supply to tissues of the body. Ischemic heart diseaserestricted blood supply to the heart muscles--is a major cause of death in most Western countries (https://www.cdc.gov/heartdisease/facts.htm).
} 
individual's weight gain. ${ }^{6}$ They find that individuals who moved to areas of higher NDI-which indicates areas of higher socioeconomic deprivation-gained more weight than those who did not move, or those who moved to areas with a lower NDI ranking. Ludwig et al. (2011) utilize data from the U.S. Department of Housing and Urban Development's Moving to Opportunity program to examine the association of randomly assigned variations in neighborhood conditions with obesity and diabetes. They find some evidence that moving from a high-poverty to a low-poverty area is associated with a decreased risk of extreme obesity and diabetes. Regarding the limitations of the samples utilized in each study, we note that the Powell-Wiley study analyzed data for a single U.S. city (Dallas, Texas), while the Ludwig et al. study was limited to households from census tracts with poverty rates greater than $40 \%$ and who chose to participate in a rent subsidy voucher lottery.

Research evaluating the effectiveness of public policy prescriptions, such as community health initiatives, often consider the socioeconomic conditions of the communities in which these policies are implemented. Hughey et al. (2017) for example, while noting that parks and park features are important for promoting physical activity and healthy weight within communities, observe that the health outcomes varied significantly across individuals from varying socioeconomic backgrounds. Baum and Ruhm (2009) and Cutler et al. (2003) provide a framework that explains how SES might contribute to obesity and body weight. Body weight is impacted by energy intake and physical activity. If low childhood SES leads to the development of poor health habits - such as excessive calorie intake and low levels of physical activity - these habits may carry over into later periods of life and lead to increased weight gain during adulthood. Previous research also suggests that the safety concerns of individuals in low SES neighborhoods results in decreased levels of physical activity (Kneeshaw-Price et al. 2015, Meyer et al. 2014).

Conversely, if individuals with high childhood SES develop healthier habits and engage in higher levels of physical activity, these behaviors might positively impact (in the normative sense) weight gain throughout later periods of life. Indeed, Whitaker et al. (1997) examine the impact of parental

\footnotetext{
${ }^{6}$ Powell-Wiley's neighborhood deprivation index was formed by considering 21 variables from the 2000 Census such as \% unemployed, \% female-headed households and $\%$ of households on public assistance.
} 
obesity on children and find evidence that parental obesity more than doubles the risk of adult obesity among children under the age of 10 . Currie et al. (2007) provide evidence that family lifestyle choices (such as nutrition) play an important role in determining child health outcomes.

This paper contributes to the previous research by using a nationally-representative sample to assess the impact of changes in SES on health outcomes. In other words, if someone born into low SES moves to a higher SES, are the negative health effects associated with low SES in any way mitigated by this upward socioeconomic movement? This is one question that we attempt to answer in this paper.

\subsection{Data}

The data utilized in this paper come from the 1979 cohort of the National Longitudinal Survey of Youth (NLSY), a nationally representative sample initially containing 12,686 young men and women who were between 14 and 22 years of age when they were first surveyed. ${ }^{7}$ Individuals were interviewed annually through 1994 and on a biennial basis thereafter. The survey collects a variety of information on each individual including data regarding physical and medical characteristics, health and lifestyle choices, family composition, as well as employment and income.

In addition to the publicly available NLSY79 data, we received access to the restricted-use, geocoded dataset that contains confidential information regarding the geographic location (U.S. county) of each individual in the survey during each year of data collection.

\section{Height, Weight, \& BMI}

The NLSY database includes information on body weight and height. In the NLSY79, data regarding body weight were collected during the following years: 1981, 1982, 1985, 1986, 1988, 1989, 1990, 1992, 1993, 1994, 1996, 1998, 2000, 2002, 2004, 2006, 2008, 2010, 2012 and 2014.

\footnotetext{
${ }^{7}$ National Longitudinal Surveys, U.S. Bureau of Labor Statistics, https://www.nlsinfo.org
} 
Data on the individual's height was collected in 1981, 1982 and 1985. Following previous research, we assume height is constant post-1985, as all individuals in the study were at least 20 years of age at that time (see e.g, Baum and Ruhm 2009).

Following the previous literature, we use body mass index (BMI) to calculate measures of obesity. Body Mass Index (BMI) is defined as weight in kilograms divided by height in meters squared and is calculated for each individual using the data from the survey. We recognize that, because BMI does not account for variations in muscle mass or fat distribution, it is less accurate than other medical measurements of body composition such as bioelectrical impedance analysis. However, it is used frequently in the medical community as a proxy for obesity. Following the descriptions provided by the Centers for Disease Control and the World Health Organization, obesity is defined as having a BMI greater than or equal to 30 , with class 3 obesity being defined as having a BMI greater than or equal to $40 .{ }^{89}$ Women who were pregnant during the survey year were excluded from the sample for that year.

Our measures of SES are also calculated using data from the survey. Following, Baum and Ruhm (2009) we use the individual's mother's highest grade completed as a proxy for childhood SES. This allows for the sample to be easily divided into three groups: low, medium, and high childhood socioeconomic status. These divisions are defined as an individual's mother having completed less than 12 years of schooling (low SES), 12 years of schooling (middle SES), or greater than 12 years of schooling (high SES), respectively. Ideally, we could have used data regarding family income during the individual's childhood as an alternative proxy for childhood socioeconomic status, but the NLSY79 does not contain questions capturing this information.

Another alternative proxy for childhood socioeconomic status is the highest grade completed by the individual's father. However, we chose to focus on maternal education due to previous research suggesting that maternal education is more strongly correlated with child health than the

\footnotetext{
${ }^{8} \mathrm{https}: / /$ www.cdc.gov/obesity/adult/defining.html

${ }^{9} \mathrm{http} / / / \mathrm{www}$. who.int/mediacentre/factsheets/fs311/en/
} 
educational attainment level of fathers. ${ }^{10}$ Further, Baum and Ruhm (2009), utilizing the same NLSY dataset, experiment with a number of different proxies-including the presence/absence of a father in the household at age 14 , as well as paternal education level-and observe results consistent with those obtained utilizing maternal education level. It is also worth noting that the NLSY education data for fathers is more often missing. However, when we utilized paternal education as an alternative proxy for childhood SES there was no significant change in the results. To identify changes in SES, we use the highest grade completed by the individual as a proxy for adult SES using the same divisions as those applied to the individual's mother $(<12,12$, or $>12$ years of schooling). Thus, changes are based on moving from one socioeconomic group to another.

\section{Other Data}

The NLSY79 also collected individual employment information including the number of jobs that individual has had over the course of his/her lifetime. We utilized this information to create a dummy variable indicating whether or not the individual has had less than 10 jobs over the course of their lifetime and interpret this as an indicator of job mobility. As job mobility is potentially correlated with changes in human capital and SES, we view its inclusion as an additional control as more than appropriate. In Table 2 we observe that, as we move from low SES to high SES, the share of individuals in our sample that has had less than 10 jobs throughout their life declines. This may suggest that individuals at higher levels of SES have increased job mobility compared to those of lower SES.

The NLSY79 also notes whether the individual was considered to be living in an urban or rural area. As urban and rural areas often differ significantly in terms of their economic opportunities and health outcomes, this is an important additional control. Details regarding how the urban/rural distinction is calculated overtime are available at the National Longitudinal Survey's website. ${ }^{11}$ As there may be differences between those who are born in the U.S., or whose parents are born in the U.S., and those from other countries, we use data on the country of birth for the individual, as

\footnotetext{
${ }^{10}$ Currie et al. (2007) and Baum and Ruhm (2009).

${ }^{11} \mathrm{http}: / / \mathrm{nl}$ sinfo.org/content/cohorts/nlsy79/other-documentation/codebook-supplement/nlsy79appendix-6-urban-rural-and
} 
well as their mother and father.

\section{County-level Industry Data}

Our utilization of the NLSY's accompanying confidential, geo-coded data allows for the linking of the individual's location with county-level employment data available from the Bureau of Economic Analysis. This allows us to control for access to employment opportunities which may be correlated with changes in SES. For our analysis, we utilized county-level employment shares in their current county in order to control for geographic differences in employment in different industries across the United States. These data were compiled by combining data from the BEA's Standard Industry Classification System (SIC) and the North American Industry Classification System (NAICS). Because the SIC and NAICS datasets cover different time periods, 1969 to 2000 and 2001 to the present, respectively, combining the two datasets required us to aggregate to larger industry classifications. ${ }^{12}$ The remaining, aggregated industry classifications that we utilize are: farming, transportation and utilities, construction, manufacturing, services, real estate and finance, and government enterprises. ${ }^{13}$

\section{Movement Between Socioeconomic Groups}

Having selected maternal education as a proxy for childhood SES and the individual's education level as a proxy for adult SES, we are now able to observe and categorize individual movements between SES groups in our sample. Table 1.1 summarizes the observed movement of individuals between their starting (childhood) SES and their potential ending (adult) SES groups.

12 The NAICS is a much more detailed system of industry classification which contains sector designations not previously contained within the SIC. After combining the two datasets, the finer level of employment data present in the NAICS was lost. Further, many of the new industry classifications present in the NAICS could not be appropriately re-aggregated to larger industry classifications, which resulted in their being excluded from our analysis.

${ }^{13}$ All other industries were excluded due to their being no obvious way to reaggregate them or if, after aggregation, their employment trends appeared disjointed. 


\begin{tabular}{|l|r|l|l|}
\hline Table 1.1 - Individual SES Movements \\
\hline Upward Movement & 6,254 & $\%$ Upward Movement & $55.7 \%$ \\
\hline No Movement & 2,484 & $\%$ No Movement & $22.2 \%$ \\
\hline Downward Movement & 2,473 & $\%$ Downward Movement & $22.1 \%$ \\
\hline Total & 11,211 & & \\
\hline
\end{tabular}

In total we observe 11,211 individuals in the NLSY dataset. Of those individuals, approximately $56 \%$ are observed to have moved up in SES, based on the our previously described SES proxy. The remaining $44 \%$ of the sample is split roughly evenly between individuals who remained in the same SES group in both childhood and adulthood, and individuals who moved to a lower SES group in adulthood.

\section{Health Behaviors}

The connection between low socioeconomic status and negative health behaviors has been well documented in the literature, with individuals of lower SES exhibiting increased rates of alcohol, tobacco, and illicit drug use, poor nutrition choices, as well as lower rates of physical activity. Unfortunately, most of the health behavior data was not collected very often, making it difficult to include in our analysis. However, we are able to get time-varying information on smoking habits, and create dummy variable for "heavy smoker, which we classify as having smoked 1.5 packs of cigarettes a day, every day, for at least a year. ${ }^{14}$

While the survey includes other health behavior data related to smoking and alcohol consumption, because the years over which these health behavior data were collected is severely limited, we are unable to include them in our analysis. However, we include them in the descriptive statistics in Table 1.2, for discussion in support of the socioeconomic group classifications previously described and not in the formal econometric analysis. ${ }^{15}$ These include dummy variables for current

\footnotetext{
${ }^{14}$ This equates to having smoked over 10,000 cigarettes in a year.

${ }^{15}$ Specifically, questions regarding the number of cigarettes smoked and the frequency of smoking were only asked during the following years: 1992, 1994, 1998, 2008, 2010, and 2012. Questions
} 
smoker; binge drinking, defined as consuming 6 or more drinks in a single session; and heavy drinking, defined as having consumed more than 60 alcoholic beverages during the previous month.

\begin{tabular}{|c|c|c|c|c|c|c|}
\hline \multirow[t]{2}{*}{ Variable } & \multirow[t]{2}{*}{ Full Sample } & \multicolumn{2}{|l|}{ Gender } & \multicolumn{3}{|c|}{ Childhood SES } \\
\hline & & Male & Female & Low & Medium & High \\
\hline BMI & 26.3 & 26.7 & 25.9 & 27.0 & 25.9 & 25.6 \\
\hline Obese & $20.9 \%$ & $22.4 \%$ & $21.6 \%$ & $24.9 \%$ & $18.7 \%$ & $16.3 \%$ \\
\hline Class 3 Obesity ( $\mathrm{BMI}>40)$ & $2.7 \%$ & $1.7 \%$ & $3.7 \%$ & $3.6 \%$ & $2.0 \%$ & $1.9 \%$ \\
\hline Early 20's Obesity & $11.4 \%$ & $10.5 \%$ & $12.3 \%$ & $14.1 \%$ & $10.1 \%$ & $7.6 \%$ \\
\hline Low Childhood SES & $42.8 \%$ & $40.6 \%$ & $44.9 \%$ & - & - & - \\
\hline Age & 33.7 & 33.6 & 33.8 & 33.7 & 33.6 & 33.8 \\
\hline Male & 49.0 & - & - & $46.5 \%$ & $50.8 \%$ & $51.3 \%$ \\
\hline White & $56.1 \%$ & $56.6 \%$ & $55.6 \%$ & $37.7 \%$ & $69.0 \%$ & $72.1 \%$ \\
\hline Married & $49.8 \%$ & $48.8 \%$ & $50.9 \%$ & $46.4 \%$ & $52.7 \%$ & $54.9 \%$ \\
\hline Number of Children & 1.4 & 1.2 & 1.5 & 1.6 & 1.2 & 1.1 \\
\hline Years of Education & 13.1 & 12.9 & 13.1 & 11.9 & 13.3 & 14.8 \\
\hline Net Family Inc. (2014 \$’s) & $70,062.9$ & $73,224.7$ & $67,023.3$ & $51,272.6$ & $75,527.8$ & $104,359.2$ \\
\hline Maternal Education & 10.9 & 10.9 & 10.8 & 8.1 & 12.0 & 15.0 \\
\hline Paternal Education & 11.0 & 11.1 & 10.9 & 8.4 & 11.9 & 14.5 \\
\hline Past Heavy Smoker & $25.4 \%$ & $26.4 \%$ & $24.5 \%$ & $27.9 \%$ & $24.7 \%$ & $20.5 \%$ \\
\hline Less than 10 Jobs & $65.7 \%$ & $62.9 \%$ & $68.3 \%$ & $68.7 \%$ & $65.7 \%$ & $57.9 \%$ \\
\hline Urban Residence & $77.3 \%$ & $77.4 \%$ & $77.3 \%$ & $75.3 \%$ & $76.6 \%$ & $84.1 \%$ \\
\hline U.S. Born & $93.6 \%$ & $93.5 \%$ & $93.7 \%$ & $90.2 \%$ & $96.3 \%$ & $95.9 \%$ \\
\hline Father U.S. Born & $90.5 \%$ & $90.3 \%$ & $90.7 \%$ & $85.0 \%$ & $94.9 \%$ & $93.6 \%$ \\
\hline Mother U.S. Born & $89.7 \%$ & $89.3 \%$ & $90.1 \%$ & $84.3 \%$ & $93.9 \%$ & $93.1 \%$ \\
\hline Sample Size & 148,171 & 72,626 & 75,545 & 63,480 & 59,372 & 25,319 \\
\hline
\end{tabular}

Table 1.2 presents descriptive statistics for the variables described above. Samples sizes represent observation years. As previously noted, most of the smoking and drinking health-risk behavior variables-with the exception of past heavy smoker-are not included as controls in the econometric analysis due to the severely limited nature of the data. They are included in Table 1.3 for discussion, and to lend support to the appropriateness of maternal education serving as a proxy for childhood SES. As there are significant differences in health-risk behaviors across childhood SES groups, these variables, limited though they are, serve to illustrate the expected behavioral trends:

regarding the consumption of alcohol were only asked during the following years: 1982-1985, 1988, 1989, 1994, and 2002. 
primarily, that negative health-risk behaviors decline as SES increases. ${ }^{16}$

\begin{tabular}{|c|c|c|c|c|c|c|}
\hline \multirow[t]{2}{*}{ Variable } & \multirow[t]{2}{*}{ Full Sample } & \multicolumn{2}{|l|}{ Gender } & \multicolumn{3}{|c|}{ Childhood SES } \\
\hline & & Male & Female & Low & Medium & High \\
\hline $\begin{array}{l}\text { Current } \\
\text { Smoker }\end{array}$ & $58.9 \%$ & $59.8 \%$ & $57.8 \%$ & $62.7 \%$ & $57.9 \%$ & $49.9 \%$ \\
\hline Heavy Drinker & $3.0 \%$ & $4.6 \%$ & $1.13 \%$ & $3.5 \%$ & $2.9 \%$ & $2.3 \%$ \\
\hline Binge Drinker & $38.8 \%$ & $49.6 \%$ & $25.8 \%$ & $43.2 \%$ & $38.2 \%$ & $31.8 \%$ \\
\hline
\end{tabular}

Notes: Heavy Drinker is defined as having consumed 60 or more alcoholic beverages within 30 days. Binge Drinker is defined as having consumed greater than 6 alcoholic beverages in one sitting within 30 days.

Indeed, these health-risk behavior variables display results consistent with those established by previous research. The prevalence of current smoking, heavy drinking and binge drinking declines as we move up the SES spectrum, indicating that these negative health behaviors are more strongly associated with lower SES.

The summary statistics indicate that average BMI, rates of obesity and rates of class 3 obesity are all lower for higher childhood SES groups, with average BMI falling from 27.0 to 25.6 between low and high SES groups respectively. ${ }^{17}$ The average rate of obesity for the low SES group is $24.9 \%$, while the high SES group has an average rate of $16.3 \%$. Rates of class 3 obesity fall from $3.6 \%$ for the low SES group, to $1.9 \%$ for the high SES group.

Early 20's Obesity indicates whether the individual was obese when between the ages of 20-23. ${ }^{18}$ This age range was selected by necessity due to the difference in ages between individuals at the time each survey was administered, as well as the fact that the survey was conducted every other

${ }^{16}$ Marmot et al. (1991) report significant differences in health-risk behaviors-such as diet, smoking, and exercise- between different socioeconomic groups, with lower SES groups engaging in higher rates of behavior detrimental to health.

${ }^{17}$ To give this difference some perspective, this amounts to an average weight difference of approximately 11 pounds $(4.99 \mathrm{~kg})$ for an individual who is $5^{\prime} 10^{\prime \prime}(1.78 \mathrm{~m})$ tall.

${ }^{18}$ Obesity at a younger age is a strong predictor of obesity in adulthood (Cavaco et al. 2014). 
year in later years. Approximately $11 \%$ of the sample was obese during this age range, though females exhibit higher rates of early 20 's obesity at $12.3 \%$ vs $10.5 \%$ for males. This condition declines from $14.1 \%$ for low SES individuals, to $7.6 \%$ for high SES individuals.

Consistent with findings in previous research (Baum and Ruhm, 2009; Cawley, 2004) obesity prevalence (but not class 3 obesity) is higher for men than for women. This is also consistent with clinical data indicating that women, though less often obese than men, exhibit higher rates of Class 3 obesity. ${ }^{19}$

Approximately $49 \%$ of our sample is male, though the percentage of males increases from $46.5 \%$ for our low SES group to $51.3 \%$ for our high SES group. Roughly $56 \%$ of our sample is white. Across our SES groups the percent white rises from $37.7 \%$ for low SES to $72.1 \%$ for high SES. Marriage rates rise from $46.4 \%$ for low childhood SES to $54.9 \%$ for high childhood SES. Conversely, the average number of children declines from 1.6 for low childhood SES to 1.1 for high childhood SES. These trends are consistent with those reported in the Bureau of Labor Statistics' Current Population Survey which has shown that individuals of higher socioeconomic status - particularly women — have fewer children and are more likely to be married, compared to their lower SES counterparts.

The individual's average educational attainment level increases from 11.9 years for low SES to 14.8 years for high SES, suggesting that maternal education likely has a positive long term impact on the educational attainment of the individual. Net family income for each individual in the current year, adjusted to 2014 dollars, also rises with childhood SES, increasing from an average of approximately $\$ 51,000$ for low SES to over $\$ 104,000$ for high SES. Mother's educational attainment follows the divisions detailed previously for determining low, medium, and high childhood SES groups. Paternal education, though not utilized in our analysis, exhibits the same trend across the SES spectrum.

As noted previously, the variable 'Less than 10 jobs' in Table 1.2 captures whether or not the

${ }^{19} \mathrm{https} / / /$ www.cdc.gov/nchs/data/databriefs/db56.pdf 
individual has had less than 10 jobs over the course of their lifetime. We observe that, as childhood SES increases, the number of individuals having had less than 10 jobs declines from $68.7 \%$ to approximately $57.9 \%$. One possible interpretation of this is that individuals of higher SES have more job mobility than those of lower SES. This makes sense from a returns to education perspective in that more education likely leads to increased job prospects, and certainly to more diverse job prospects.

The variable 'Urban Residence' captures whether or not the individual lived in an urban or rural area at the time of the survey. Urban residence increases across childhood SES groups which may be due to access to education by mothers in more urban areas.

The final variables indicate whether or not the individual, their mother and their father were born in the United States. Individuals at higher levels of childhood SES are, on average, more likely to have been born in the U.S. Individuals with low childhood SES are less likely, on average, to have had a mother or father that was born in the U.S.

\section{BMI Across SES Groups \& Over Time}
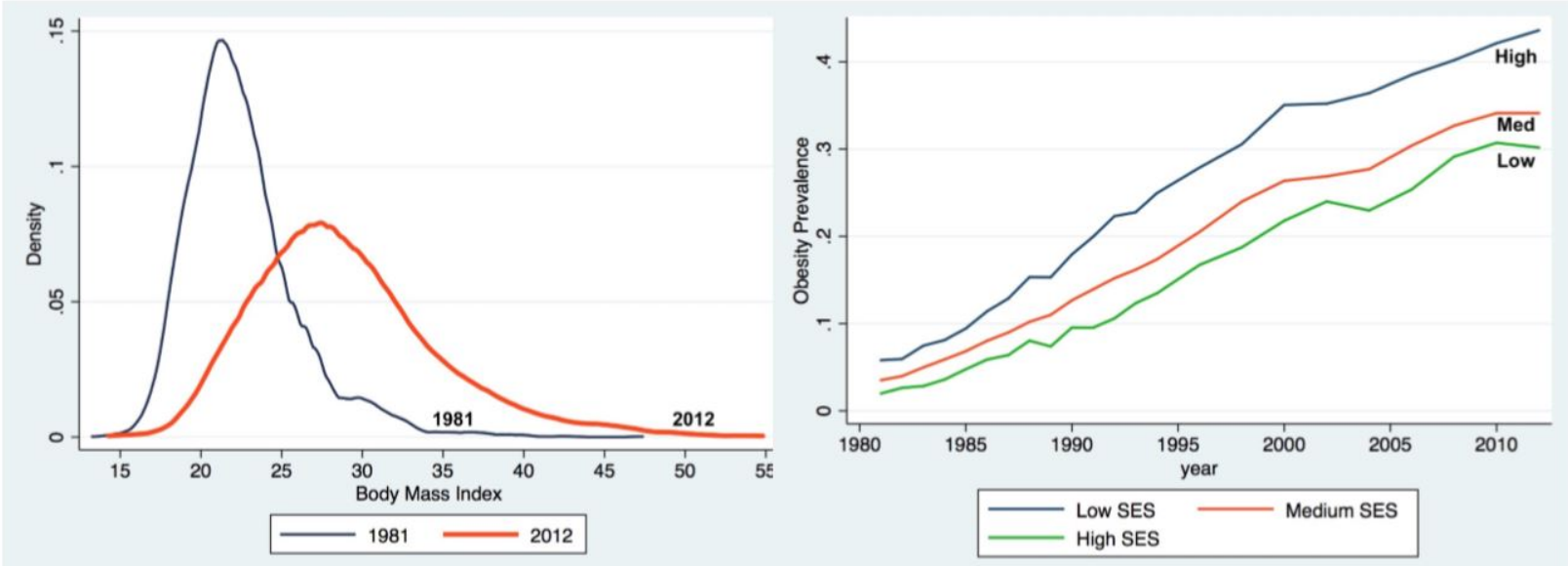

Figure 1.1: BMI in 1981 and 2012 \& Figure 1.2: Childhood SES and Obesity Prevalence

Figure 1.1 presents a kernel density estimate showing growth of BMI in the 1979 NLSY cohort 
over time. ${ }^{20}$ This is consistent with results discussed in Baum and Ruhm's (2009) paper on age and socioeconomic status, in that age is positively correlated with BMI growth. Figure 1.2 shows rates of obesity prevalence across individuals separated into childhood SES groups using the maternal education proxy. This figure provides some evidence that maternal education is a good proxy for childhood SES in that the results are intuitively consistent and also in line with the findings of previously discussed research. Further, we are able to observe that differences in obesity prevalence are smaller between groups earlier in life but widen over time, with the gap widest for the low childhood SES group.

Figures 1.3 and 1.4 display kernel density estimates broken down by socioeconomic group. These figures suggest that the BMI distribution of individuals from various SES groups differs both in childhood and later on in life. The distribution of BMI in the year 1981 is more highly concentrated at the lower end of the BMI spectrum for individuals from high SES backgrounds, while the distribution for individuals with low childhood SES status shifts to the right, indicating a higher concentration of individuals on the heavier end of the BMI spectrum. Similar differences are observed in 2012, after the sample population has aged some thirty years.
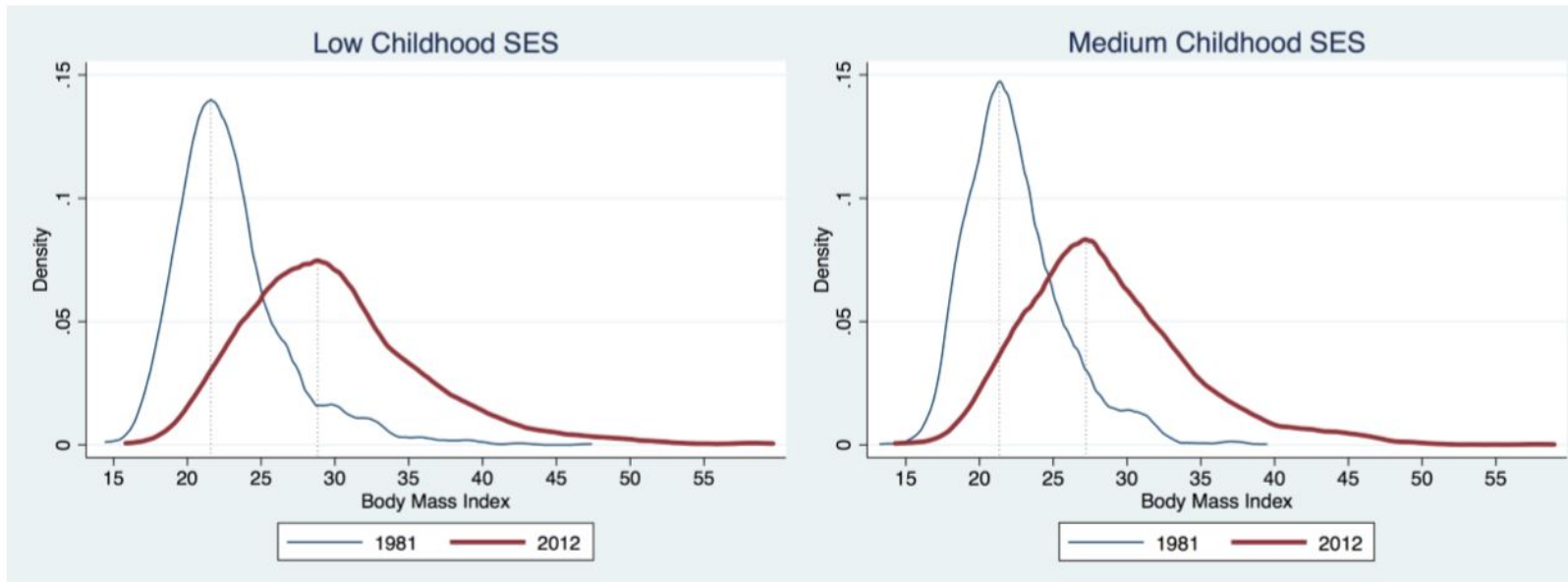

Figure 1.3: BMI in 1981 and 2012 - Low Childhood SES \& Medium Childhood SES

\footnotetext{
${ }^{20}$ Baum and Ruhm (2009) present a similar figure in their paper. This figure contains more recently available NLSY data showing a continued shift to the right across the distribution.
} 

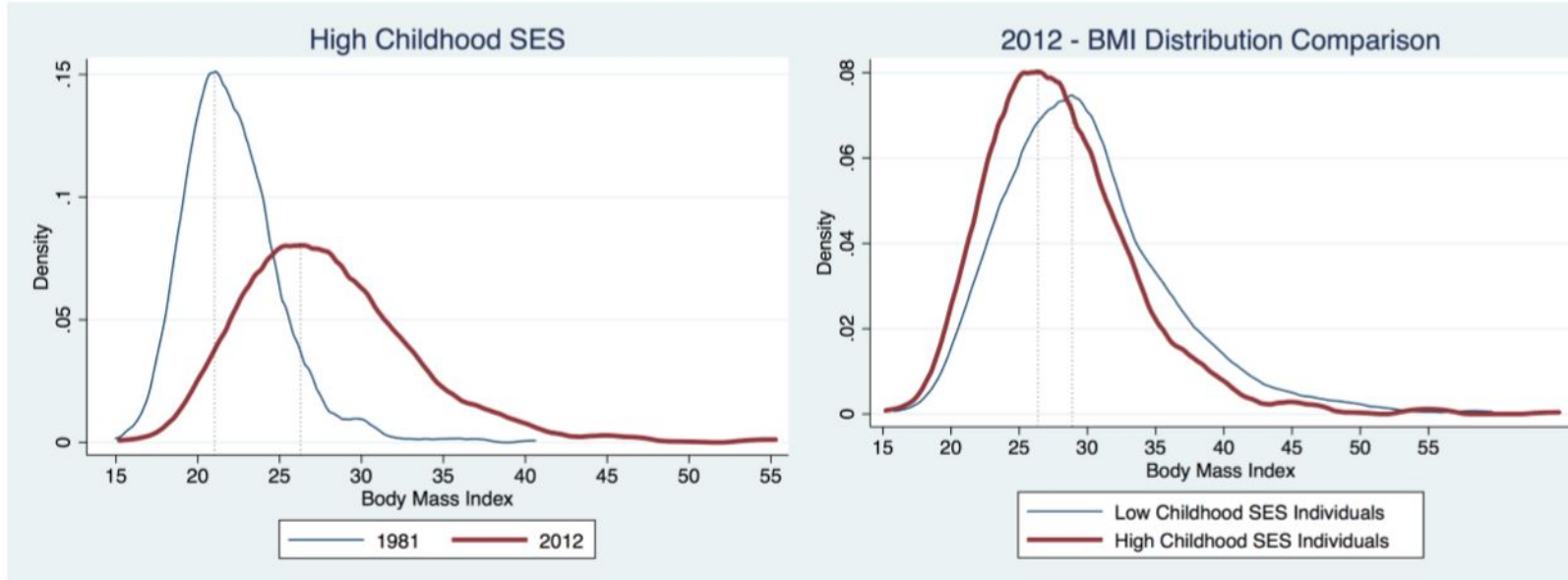

Figure 1.4: BMI in 1981 and 2012 - High Childhood SES \& 2012 Low/High Childhood SES

While we would expect the aging populations of all three SES groups to exhibit a shifting distribution of BMI over time--which is observed and highlighted in Figure 1.1-the shift is not consistent across SES groups. The distribution for individuals with high childhood SES status is concentrated at the lower end of the BMI spectrum, while medium and low childhood SES groups have shifted farther right. The right hand panel of Figure 1.4: 2012 BMI Distribution Comparisondisplays this observation more clearly. We see that the population of individuals who had low childhood SES exhibit a BMI distribution that shifts farther to the right than that of the population of individuals who had high childhood SES, indicating higher BMI growth among individuals from low childhood SES backgrounds.

\subsection{Econometric Model}

To estimate the effect of changes in SES on obesity, we use a binary logit model where the dependent variable, Obese, takes the value of 1 if the individual is obese and 0 if otherwise. The dummy variables SES_Up and SES_Down capture the impact of SES movements relative to individuals who remain at the same SES level. Thus, if an individual who was classified as having low SES as a child moved into the high SES group as an adult, the variable SES_Up would take the value of 1 . Conversely, if an individual was classified as having high childhood SES but then moved into the low SES group as an adult, SES_Down would take the value of 1 . X is a vector of 
controls including individual and county-level industry variables listed in the regression tables that follow. State and time fixed effects, captured by $\alpha_{s}$ and $\delta_{t}$ respectively, are included to account for any state-specific policies in the adult location that might impact health outcomes and any changes over time that might affect obesity - such as regional health initiatives.

The logit model is illustrated by equation (1), where $\mathrm{G}$ is the logistic function:

$$
\operatorname{Pr}(\text { Obese }=1)=G(z)=\frac{e^{z}}{1+e^{z}}
$$

And where

$$
z_{i s t}=\beta_{0}+\beta_{1} S E S_{-} U p_{i s t}+\beta_{2} S E S_{-} D o w n_{i s t}+\beta_{3} X_{i s t}+\alpha_{s}+\delta_{t}+\varepsilon
$$

As noted in an earlier section and illustrated in Table 1.1, the majority of SES movements that are observed in this analysis will be upward movements. Individuals in the sample who were born into the high childhood SES group, for example, were very likely to remain in the high SES group as an adult. In contrast, individuals who were classified as having low childhood SES exhibited upward movement. Only $22 \%$ of the individuals in our sample exhibited downward SES movement.

\begin{tabular}{|l|c|c|}
\hline Table 1.4 - Regression Results - Obesity and SES Movements - Marginal Effects \\
\hline & Full Sample & Southern Sample \\
\hline Variable & Model (1) & Model (2) \\
\hline & & $-1.31 \% * * *$ \\
\hline Upward SES Movement & $-1.23 \% * * *$ & $(0.008)$ \\
\hline & $(0.004)$ & $0.79 \%$ \\
\hline Downward SES Movement & $0.95 \%$ & $(0.017)$ \\
\hline & $(0.008)$ & $1.06 \% * * *$ \\
\hline Age & $0.61 \% * * *$ & $(0.002)$ \\
\hline & $(0.001)$ & $0.19 \%$ \\
\hline Male & $0.48 \%$ & $(0.009)$ \\
\hline & $(0.005)$ & $-8.66 \% * * *$ \\
\hline White & $-6.14 \% * * *$ & $(0.012)$ \\
\hline
\end{tabular}




\begin{tabular}{|c|c|c|}
\hline Family Income (2014 \$1000's) & $-0.00 \% * * *$ & $-0.00 \%$ \\
\hline & $(0.000)$ & $(0.000)$ \\
\hline \multirow[t]{2}{*}{ Married } & $1.94 \% * * *$ & $3.04 \% * * *$ \\
\hline & $(0.003)$ & $(0.005)$ \\
\hline \multirow[t]{2}{*}{ Number of Children } & $0.14 \%$ & $0.31 \%$ \\
\hline & $(0.001)$ & $(0.002)$ \\
\hline \multirow[t]{2}{*}{ Years of Education } & $-0.33 \% * * *$ & $-0.33^{*}$ \\
\hline & $(0.001)$ & $(0.003)$ \\
\hline \multirow[t]{2}{*}{ Urban Residence } & $0.29 \%$ & $0.47 \%$ \\
\hline & $(0.003)$ & $(0.005)$ \\
\hline \multirow[t]{2}{*}{ Less than 10 Jobs } & $-0.52 \%$ & $-1.01 \%$ \\
\hline & $(0.003)$ & $(0.006)$ \\
\hline \multirow[t]{2}{*}{ Past Heavy Smoker } & $-3.24 \% * * *$ & $-3.50 \% * * *$ \\
\hline & $(0.006)$ & $(0.011)$ \\
\hline \multirow[t]{2}{*}{ Early 20's Obesity } & $37.39 \% * * *$ & $43.33 \% * * *$ \\
\hline & $(0.015)$ & $(0.023)$ \\
\hline \multirow[t]{2}{*}{ Low Childhood SES } & $1.60 \% * *$ & $-0.42 \%$ \\
\hline & $(0.006)$ & $(0.011)$ \\
\hline \multirow[t]{2}{*}{ U.S. Born } & $-2.98 \% *$ & $-3.59 \%$ \\
\hline & $(0.013)$ & $(0.025)$ \\
\hline \multirow[t]{2}{*}{ Father U.S. Born } & $0.14 \%$ & $4.78 \% *$ \\
\hline & $(0.012)$ & $(0.024)$ \\
\hline \multirow[t]{2}{*}{ Mother U.S. Born } & $5.87 \% * * *$ & $3.95 \%$ \\
\hline & $(0.012)$ & $(0.024)$ \\
\hline \multirow[t]{2}{*}{ Farming Share } & $0.00 \%$ & $-0.10 \%$ \\
\hline & $\overline{(0.001)}$ & $(0.001)$ \\
\hline \multirow[t]{2}{*}{ Transportation \& Utilities Share } & $-0.00 \%$ & $0.08 \%$ \\
\hline & $(0.001)$ & $(0.001)$ \\
\hline \multirow[t]{2}{*}{ Construction Share } & $-0.02 \%$ & $0.02 \%$ \\
\hline & $(0.001)$ & $(0.001)$ \\
\hline \multirow[t]{2}{*}{ Manufacturing Share } & $0.03 \%$ & $0.04 \%$ \\
\hline & $(0.000)$ & $(0.001)$ \\
\hline \multirow[t]{2}{*}{ Services Share } & $-0.01 \%$ & $-0.01 \%$ \\
\hline & $(0.000)$ & $(0.000)$ \\
\hline \multirow[t]{2}{*}{ Real Estate \& Finance Share } & $0.04 \%$ & $-0.12 \%$ \\
\hline & $(0.001)$ & $(0.001)$ \\
\hline \multirow[t]{2}{*}{ Government Share } & $-0.00 \%$ & $-0.00 \%$ \\
\hline & $(0.000)$ & $(0.000)$ \\
\hline
\end{tabular}




\begin{tabular}{|l|c|c|}
\hline Time FE & $\mathrm{Y}$ & $\mathrm{Y}$ \\
\hline State FE & $\mathrm{Y}$ & $\mathrm{Y}$ \\
\hline Observations & 61,637 & 23,931 \\
\hline Standard errors in parentheses. ${ }^{*} \mathrm{p}<0.05, * * \mathrm{p}<0.01, * * * \mathrm{p}<0.001$ \\
\hline
\end{tabular}

\subsection{Results}

The results of two different model specifications are presented in Table 1.4. Model (1) consists of observations for all individuals in our sample, while Model (2) is restricted to observations for individuals residing in southern states where obesity prevalence tends to be more severe. The marginal effects have been calculated and are present here in order to make the results comparable. In terms of interpretation, the marginal effect for each variable is the change in the probability that the individual is obese.

Of primary interest are the observed marginal effects for our variables capturing upward and downward SES movement. Across both model specifications, Upward SES movement is associated with a decreased likelihood of being obese, compared to those who remain at the same SES level. We interpret these results as suggesting that individual upward SES movement, relative to individuals who do not change SES, helps ameliorate the negative health outcomes often associated with children from lower socioeconomic backgrounds. It is also interesting to note that the magnitude of the observed effects on our Upward SES movement variable is larger for our sample that is restricted to individual residing in southern states. This is not entirely surprising given that the prevalence of obesity in southern states is more severe and, thus, there is more to be gained from the mitigating effects of upward SES movement. Downward SES movement exhibits a positive coefficient across both samples but is not statistically significant in either sample.

Other results are as expected. Being older increases the likelihood of being obese, though age appears to be a stronger predictor of obesity in our southern sample. Being white significantly decreases the likelihood of an individual being obese in both samples. This is not surprising due to consistently higher rates of obesity among the black population in general, though among black women in particular, with black women exhibiting an approximately $20 \%$ higher rate of obesity 
than their male counterparts. ${ }^{2122}$ In contrast, the gap in obesity rates between white men and white women is effectively zero. ${ }^{23}$ Being married is associated with an increased likelihood of being obese across both samples but is a stronger predictor of obesity in our southern sample.

Income is statistically significant across our full sample, but loses its significant in our restricted sample of individuals living in the south. Regardless of significance, the magnitude of the marginal effects observed on income are effectively zero and do not appear to be a contributing (or mitigating) factor in regard to obesity prevalence. This result is consistent with previous research by Baum and Ruhm (2009) who observed that, when also including controls for the individual's education level, the effect of income on weight outcomes is significantly reduced.

No statistically significant effect was observed with regard to the urban/rural distinction among individuals or from having had less than 10 jobs, contrary to our expectation.

A prior history of heavy smoking is associated with a decreased likelihood of being obese across all model specifications. As smoking is an appetite suppressant, this is not entirely surprising.

Our Early 20's Obesity variable is strongly and positively associated with an increased likelihood of (currently) being obese. Indeed, the marginal effects observed on this variable indicate an increased likelihood of being obese of approximately $37 \%$ for our full sample and $43 \%$ for our southern sample. This potentially alarming magnitude is supported by the obesity literature, which shows that early life obesity is a strong predictor of obesity during adulthood. ${ }^{24}$ Another possible interpretation for this observed effect is that it becomes more difficult to escape obesity after an individual is no longer in their early 20 's.

${ }^{21}$ The prevalence of obesity among black men and women aged 20 or older is $37.1 \%$ and $56.6 \%$, respectively.

22 https://www.cdc.gov/nchs/products/databriefs/db131.htm

${ }^{23}$ CDC/NCHS, National Health and Nutrition Examination Survey, 2011-2012.

${ }^{24}$ See Simmonds et al (2015) for a thorough review of early childhood obesity's impact on adult obesity prevalence. 
Controlling for an individual having been of low SES status during childhood exhibited a positive and statistically significant effect in our full sample, but switches signs and loses significant in our southern sample.

Having been born in the United States decreases the likelihood of an individual being obese in our full sample and, while the observed effect is negative in our southern sample, it is no longer significant. Having a mother that was U.S. born increases the likelihood that an individual will be obese but this variable is not significant for our southern sample. Having a father that was U.S. born does not appear to impact the likelihood of an individual being obese across our full sample. However, having a U.S. born father increased the likelihood that an individual will be obese in our southern sample. No consistent patterns in effect or statistical significance are observed across any of the county-level employment shares included in our analysis. However, they may be affecting whether or not upward SES was possible and, thus, remain important control variables.

\subsection{Conclusion}

The connection between socioeconomic status and health outcomes has been well established. That the early life SES of children has lingering, long-term, effects that manifest themselves in their adult health outcomes also seems clear. However, whether or not these effects can be mitigated by changes in SES is a research question that has not been thoroughly examined. Though this paper does not investigate the specific mechanisms by which health outcomes might differ between individuals moving between SES groups, it provides some preliminary evidence that changes in SES do impact the health outcomes of individuals. Put differently, we provide evidence in support of the idea that important differences in health outcomes exist between individuals seeking to improve their individual socioeconomic status in the United States. That the pursuit of the "American Dream" may yield financial, social, and professional benefits to individuals is generally accepted. That the pursuit may yield significant improvements in health outcomes is an assertion that deserves greater attention. Our results support this assertion by providing evidence that individual improvement in one's socioeconomic status - that achieving the "American Dream" - decreases the likelihood that an individual will be obese. 
Our analysis also suggests that the impact of upward SES movement on obesity prevalence will likely vary regionally. By restricting our analysis to southern births only, we observe slightly larger coefficients on our upward SES movement variable, thereby illustrating this point. Together these results confirm the findings of previous research connecting SES and health outcomes, but suggest that, if low childhood SES has long-term negative effects on adult health outcomes, moving to a higher SES may mitigate some of these effects. Whether or not the mitigation occurs because of education, the increased income associated with higher levels of human capital, or because of increased cognitive ability is beyond the scope of the of this paper. ${ }^{25}$ Further research will need to be conducted using alternative datasets to tease out the causal relationships and socioeconomic mechanisms at play.

\subsection{The Impact of Municipal Incorporation on Property Values: Introduction}

Municipal formation by voter approval should reflect the costs and benefits associated with the more localized control and provision of public services. To the extent that the benefits associated with incorporation exceed the costs, the impact of a new municipal formation should be positively capitalized into housing values within the new municipality. Using housing transactions data from 2000 to 2014, we investigate the impact of four new municipal incorporations on housing values in Riverside County, California. By combining a difference-in-difference approach with matching techniques that pair properties in the newly incorporated areas with similar houses not subject to the new incorporation, we are able to generate well-balanced treatment and control groups for use in our analysis. We find that, unlike in some previous studies in other regions, there appears to be a negative capitalization effect observed post-incorporation across the new cities of Riverside County. Our results are robust to multiple model and matching specifications. In the latter portion of this chapter we discuss regional differences that potentially explain the observed, negative,

\footnotetext{
${ }^{25}$ For a discussion of the multidimensional relationship between socioeconomic status and health, see Cutler et. al. (2008).
} 
capitalization effect of new city formation into property values in our sample, relative to previous research.

\subsection{Background and Motivation}

There has been a growing trend of voluntary government unit formation across the United States with the U.S. Census Bureau reporting that at least 203 new municipal governments were created between 2000 and 2014. Following Tiebout (1956), the literature suggests that these new municipal incorporations may be due to differences in preferences for the provision of local public goods, policies and tax rates, or due to differences in preferences of living with different groups of people. To the extent that residents value the new municipal formations, this should be capitalized into housing prices. However, there is evidence that capitalization may depend on the size of the community and that the extent of property value capitalization will be heterogeneous across different municipalities (Hoyt, 1999). Consistent with this finding, previous research to consider the impact of new municipal formation on property values has found somewhat mixed results.

During this period of increased interest in, and the formation of, new municipalities in the United States, Riverside County, in Southern California experienced four new incorporations. Specifically, between 2008 and 2011, the new cities of Wildomar, Menifee, Eastvale and Jurupa Valley were created by popular vote. The municipal incorporations in question were concentrated in the western portion of Riverside County. Figure 2.1 shows the location of the four cities of interest as well as their geographic proximity to the major cities of Los Angeles and San Bernardino. 


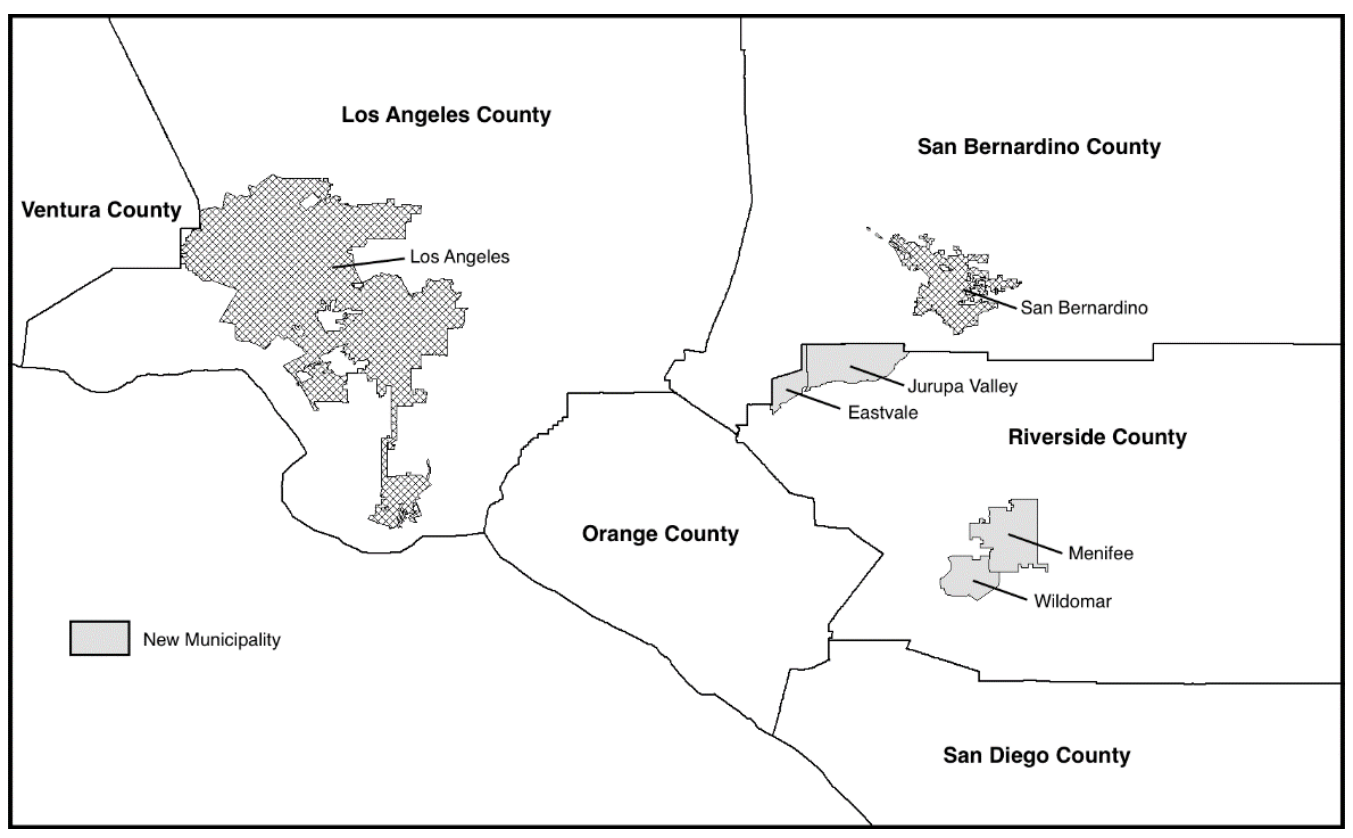

\section{Figure 2.1: Four new municipal formations of Riverside County, California.}

These municipal incorporations in Riverside County provide us an opportunity to further explore the question of whether or not, and to what extent, municipal incorporations are capitalized into property values. Put differently, our research examines the extent to which these municipal incorporations in Riverside County, California, were valued by local residents. To do so, we look at the impact on residential property values by utilizing a difference-in-difference approach combined with a preprocessing of our data using a process known as coarsened exact matching.

Our research contributes to the literature in several ways. First, there has been no previous research conducted on property value capitalization of these municipal incorporations in the state of California. Further, there has been very little research related to the impact of general purpose incorporations on property values, to our knowledge, with Patrick and Mothorpe (2017) having made the only contribution to the literature thus far in that regard. Other researchers have focused on the impact of other types of municipal boundaries such as school and special purpose districts (Billings and Thibodeau, 2011), as well as homeowner's associations (Meltzer and Cheung, 2014).

Additionally, it is possible that property tax limitations and other policies unique to California may affect the capitalization of any benefits into property values. For example, in Georgia, where Patrick and Mothorpe (2017) examined the effect of municipal incorporations on residential property values, property is assessed at the county level at a rate of $40 \%$ of the fair market value 
and properties are reassessed regularly. In California, property taxes are limited to $1 \%$ of the acquisition value of the property and increases cannot exceed $2 \%$ per year. Thus, properties in California are only reassessed at market value when they change hands. This inherently places downward pressure on housing turnover in the state of California, which may decrease the observed impact of municipal incorporation by making it more costly for individuals to "vote with their feet" (Tiebout, 1956). ${ }^{26}$ Further, this property tax limitation can severely limit the ability of local governments to collect property taxes necessary for the funding and provision of local public goods which, in turn, necessitates the raising of funds via alternative taxation structures. Rosen (1982) notes that California's tax limitation initiative did not initially impact the level of public service provision due to the state's large budget surplus at the time, though it did generate significant uncertainty regarding the future.

The municipalities in Riverside County are also considerably smaller in terms of geographic size and the percent of overall county population that is affected than those in Patrick and Mothorpe (2017) whose analysis was conducted on new municipalities formed in and around the greater Atlanta metropolitan area. For example, the average percent of county population impacted by each municipal formation in the Atlanta metropolitan area was approximately $6 \%$ (with a high of $10.23 \%$ ), while the average percent of county population impacted in each new city formed in Riverside County was less than half that, at 2.94\% (with a high of 4.34\%). Since Hoyt (1999) suggests that smaller cities may benefit more from incorporation, our hypothesis is that the new municipalities in Riverside County will exhibit higher rates of capitalization than those examined in Georgia.

Finally, we also consider differences in voter sentiment with regard to incorporation - which may reflect differences in preferences and impact the capitalization benefit. We note for instance that, of the seven new municipal incorporations examined by Patrick and Mothorpe, five had greater than $80 \%$ of voters voting "yes" for incorporation (with a high of $94 \%$ in Sandy Springs, Georgia). In contrast - and as observed in Table 2.1 - no new municipality in Riverside County, California had more than $66 \%$ of voters voting "yes" on incorporation, suggesting that the issue of

\footnotetext{
${ }^{26}$ For a discussion of the impact of California's tax limitation initiative, known as Proposition 13, on housing turnover, see Ferreira (2010).
} 
incorporation may have been much more contentious among the affected residents of California than those in Georgia.

\begin{tabular}{|c|c|c|c|c|c|c|c|}
\hline City name & Vote date & $\begin{array}{c}\text { Incorporation } \\
\text { date }\end{array}$ & $\begin{array}{c}\text { Vote } \\
\text { Yes \% }\end{array}$ & $\begin{array}{c}\text { \% of } \\
\text { County } \\
\text { Population }\end{array}$ & $\begin{array}{c}\text { \% of } \\
\text { County } \\
\text { Area } \\
\end{array}$ & $\begin{array}{c}\text { Land } \\
\text { Area (sq. } \\
\text { miles) } \\
\end{array}$ & $\begin{array}{c}\text { Population } \\
(2010 \\
\text { Census }) \\
\end{array}$ \\
\hline $\begin{array}{l}\text { Jurupa } \\
\text { Valley }\end{array}$ & 8-Mar-2011 & 1-Jul-2011 & 54.5 & 4.34 & 0.61 & 43.7 & 95,005 \\
\hline Eastvale & 8-Jun-2010 & 1-Oct-2010 & 65.77 & 2.45 & 0.16 & 11.4 & 53,683 \\
\hline Menifee & 3-Jun-2008 & 1-Oct-2008 & 61.96 & 3.54 & 0.64 & 46.5 & 77,519 \\
\hline Wildomar & 5-Feb-2008 & 1-Jul-2008 & 61.56 & 1.47 & 0.33 & 23.7 & 32,220 \\
\hline \multicolumn{6}{|c|}{ Riverside County Overall } & $7,206.5$ & $2,189,641$ \\
\hline
\end{tabular}

California's unique property tax structure and the inherent downward pressure on housing turnover associated with it, combined with differences in the geographic size and overall population that is affected, relative to previous research, suggests that the effect of capitalization may vary significantly. It thus remains an unanswered empirical question whether or not the magnitude of property value capitalization in California due to municipal incorporation is comparable to that observed in the greater Atlanta metropolitan area (or other areas), or if it is affected by regional policy and population differences.

Indeed, our results suggest that, unlike in Patrick and Mothorpe (2017) municipal incorporation is not positively capitalized into residential property values in the four cities we examine in Riverside County, California. Specifically, we observe a small, though statistically significant, negative effect on property values across our sample with respect to new city formation. Further, though we utilize an approach very similar to that described in Patrick and Mothorpe (2017), we are unable to generate accurate predictions with regard to the characteristics of a community that would make it most likely to incorporate. These results are, in essence, the exact opposite of the results found in the Georgia study, suggesting that regional differences in policy and populations do play an important role in determining the capitalization of municipal incorporations into residential property values. Given that certain regional policy difference make it more difficult (or costly) for residents to "vote with their feet," and that municipal incorporation among the Riverside County cities seemed to be a relatively contentious issue, this is perhaps not surprising.

In what follows, we review the previous literature and discuss the process of municipal formation in California. We then present our econometric approach and describe the data used in our analysis. 
The results of several different specifications are presented, after which we provide some final comments and policy conclusions.

\subsection{Previous Research}

The economics literature suggests a number of reasons why citizens may choose to engage in municipal incorporation. Tiebout's (1956) modelling of municipal competition provides a theoretical framework under which people "vote with their feet" by relocating to jurisdictions that provide their preferred mix of local public good provision, policies, and tax rates. Thus, from a Tiebout perspective, new municipal incorporations may reflect the preferences of local residents to obtain a different mix of public goods or to obtain greater local control over the provision of the public good itself. Indeed, as shown in Table 2.2, of the reasons given by each of the new municipalities formed in Riverside County, and listed explicitly on each city's application for municipal incorporation, "increased local control," and "greater community voice," were both at the top of the list for all four cities. To the extent that these successful municipal incorporations reflect the preferences of local residents, we would expect the costs and benefits of incorporation to be capitalized into housing prices.

\begin{tabular}{|l|c|c|c|c|}
\hline Table 2.2 - Reasons given for municipal incorporation \\
\hline Reason Text & $\begin{array}{c}\text { Wildomar } \\
\mathbf{( 2 0 0 8 )}\end{array}$ & $\begin{array}{c}\text { Menifee } \\
\mathbf{( 2 0 0 8 )}\end{array}$ & $\begin{array}{c}\text { Eastvale } \\
\mathbf{( 2 0 1 0 )}\end{array}$ & $\begin{array}{c}\text { Jurupa } \\
\text { Valley } \\
\mathbf{( 2 0 1 1}\end{array}$ \\
\hline $\begin{array}{l}\text { Increased local control over } \\
\text { planning, public service provision } \\
\text { and infrastructure. }\end{array}$ & $\mathbf{X}$ & $\mathbf{X}$ & $\mathbf{X}$ \\
\hline $\begin{array}{l}\text { Provide the community a greater } \\
\text { voice and promote increased citizen } \\
\text { participation. }\end{array}$ & $\mathbf{X}$ & $\mathbf{X}$ & $\mathbf{X}$ & $\mathbf{X}$ \\
\hline $\begin{array}{l}\text { Locally accountable government for } \\
\text { the community. }\end{array}$ & $\mathbf{X}$ & $\mathbf{X}$ & $\mathbf{X}$ & $\mathbf{X}$ \\
\hline $\begin{array}{l}\text { Preserve the community's identity, } \\
\text { environment and heritage. }\end{array}$ & $\mathbf{X}$ & $\mathbf{X}$ & $\mathbf{X}$ \\
\hline $\begin{array}{l}\text { Retain local revenues for benefit in } \\
\text { the community. }\end{array}$ & $\mathbf{X}$ & $\mathbf{X}$ & $\mathbf{X}$ & \\
\hline $\begin{array}{l}\text { Promote orderly government } \\
\text { boundaries. }\end{array}$ & & $\mathbf{X}$ & \\
\hline Source: The California Association of Local Agency Formation Commissions \\
\hline
\end{tabular}


Following Tiebout, economists have contributed a number of empirical examples of, and motivations for, the formation of new municipalities. These contributions often emphasize the role that heterogeneous populations play in driving the formation of new municipalities, with particular emphasis on how municipalities may be the result of efforts by residents to limit interactions between people of different social and economic groups. For example, Alesina, Baqir and Hoxby (2004) find that people are willing to sacrifice economies of scale in the provision of public goods in order to limit interactions with people of different income/racial groups. LeonMoreta (2015) also finds evidence supporting the notion that population heterogeneity plays an important role in predicting the formation of new cities, though their results suggest income heterogeneity plays a much larger role than racial and ethnic heterogeneity. Supporting this view, Musso (2001) finds that wealthier communities in high-growth areas are more likely to propose the formation of a new city. However, Musso also notes that community characteristics had little impact on the likelihood of municipal formation actually occurring.

While the reasons for incorporation in Riverside County appear to be primarily based on increasing local control, another stated goal that appears on three of the four city's application for incorporation is, "preserv[ing] the community's identity, environment and heritage." To the extent that this statement reflects a desire by some subset of the Riverside County population to "break away" and form (or protect) a community based on shared identity and heritage, this is consistent with the motivations observed in the previous research regarding heterogeneous populations and municipal incorporation described above.

Another stated reason for incorporation in the communities we examine in Riverside County, California, was the goal of "retain[ing] local revenues for benefit in the community." This reason appeared to be at least as important as preserving the community's shared identity and heritage, and may have reflected a desire by wealthier residents to avoid redistribution via the subsidization of public goods provision for lower income residents (Patrick and Mothorpe, 2017). Kenny and Reinke's (2011) research building on a city-county consolidation model (Filer and Kenny, 1980) also supports this view by illustrating that the richest neighborhoods have the strongest incentives to incorporate in order to avoid redistribution through taxation and local public goods provision. Thus, if the citizens of what would later become new cities were dissatisfied with the level of public goods provision given the tax revenues they were providing to the community at large, they 
would have a strong incentive to ensure those revenues remained "local" as well as to obtain greater local control over how those revenues were spent.

Despite all of this, the results in the literature with respect to the decentralized provision of public goods and the extent of its capitalization in housing prices are mixed. On the positive side, Banzhaf and Bhalla (2012) find that the sudden breakup of the Los Angeles Unified School District into eleven minidistricts was positively capitalized into housing prices, particularly among wealthier neighborhoods. This is consistent with previous research dealing with property value capitalization and income heterogeneity. In their study of greater Atlanta, Patrick and Mothorpe (2017) also find positive rates of capitalization in response to municipal incorporation and the subsequent city-level provision of public services that were previously provided at the county-level. However, Billings and Thibodeau (2009), in their examination of the increase in the number of local governments in the state of Colorado, conclude that institutional decentralization, in general, had no influence on housing prices. At the same time, however, though Billings and Thibodeau did not observe a positive capitalization effect in response to institutional decentralization in general, they did observe a positive capitalization effect with respect to the areas in their study with greater income heterogeneity. Hoyt's (1999) model of government expenditures and capitalization predicts that capitalization will occur, but that the rate of capitalization is effected by the size of the community. Specifically, the rate of capitalization is weaker in larger communities. Using housing sales from the six largest metropolitan areas of Ohio, Brasington (2001) empirically tests Hoyt's model and confirms the prediction that smaller communities experience greater rates of capitalization with regard to decentralized public service provision. Thus, there is support in the literature for the idea that the effects of municipal incorporation on property values may vary widely across regions and across different municipal formations.

\subsection{Process of Municipal Incorporation in California}

Another potential factor that may impact the observed capitalization effect of new city formation may be variations in the process by which municipal incorporation is undertaken in different 
states. ${ }^{27} 28$ Similar to most other states, in California, the process begins with a group of residents forming a committee to discuss the possibility of incorporation. The purpose of this committee is to lay out the goals of incorporation, raise funds, collect signatures, and advance the application process. This process is guided by a county-level Local Agency Formation Commission (LAFCO). The purpose of a LAFCO is to act as an intermediary and facilitator of the municipal incorporation process and to assist with the completion of a mandated feasibility study and the compilation of application materials. ${ }^{29}$

After initiating the incorporation process, proponents must prepare and submit an application to their LAFCO. Upon receipt of the application, the LAFCO determines whether or not proponents of incorporation have satisfied all legal requirements for applications of incorporation, including a comprehensive fiscal analysis, a review of the proposed legal boundaries, as well as a plan for the transfer and provision of public services. If the application is deemed complete by LAFCO, a public hearing is then scheduled. If the move to incorporate survives the public hearing and potential objections from opponents, the incorporation is then placed on the ballot of the next general election. In California, a simple majority vote is required for the proponents of incorporation to succeed. ${ }^{30}$ If the vote for incorporation is successful, the new municipality will begin operation on the date specified on its application. As observed in Table 2.1, new municipalities in California typically begin operation approximately four months after a successful vote.

\footnotetext{
${ }^{27}$ For a state-by-state summary, see the Carl Vinson Institute of Government's, "A Brief Summary of Municipal Incorporation Procedures by State."

${ }^{28}$ While most states have a process similar to California, two interesting outliers to the general process of municipal incorporation are Hawaii, which has only two levels of government, state and county and, therefore, has no incorporation statutes, and Delaware, which effectively has no unincorporated territory left.

${ }^{29}$ A guide to the LAFCO process for incorporations: http://opr.ca.gov/docs/LAFCO_Appendices_Final.pdf.

30 The vast majority of municipal incorporation votes in the United States are decided via simple majority vote of the affected populace, though some states limit voting to citizens who are both land-owners and residents of the area that is to be incorporated.
} 


\section{Public Service Provision Post-Incorporation}

\begin{tabular}{|l|c|c|c|c|c|c|}
\hline Table 2.3 - New City Services and Provision Structure \\
\hline City name & $\begin{array}{c}\text { Planning } \& \\
\text { Zoning }\end{array}$ & $\begin{array}{c}\text { Code } \\
\text { Enforcement }\end{array}$ & $\begin{array}{c}\text { Police } \\
\text { Services }\end{array}$ & $\begin{array}{c}\text { Fire } \\
\text { Services }\end{array}$ & $\begin{array}{c}\text { Water \& } \\
\text { Sewage }\end{array}$ & $\begin{array}{c}\text { Parks \& } \\
\text { Recreation }\end{array}$ \\
\hline $\begin{array}{l}\text { Jurupa } \\
\text { Valley }\end{array}$ & D & D & IG-RC & IG-RC & D-IG & D \\
\hline Eastvale & D & D & IG-RC & IG-RC & D-IG & D-IG \\
\hline Menifee & D & D & IG-RC & IG-RC & D-IG & D \\
\hline Wildomar & D & D & IG-RC & IG-RC & D-IG & D \\
\hline
\end{tabular}

Notes: D: Direct City Provision; IG-RC: Intergovernmental Provision via agreement with Riverside County; DIG: Direct City Provision via Intergovernmental Agreement.

As noted in Table 2.2, among the reasons given for municipal incorporation was increased local control over public service provision. Table 3 shows the major public services offered within each municipality in our study area and their structure of provision. Immediately upon incorporation, the newly formed city councils took direct control of the provision of planning, zoning and code enforcement services. This direct city provision is consistent with resident's desire for "Increased local control over planning, public service provision and infrastructure," described explicitly on each municipality's application for incorporation. It appears then that incorporation, at least to some degree, helped to address resident's desire for greater control over public service provision as well as to have a governing body that could be held locally accountable.

However, direct responsibility for the provision of some crucial public services was not assumed by the new municipalities. For example, the provision of police and fire services are provided by Riverside County Sheriff's Department and Riverside County Fire Department, respectively, and reflect contracts negotiated between the new city councils and the public service providers. Water and sewage provision is similarly a function of intergovernmental provision, with each municipality contracting with its local water district.

The municipalities examined by Patrick and Mothorpe (2017) were also observed to have similarly taken control of the provision of certain public services, while also contracting with the county for others. However, unlike in California, the Georgia municipalities were also observed to have increased property taxes which is expressly prohibited in California.

\subsection{Econometric Approach}


We are interested in identifying the causal effect of municipal incorporation on property values within a newly incorporated area. However, econometric challenges immediately arise due to the fact that the formation of a new municipality is not random. Further, there exists the ever-present possibility that the observable housing characteristics do not adequately control for unobservables or that counterfactual trends are invalid (Ferraro and Miranda, 2014a). As noted in Patrick and Mothorpe (2017), the difference-in-difference (DID) hedonic methodology addresses some, though not all, of these econometric challenges. While hedonic DID allows for the identification of the capitalization effect, by comparing the differences in housing sales prices before and after municipal incorporation between treated and untreated groups, it does not guarantee a causal estimate.

Following Patrick and Mothorpe (2017), we utilize a combination of the familiar difference-indifference (DID) with a preprocessing of the data via an econometric tool called coarsened exact matching (CEM). This underutilized technique is described in several contributions to the econometrics literature, which illustrate that combining DID with data preprocessing provides estimates close to that of an ideal experiment (Blundell and Dias, 2009; Imbens and Woolridge, 2009). For a detailed review of the CEM approach and a discussion of its benefits see Iacus, King and Porro (2011 \& 2012) as well as Blackwell et al. (2009). A brief overview of CEM follows below.

The goal of coarsened exact matching is to reduce the imbalance between covariates among the treated and control groups in order to obtain a more reliable counterfactual. To summarize from Iacus et al. (2012), CEM places each covariate into similar groups, exact matches based on a determined range (or strata) within each covariate, and then prunes unmatched units, retaining only observations within the strata that contain both treated and control units. A simple example would be the covariate number of bedrooms being stratified (or coarsened) such that houses within the covariate range of 3-4 bedrooms would be matched together, as opposed to a typical exact matching approach where only houses with the same value for number of bedrooms are matched. While the latter matching method provides perfect balance, it typically produces few matches. Ultimately, the idea of CEM is to temporarily coarsen each variable into substantively meaningful groups, exact match on the coarsened data for all the covariates, and then retain only the treated and untreated observations which can be matched (Blackwell et al. 2009). 
In a later section, we detail the matching process, our selection of preprocessing variables, and compare the treated and control groups that were ultimately generated. After preprocessing our data with CEM to match parcels in new cities with parcels sharing similar pre-treatment characteristics and using the set of counterfactual sales drawn from this matching, we estimate the following:

$$
\begin{aligned}
\ln \left(P_{\text {hjnt }}\right)=\beta & X_{h}+\delta(\text { NewCityArea })_{j}+\varphi(\text { NewCityTime })_{n t} \\
& +\theta\left\{(\text { NewCityArea })_{j} \times(\text { NewCityTime })_{n t}\right\}_{j n t}+\alpha_{c}+\mu_{t}+\varepsilon_{\text {hjnt }}
\end{aligned}
$$

where $\mathrm{P}_{\text {hjnt }}$ is the normalized sales price of house $h$ in location $j$ in new city $n$ at time $t, X_{h}$ is a vector of characteristics for house $h$, (NewCityArea) ${ }_{j}$ is a dummy variable taking the value of 1 if location $j$ is within the geographic area that eventually becomes a new city, (NewCityTime $)_{n t}$ is a dummy variable that takes the value of 1 if time $t$ is after the new city $n$ is created. The coefficient $\theta$ captures the interaction between $(\text { NewCityArea })_{j}$ and $(\text { NewCityTime })_{n t}$ which becomes a dummy variable equal to 1 if the location $j$ is in the area that becomes part of new city $n$ at time $t$ after incorporation. The vectors $\alpha_{c}$ and $\mu_{t}$ are county and time (year) fixed effects, respectively. The parameter of interest is $\theta$ and is identified from the difference-in-differences within the sets of CEM matched parcels for each new city based on housing characteristics and fixed effects.

\subsection{Data}

Our primary dataset consists of home sales and characteristics for all single-family homes in San Bernardino and Riverside Counties taking place between the years 2000 through 2014 obtained from Dataquick. Though all of the municipal incorporations in question occurred in Riverside County, we include San Bernardino in our sample for several reasons. First, the dual-county area has long been referred to as one larger metropolitan entity, with the term "Inland Empire" having been used as early as 1914 and which is still in use today to refer to the general concentration of cities located within the western portion of each county. Further, the combined Riverside, San Bernardino area is considered a single metropolitan area by the U.S. Census Bureau and is regularly described as a single housing market in real estate reporting. 
San Bernardino County has not had a municipal incorporation since 1991 and, thus, should provide a sample of housing transactions free of the influence of recent new city formation. In contrast, neighboring Orange County has had two municipal incorporations that occur within the timeframe of our dataset. Also, despite its proximity, Orange County is separated from Riverside and San Bernardino counties by a not unsubstantial number of state parks as well as a mountain range that severely limits travel access between the two counties to two major roads. Finally, Riverside and San Bernardino counties are substantially similar in terms of overall population, age and racial demographics, housing market, and local income characteristics. Los Angeles and Orange counties, however, differ substantially from the "Inland Empire" across a range of county-level characteristics examined.

We restrict our sample to transactions taking place within the western, more densely populated areas of each county. This decision was made based on the enormous size of each county and the large variance in regional characteristics observed over their respective land areas. Indeed, San Bernardino County is the largest county in the United States with a land area of over 20,000 square miles, while Riverside County covers over 7,000 square miles. Both of these are well above the average U.S. county land area of approximately 1,200 square miles.

Our transactions dataset contains information on housing characteristics, parcel location, sales information and owner information. Housing characteristics present in the dataset include lot size, construction date, building square footage, number of bedrooms, etc. Location information consists of the property's address, county, as well as latitude and longitude. The transactions data provides information regarding the sale price, sale date, the mortgage date and amount, as well as the name and address of the owner. We also construct additional variables for inclusion in our analysis by linking housing transactions data to other geospatial data.

For the basis of our analysis, we limit the transactions in our sample to arms-length, fair-market value transactions for residential, single-family homes. We also eliminate any obvious errors with regard to sales price or housing characteristics, missing or zero values for the relevant variables, as well as any transactions that appear as significant statistical outliers. With regard to outliers, we follow the suggestion of Klaiber (2010) and use the $1^{\text {st }}$ and $99^{\text {th }}$ percentile as the limits of the transactions included in our final dataset. Thus, all transaction variables fall within the following bounds: 
- $\$ 50,000 \leq$ transaction amount $\leq \$ 835,000$

- $0.02 \leq$ lot size $($ acres $)<2.5$

- $750 \leq$ square feet $\leq 4100$

- $1 \leq$ number of bedrooms $\leq 6$

- $\quad$ Age of house $\leq 95$

- Sale price/Square Feet $\leq \$ 300$

Figure 2.2 shows the geographic distribution of transactions in our full sample, followed by the distribution of transactions left after data cleaning and restricting of the sample to the western portion of each county in Figure 3. After data cleaning and the bounding criteria described above are applied to the dataset we are left with 579,599 transactions in our overall sample.

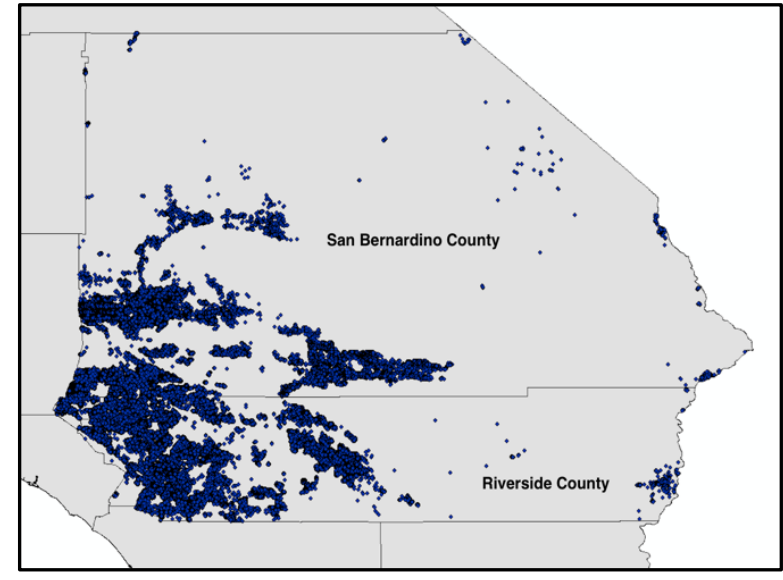

Figure 2.2: Initial Transaction Distribution

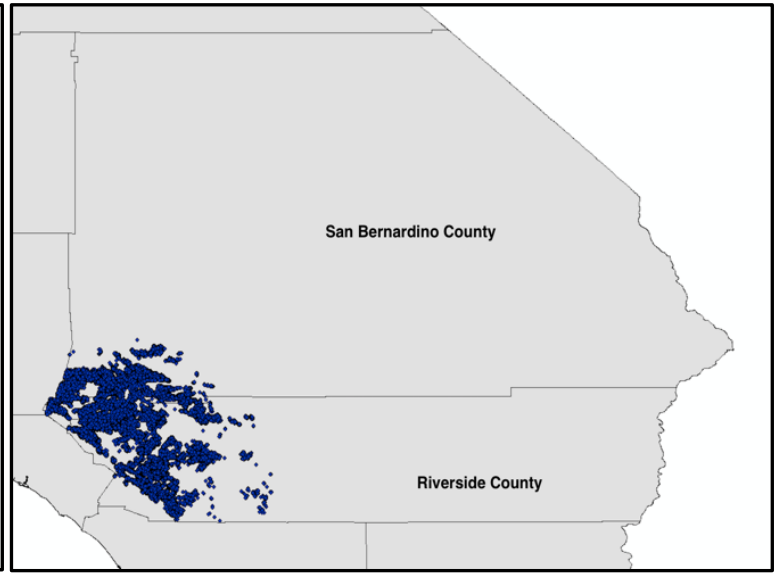

Figure 2.3: Remaining Transactions after Cleaning

\section{Neighborhood Characteristics}

Using the location information included in our primary dataset of housing transactions, we link each parcel to geospatial data for inclusion in our analysis. We begin by obtaining U.S. Census cartographical boundary shapefiles and assigning each housing parcel in our sample to its appropriate Census block group. We then implement an approach similar to that of Patrick and Mothorpe (2017) whereby we define a unique neighborhood for each individual parcel that consists of all other parcels included in our dataset within 0.25 miles from the initial parcel. ${ }^{31}$

${ }^{31}$ As Patrick and Mothorpe (2017) note, 0.25 miles is typically considered walking distance. 
These neighborhoods are defined without regard to political boundaries. This neighborhood designation is then used to compute neighborhood characteristics for each parcel in our sample. These neighborhood characteristics include average annual sales price, age, lot size, square feet and number of bedrooms for each parcel's neighborhood.

We also utilize data from the Census Bureau's Longitudinal Employer-Household Dynamics (LEHD) project, which provides information at the block group level regarding employed residents' age range, monthly income and industry of employment. ${ }^{32}$ We use the LEHD data to calculate employed resident age, income, and employment shares for each neighborhood in our sample. ${ }^{33}$ Specifically, we calculate the share of employed residents between the ages of 30-54 and over 55 for each neighborhood, as well as the share of employed residents earning between \$1251-\$3333 and greater than \$3333 each month. We also calculate employment shares for the 20 major NAICS sectors detailed in the LEHD dataset, but do so at a range of 1 kilometer from each parcel, rather than our initial 0.25 mile neighborhood range.

\subsection{Proposition 13: Property Taxes in California}

It should be noted that, in contrast to Patrick and Mothorpe (2017), we are unable to include the characteristics of parcels that have not recently been sold into our analysis — or that have not sold at any point during the timeframe covered by our dataset - due to California's fairly unique property tax system. Patrick and Mothorpe, while examining the impact of municipal incorporation on housing prices near Atlanta, Georgia, were able to include information on parcels that had not recently been sold into their analysis due to the availability of annual fair market value assessments of each property compiled by the state's Board of Tax Assessors for the purpose of calculating and collecting annual property taxes. ${ }^{34}$ In contrast, California's property tax system is governed by Proposition 13 - officially named the People's Initiative to Limit Property Taxation - which dictates that properties are only assessed at fair-market value when they change hands. Further, Proposition 13 limits the annual increase of the assessed value for property to a maximum of $2 \%$

\footnotetext{
${ }^{32} \mathrm{https}: / /$ lehd.ces.census.gov/data/

${ }^{33}$ Note that the LEHD data only contain information on employed residents.

${ }^{34}$ Georgia Department of Revenue: https://dor.georgia.gov/property-tax-valuation
} 
a year. ${ }^{35} 36$ Thus, tax assessor roles in California would not include valid assessments of the fair market value of the properties in question. To illustrate this point, a single-family home purchased in 1998 and held until 2018 would be assessed at its original 1998 purchase price plus an annual increase in assessed value of not more than $2 \%$ a year. ${ }^{37}$ Any reported assessment by a California tax assessor's office would therefore reflect a property value assessment divorced entirely from trends in the housing market over the twenty years that the property has been owned.

\section{“At Risk” Estimation and Data Preprocessing}

Following Patrick and Mothorpe (2017) we also attempted to identify the factors that make a parcel "at risk" of incorporation. To do this, we used our neighborhood characteristics and ran multiple regressions with a dummy variable for municipal incorporation as the outcome variable. That is, apart from the directly observed housing characteristics presented in our primary dataset, we investigated whether there are more general conditions that would lead to an increased likelihood of a parcel being at risk of incorporation. The results of our initial estimations of the probability of incorporation are presented in Table 2.5 along with the adjusted R-squared, Akaike Information Criteria (AIC), and Bayesian Information Criteria (BIC).

In their similar analysis, Patrick and Mothorpe (2017) found the most significant predictors of municipal incorporation to be average neighborhood sales price, the neighborhood to county price ratio and neighborhood resident age group shares. They did not find average neighborhood housing characteristics, in general, to be significant in the prediction of incorporation, nor did resident income shares appear to be important.

\footnotetext{
35 The passage of Property 13 coincided with a time of increased national interest in tax limitation initiatives that resulted in similar legislation being adopted in several other states. Massachusetts' Proposition 2.5, for example, limited annual property taxes and annual increases to 2.5\% (Cutler et al., 1999).

${ }^{36}$ For a detailed account of the circumstances surrounding the passage of Proposition 13, see O'Sullivan's (1995) "Property taxes and tax revolts: the legacy of Proposition 13."

${ }^{37}$ Wasi and White (2005) find that the average tenure length of a homeowner in California postProposition 13 increases sharply relative to the amount of tax "subsidy" they receive by remaining in their home, rather than moving into a different property and potentially facing an increased tax burden.
} 
While we also find that the neighborhood to county price ratio and resident age group shares are strong predictors of municipal incorporation, we find some significant differences with regard to our California analysis. First, the sign on our resident age group shares is positive, suggesting that areas with higher concentrations of older residents are more likely to incorporate. This is in contrast to Patrick and Mothorpe who observe a decreased likelihood of incorporation associated with older population shares across the neighborhoods in their greater-metro-Atlanta analysis. Further, we find that our neighborhood resident income shares are also significant to predicting incorporation, while this was not true of the Atlanta study.

However, and more importantly, there appear to be significant differences in the overall ability of these variables to meaningfully predict the probability of incorporation across different geographical regions. The models that Patrick and Mothorpe used to predict municipal incorporation had adjusted R-squared measures of approximately 0.63 . However, our models constructed similarly in the spirit of replicability - do not provide any adjusted R-squared measures greater than 0.057 . Thus, we are forced to conclude that these types of variables, while useful in predicting incorporation in some geographic locations, are not necessarily associated with incorporation in California.

\begin{tabular}{|l|c|c|c|}
\hline Table 2.5 - Predicting the probability of incorporation & \multicolumn{1}{|c|}{$(\mathbf{2})$} \\
\hline Neighborhood characteristics & $(\mathbf{1})$ & $0.383^{* * * *}$ & $0.346^{* * *}$ \\
\hline $\begin{array}{l}\text { Neighborhood to County } \\
\text { Price Ratio }\end{array}$ & $0.337^{* * *}$ & $(0.00467)$ & $(0.00462)$ \\
\hline & $(0.00464)$ & & $-0.00000116^{* * *}$ \\
\hline Average Sales Price & $-0.00000115^{* * *}$ & $-0.00000124^{* * *}$ & $(1.51 \mathrm{e}-08)$ \\
\hline & $(1.51 \mathrm{e}-08)$ & $(1.52 \mathrm{e}-08)$ & $-0.000704^{* * *}$ \\
\hline & & & $(0.0000205)$ \\
\hline Average Age & $-0.000675^{* * *}$ & & $0.0111^{* * *}$ \\
\hline & $(0.0000205)$ & & $(0.00141)$ \\
\hline & & & $0.00000276^{* * *}$ \\
\hline Average lot size (acre) & $0.0118^{* * *}$ & & $(0.000000772)$ \\
\hline & $(0.00141)$ & & $-0.00877^{* * *}$ \\
\hline Average Square Feet & & & $(0.000459)$ \\
\hline & $0.00000312^{* * *}$ & & \\
\hline & $(0.000000772)$ & & $0.0216^{* * *}$ \\
\hline Average \# of Beds & & & $(0.000296)$ \\
\hline & $-0.00858^{* * *}$ & & \\
\hline Average \# of Baths & $(0.000459)$ & & \\
\hline & & & \\
\hline
\end{tabular}




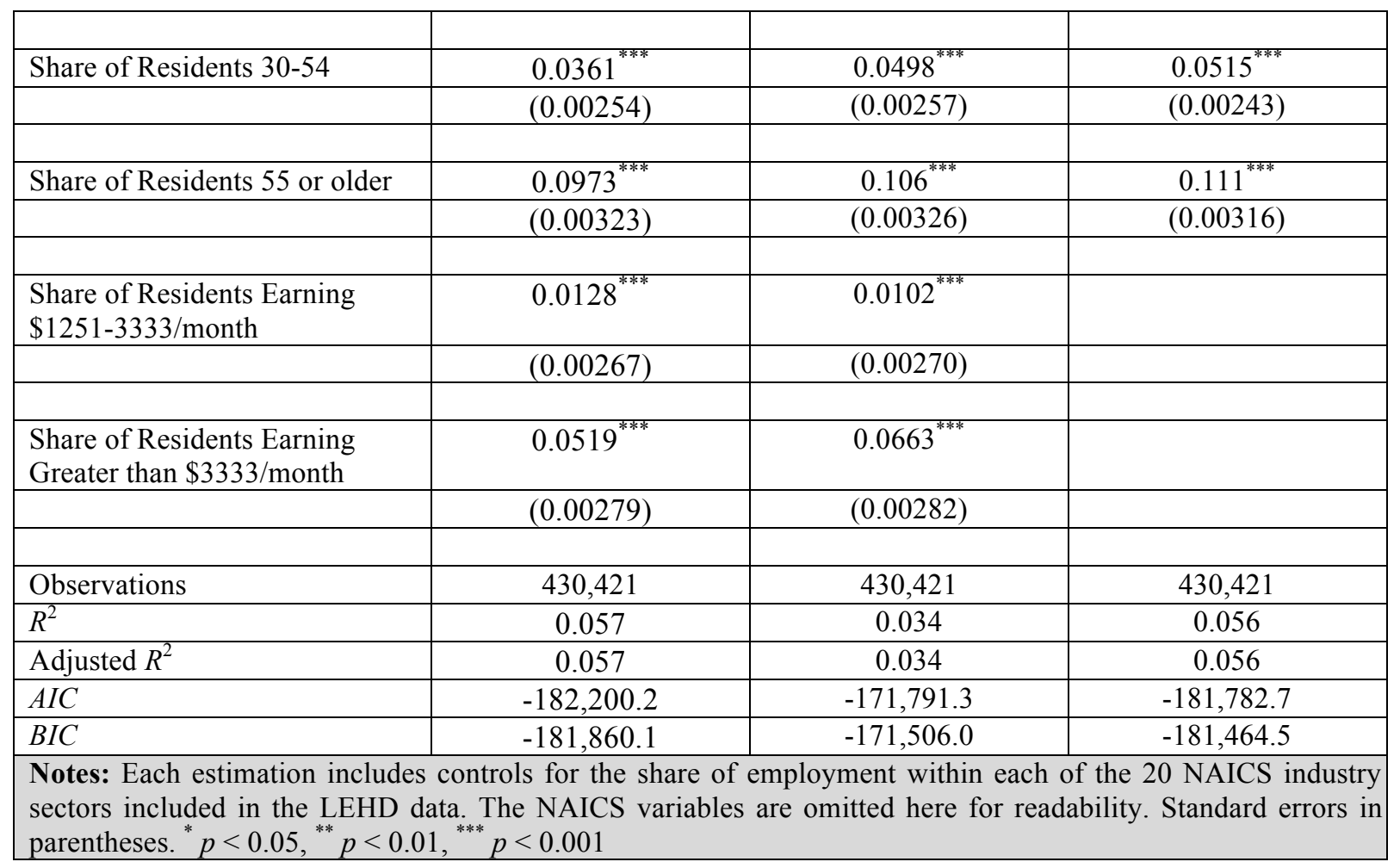

Because the results presented in Table 2.5 failed to provide us with meaningful estimates of the probability of incorporation across our area of analysis, we compiled additional variables potentially relevant to the likelihood of incorporation and produced further estimates. Specifically, we calculated the distance to the nearest interstate for each parcel as well as the distance to the downtown center of the three nearest major metropolitan areas: the cities of Los Angeles, Riverside and San Bernardino. The results of estimates of models including variable combinations with these additional controls are presented in Table 2.6. Here we observe that, despite slight improvements in our adjusted R-squared and AIC/BIC measurements, these estimates still do not adequately predict the likelihood of incorporation.

While our attempts at mimicking the approach utilized by Patrick and Mothorpe (2017) in our California analysis did not yield meaningful information with regard to predicting incorporation, we found the exercise to be of value in that it illustrates the potential for confounding results due to heterogeneity across regions. Put differently, it signals that the factors associated with increased likelihood of municipal incorporation likely vary significantly from location to location. 


\begin{tabular}{|c|c|c|c|}
\hline Neighborhood characteristics & (1) & $(2)$ & (3) \\
\hline \multirow[t]{2}{*}{$\begin{array}{l}\text { Neighborhood to County Annual Price } \\
\text { Ratio }\end{array}$} & $0.317^{* * *}$ & $0.347 * * *$ & $0.332^{* * * *}$ \\
\hline & $(0.00461)$ & $(0.00460)$ & $(0.00459)$ \\
\hline \multirow[t]{2}{*}{ Average Sales Price } & $-0.00000121^{* * *}$ & $-0.00000118^{* * *}$ & $-0.00000127^{* * *}$ \\
\hline & $(1.50 \mathrm{e}-08)$ & $(1.50 \mathrm{e}-08)$ & $(1.50 \mathrm{e}-08)$ \\
\hline \multirow[t]{2}{*}{ Average Age } & $-0.000716^{* * *}$ & & $-0.000774^{* * *}$ \\
\hline & $(0.0000207)$ & & $(0.0000206)$ \\
\hline \multirow[t]{2}{*}{ Average lot size (acre) } & $0.0296^{* * *}$ & & $0.0282^{* * *}$ \\
\hline & $(0.00142)$ & & $(0.00143)$ \\
\hline \multirow[t]{2}{*}{ Average Square Feet } & $0.0000160^{* * *}$ & & $0.0000241^{* * *}$ \\
\hline & $(0.000000805)$ & & $(0.000000764)$ \\
\hline \multirow[t]{2}{*}{ Average \# of Beds } & $-0.00894^{* * *}$ & & $-0.00784^{* * *}$ \\
\hline & $(0.000458)$ & & $(0.000457)$ \\
\hline \multirow[t]{2}{*}{ Average \# of Baths } & $0.0167^{* * *}$ & & \\
\hline & $(0.000531)$ & & \\
\hline \multirow[t]{2}{*}{ Share of Residents 30-54 } & $0.0339^{* * *}$ & $0.0397^{* * *}$ & $0.0460^{* * *}$ \\
\hline & $(0.00252)$ & $(0.00255)$ & $(0.00241)$ \\
\hline \multirow[t]{2}{*}{ Share of Residents 55 or older } & $0.112^{* * *}$ & $0.117^{* * *}$ & $0.121^{* * *}$ \\
\hline & $(0.00321)$ & $(0.00324)$ & $(0.00315)$ \\
\hline \multirow{2}{*}{$\begin{array}{l}\text { Share of Residents Earning \$1251- } \\
\text { 3333/month }\end{array}$} & $0.0121^{* * *}$ & $0.0221^{* * *}$ & \\
\hline & $(0.00264)$ & $(0.00267)$ & \\
\hline \multirow[t]{2}{*}{$\begin{array}{l}\text { Share of Residents Earning Greater than } \\
\$ 3333 / \text { month }\end{array}$} & $0.0394^{* * *}$ & $0.0580^{* * *}$ & \\
\hline & $(0.00277)$ & $(0.00279)$ & \\
\hline \multirow[t]{2}{*}{ Distance to Nearest Interstate } & $-0.599^{* * *}$ & $-0.616^{* * *}$ & $-0.614^{* * *}$ \\
\hline & $(0.00749)$ & $(0.00755)$ & $(0.00749)$ \\
\hline \multirow[t]{2}{*}{ Distance to downtown Los Angeles } & $-0.00104^{* * *}$ & $0.000835^{* * *}$ & $-0.000187^{* * *}$ \\
\hline & $(0.0000454)$ & $(0.0000332)$ & $(0.0000360)$ \\
\hline \multirow[t]{2}{*}{ Distance to downtown Riverside } & $-0.00160^{* * *}$ & $-0.00501^{* * *}$ & $-0.00412^{* * *}$ \\
\hline & $(0.000105)$ & $(0.0000678)$ & $(0.0000683)$ \\
\hline \multirow[t]{2}{*}{ Distance to downtown San Bernardino } & $0.00253^{* * *}$ & $0.00494^{* * *}$ & $0.00453^{* * *}$ \\
\hline & $(0.0000783)$ & $(0.0000480)$ & $(0.0000482)$ \\
\hline Observations & 430,421 & 430,421 & 430,421 \\
\hline$R^{2}$ & 0.077 & 0.054 & 0.075 \\
\hline
\end{tabular}




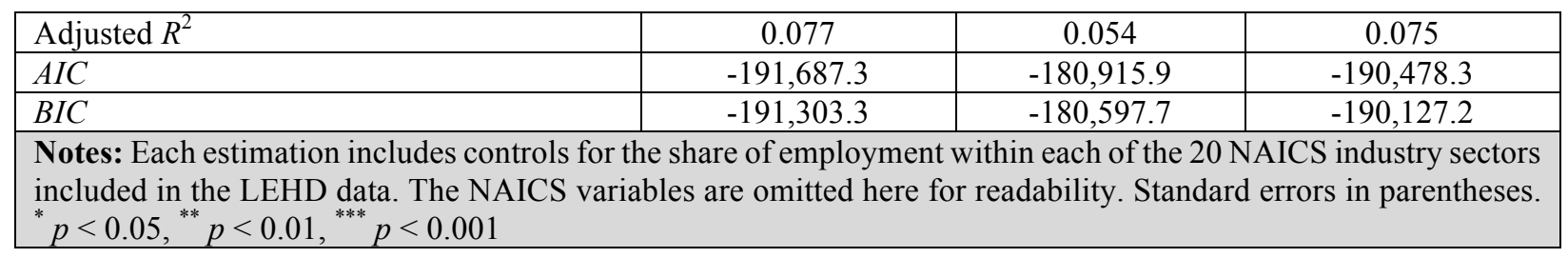

\subsection{Coarsened Exact Matching (CEM) and Counterfactual Sales}

Having investigated the potential for neighborhood characteristics to predict the probability of incorporation, we now turn to a description of our matching process. The literature has shown that pre-processing data through matching can greatly reduce model dependence and improve causal inference (Ho et al., 2007). Although the neighborhood characteristics did not prove useful in predicting the likelihood of municipal incorporation in Riverside and San Bernardino Counties, they are still potentially useful in identifying counterfactual parcels during data pre-processing via coarsened exact matching. Thus, we utilize many of the neighborhood characteristics we calculated for each of the parcels in our sample as covariates in our matching via CEM. Specifically, we pre-process our data by matching parcels based on their neighborhood housing characteristics - average sales price, age, lot size, square footage, bedrooms, and the neighborhood-to-county price ratio - as well as their neighborhood resident age and income shares. We also experiment with matching on other combinations of variables, such as utilizing our mean neighborhood characteristics along with the specific characteristics of each parcel in our sample. However, matching on mean neighborhood housing characteristics, resident income and age characteristics, as well as the individual housing characteristics produces, unsurprisingly, a very restrictive matched sample.

Neighborhood characteristics act as proxies for local economic conditions and potentially signal preferences related to resident's preferred level of public service provision. As noted previously, income heterogeneity has been shown to be a motivating factor in previous municipal incorporations. Not only does matching on neighborhood resident income levels address this potential reason for incorporation, it also proxies for the general economic conditions of the area in which the parcel is located. The annual neighborhood shares of residents in each age group proxies for public service level preferences. The neighborhood-to-county price ratio gives some 
indication of the potential for redistribution, which has also been shown to be a significant predictor of municipal incorporation. However, unlike in Patrick and Mothorpe (2017), our neighborhood characteristics are based only on houses that appear in our transactions data, due to the structure of California's property tax system discussed previously. An additional limitation is that our resident characteristics are only for employed residents. However, Patrick and Mothorpe were also limited in this regard.

The variable means for our treated and control groups after matching on mean neighborhood housing characteristics is presented in Table 2.7. Panel A of Table 2.7 confirms that, after matching on our neighborhood characteristics, we are left with a sample that is well balanced in terms of individual parcel characteristics. Panel B shows the variables means for unmatched treated and controls groups. Note that, compared to our matched sample in Panel A, the unmatched treated and control groups fail to produce a balanced sample for analysis. ${ }^{38}$

\begin{tabular}{|l|c|c|c|c|c|c|}
\hline \multicolumn{7}{|l|}{ Table 2.7 - Variable means, treated and control groups - San Bernardino and Riverside Counties } \\
\hline & \multicolumn{2}{|c|}{ Panel A: CEM } & \multicolumn{2}{l|}{ Panel B: Unmatched } \\
\hline & Treated & Control & t-test & Treated & Control & t-test \\
\hline (ln) Sales Price & 12.53 & 12.58 & 0.93 & 12.54 & 12.54 & 0.33 \\
\hline Age & 21.24 & 22.13 & 0.23 & 21.27 & 31.52 & 0.00 \\
\hline Square Ft (1000's) & 2.20 & 2.22 & 0.34 & 2.20 & 1.94 & 0.00 \\
\hline Bedrooms & 3.53 & 3.55 & 0.00 & 3.53 & 3.42 & 0.00 \\
\hline Lot size (acre) & .21 & .21 & 0.58 & .23 & .21 & 0.00 \\
\hline
\end{tabular}

Notes: Parcels matched via CEM on mean neighborhood housing characteristics for transactions occurring in San Bernardino and Riverside Counties.

\section{DID with matched sales after CEM data pre-processing}

As mentioned previously, we utilized several different combinations of variables to construct our matched treated and control groups during data pre-processing via coarsened exact matching. Table 2.8 presents the results for four different regressions run after data pre-processing via CEM

\footnotetext{
${ }^{38}$ We experimented with matching on many other combinations of variables but, for readability, we do not supply the sample means that results from every combination of variables utilized during CEM. However, the overall results were similar and are available upon request.
} 
with four different combinations of matching variables. Specifically, transactions in Model (1) were matched on mean neighborhood housing characteristics, resident income and resident age, while transactions in Model (2) were matched only on mean neighborhood housing characteristics (those that are shown in Table 2.7). Transactions for Model (3) were matched only on individual parcel characteristics while transactions for Model (4) were matched on mean neighborhood housing characteristics, individual parcel characteristics, as well as resident age and resident income.

It should be noted that certain combinations of variables make individual parcels more difficult to match and, thus, samples sizes are, in some cases, substantially reduced. For example, while matching specifications for Models (2) and (3) produced matched samples of 280,907 and 486,535, respectively, the matching specifications utilized for Models (1) and (4) produced substantially smaller samples of treated and matched houses of 32,710 and 3,460. That being said, the results presented in Table 2.8 remain consistent across all four matching specifications, and reflect a consistently negative effect of municipal incorporation on housing values.

Recall that our variable of interest, municipal incorporation, is meant to capture the effect of municipal incorporation on the value of single-family homes within the newly created municipality. Across all four models the effect is statistically significant and consistently negative, ranging from an estimated decline in single family housing values from $-1.5 \%$ to $-3.0 \%$. Relative to the findings of Patrick and Mothorpe (2017) and their metro-Atlanta study, our results are markedly different. Across the new municipalities and time frame examined in their analysis they found that municipal incorporation resulted in an overall increase in housing values of $13 \%$.

The variable 'New Municipal Area' is a dummy variable indicating whether or not the transaction took place within the boundaries of the new municipality and is followed by variables for the housing characteristics specific to each transaction. The coefficients on our housing characteristic variables are intuitively consistent, with increased age decreasing the value of a home, and larger plots of land, more bedrooms, and more square footage increasing the value of a home. ${ }^{39} \mathrm{We}$ also include a control for distance to the nearest interstate. This variable exhibited a consistently

\footnotetext{
${ }^{39}$ The coefficient on number of bedrooms does flip to negative in Model (4) but we interpret this to be a peculiar consequence of the incredibly small sample size that resulted from the very specific matching criteria utilized via CEM for Model (4).
} 
negative coefficient, suggesting that being further away from major roadways has a negative effect on the value of homes across our sample area. We also include controls for distance to the three nearest major metropolitan areas, the cities of Los Angeles, Riverside and San Bernardino. We also matched each transaction to its respective school district and included this as a simple control for local public service provision. Time and county fixed effects were included in all models.

\begin{tabular}{|c|c|c|c|c|}
\hline & Model (1) & Model (2) & Model (3) & Model (4) \\
\hline \multirow{2}{*}{\begin{tabular}{|l|} 
Municipal \\
Incorporation \\
\end{tabular}} & $-0.0223^{* * *}$ & $-0.0155^{* * *}$ & $-0.0302^{* * *}$ & $-0.0239^{*}$ \\
\hline & $(0.00370)$ & $(0.00196)$ & $(0.00208)$ & \begin{tabular}{|l|}
$(0.0103)$ \\
\end{tabular} \\
\hline \multirow[t]{2}{*}{ Age of House } & $-0.00882^{* * *}$ & $-0.00819^{* * *}$ & $-0.00629^{* * *}$ & $-0.0114^{* * * *}$ \\
\hline & $(0.000118)$ & $(0.0000407)$ & $(0.0000334)$ & $(0.000521)$ \\
\hline \multirow[t]{2}{*}{ Lot size (acre) } & $0.285^{* * *}$ & $0.203^{* * *}$ & $0.160^{* * * *}$ & $0.472^{* * *}$ \\
\hline & $(0.00920)$ & $(0.00247)$ & $(0.00176)$ & \begin{tabular}{|l}
$(0.0588)$ \\
\end{tabular} \\
\hline \multirow{2}{*}{ No. of Bedrooms } & $0.0120^{* * * *}$ & $0.0236^{* * *}$ & $0.0191^{* * * *}$ & $-0.0165^{* * * *}$ \\
\hline & $(0.00131)$ & $(0.000630)$ & $(0.000546)$ & \begin{tabular}{|l}
$(0.00370)$ \\
\end{tabular} \\
\hline \multirow[t]{2}{*}{ Square Ft. (in 1000's) } & $0.184^{* * *}$ & $0.208^{* * *}$ & $0.223^{* * *}$ & $0.201^{* * *}$ \\
\hline & $(0.00191)$ & $(0.000906)$ & $(0.000801)$ & $(0.00694)$ \\
\hline \multirow{2}{*}{$\begin{array}{l}\text { Dist. to Nearest } \\
\text { Interstate }\end{array}$} & $-0.838^{* * *}$ & $-0.599^{* * *}$ & $-0.430^{* * * *}$ & $-1.063^{* * *}$ \\
\hline & $(0.0565)$ & $(0.0247)$ & \begin{tabular}{|l}
$(0.0195)$ \\
\end{tabular} & $(0.191)$ \\
\hline \multirow{2}{*}{ Dist. to Los Angeles } & $-0.0120^{* * *}$ & $-0.00960^{* * *}$ & $-0.0130^{* * *}$ & $-0.0105^{* * *}$ \\
\hline & $(0.000582)$ & $(0.000237)$ & $(0.000183)$ & $(0.00247)$ \\
\hline \multirow[t]{2}{*}{ Dist. to Riverside } & $0.0101^{* * *}$ & $0.0136^{* * *}$ & $0.00964^{* * * *}$ & $0.0303^{* * *}$ \\
\hline & $(0.00117)$ & $(0.000492)$ & $(0.000357)$ & $(0.00577)$ \\
\hline \multirow{2}{*}{$\begin{array}{l}\text { Dist. to San } \\
\text { Bernardino } \\
\end{array}$} & $0.00933^{* * *}$ & $0.00636^{* * *}$ & $0.0129^{* * *}$ & $-0.0137^{* *}$ \\
\hline & $(0.000974)$ & $(0.000408)$ & \begin{tabular}{|l}
$(0.000288)$ \\
\end{tabular} & \begin{tabular}{|l|}
$(0.00475)$ \\
\end{tabular} \\
\hline School District ID & $\mathrm{Y}$ & $\mathrm{Y}$ & $\mathrm{Y}$ & $\mathrm{Y}$ \\
\hline Time FE & $\mathrm{Y}$ & $\mathrm{Y}$ & $\mathrm{Y}$ & $\mathrm{Y}$ \\
\hline County FE & $\mathrm{Y}$ & $\mathrm{Y}$ & $\mathrm{Y}$ & $\mathrm{Y}$ \\
\hline & & & & \\
\hline
\end{tabular}




\begin{tabular}{|l|c|c|c|c|}
\hline Observations & 32,710 & 280,907 & 486,535 & 3,460 \\
\hline$R^{2}$ & 0.732 & 0.713 & 0.659 & 0.728 \\
\hline Adjusted $R^{2}$ & 0.731 & 0.713 & 0.659 & 0.724 \\
\hline$A I C$ & -29398.2 & -61451.4 & 1274.4 & -4180.9 \\
\hline$B I C$ & -28936.5 & -60871.4 & 1895.7 & -3879.6 \\
\hline
\end{tabular}

Notes: Each model represents an estimate based on a different combination of variables used during coarsened exact matching. Transactions for Model (1) were matched on mean neighborhood housing characteristics and resident income and age. Transactions for Model (2) were matched only on mean neighborhood housing characteristics. Transactions for Model (3) were matched on individual parcel characteristics. Transactions for Model (4) were matched on mean neighborhood housing characteristics, individual parcel characteristics, as well as resident age and income. The variables NewCityArea and NewCityTime shown in the econometric model are suppressed. Standard errors in parentheses. ${ }^{*} p<0.05,{ }^{* *} p<0.01,{ }^{* * *} p<0.001$

As mentioned in an earlier section, for the purposes of our initial analysis we included transactions for both Riverside County, in which the municipal incorporations of interest took place, and neighboring San Bernardino County. As a check on the validity of including housing transactions from San Bernardino, we conducted additional analysis on a sample restricted to only transactions occurring in Riverside County. After restricting our sample to Riverside County, we again utilized CEM to match on the four combinations of matching variables described previously, and noted in the bottom of Table 2.8. We then utilized the matched treated and control groups to generate additional estimates of the effect of municipal incorporation on housing values for our restricted, Riverside only, sample.

Table 2.9 presents the results of estimates run on our restricted sample generated using identical matching criteria as the estimates in Table 2.8. Our variable of interest, municipal incorporation, is again consistently negative and statistically significant across all four models. The estimated effect of municipal incorporation on housing values in our restricted sample now ranges from approximately $-0.7 \%$ to $-4.6 \%$. It should be noted that, as was true of the matching results presented for our full sample in Table 2.8, the strict matching criteria utilized in Models (1) and (4) resulted in substantially reduced matched samples. That said, the results across all four model specifications in our restricted sample are consistent and remain markedly different from those observed in previous research. 


\begin{tabular}{|c|c|c|c|c|}
\hline & Model (1) & Model (2) & Model (3) & Model (4) \\
\hline \multirow{2}{*}{$\begin{array}{l}\text { Municipal } \\
\text { Incorporation }\end{array}$} & $-0.0112^{* *}$ & $-0.00760^{* * * *}$ & $-0.0172^{* * *}$ & $-0.0469^{* * *}$ \\
\hline & $(0.00370)$ & $(0.00208)$ & $(0.00222)$ & $(0.0107)$ \\
\hline \multirow[t]{2}{*}{ Age of House } & $-0.00900^{* * *}$ & $-0.00842^{* * *}$ & $-0.00718^{* * *}$ & $-0.0159^{* * *}$ \\
\hline & $(0.000128)$ & $(0.0000490)$ & $(0.0000451)$ & $(0.000506)$ \\
\hline \multirow[t]{2}{*}{ Lot size (acre) } & $0.284^{* * *}$ & $0.160^{* * *}$ & $0.146^{* * *}$ & $0.229^{* * *}$ \\
\hline & $(0.00827)$ & \begin{tabular}{|l|}
$(0.00281)$ \\
\end{tabular} & $(0.00243)$ & $(0.0584)$ \\
\hline \multirow[t]{2}{*}{ No. of Bedrooms } & 0.00241 & $0.0219^{* * * *}$ & $0.0274^{* * * *}$ & $-0.0183^{* * *}$ \\
\hline & $(0.00135)$ & $(0.000733)$ & $(0.000724)$ & $(0.00377)$ \\
\hline \multirow{2}{*}{ Square Ft. (in 1000's) } & $0.191^{* * *}$ & $0.200^{* * * *}$ & $0.210^{* * *}$ & $0.206^{* * *}$ \\
\hline & $(0.00199)$ & $(0.00105)$ & $(0.00107)$ & $(0.00709)$ \\
\hline \multirow{2}{*}{$\begin{array}{l}\text { Dist. to nearest } \\
\text { interstate }\end{array}$} & $-0.754^{* * *}$ & $-0.696^{* * * *}$ & $-0.741^{* * *}$ & $-1.549^{* * *}$ \\
\hline & $(0.0603)$ & $(0.0286)$ & $(0.0253)$ & $(0.217)$ \\
\hline \multirow[t]{2}{*}{ Dist. to Los Angeles } & $-0.0113^{* * *}$ & $-0.0118^{* * *}$ & $-0.0124^{* * *}$ & $-0.00993^{* *}$ \\
\hline & $(0.000664)$ & \begin{tabular}{|l}
$(0.000297)$ \\
\end{tabular} & $(0.000273)$ & $(0.00322)$ \\
\hline \multirow[t]{2}{*}{ Dist. to Riverside } & $0.00771^{* * *}$ & $0.0152^{\text {**** }}$ & $0.00917^{* * *}$ & -0.00294 \\
\hline & $(0.00155)$ & $(0.000679)$ & $(0.000570)$ & $(0.00780)$ \\
\hline \multirow{3}{*}{$\begin{array}{l}\text { Dist. to San } \\
\text { Bernardino }\end{array}$} & $0.0123^{* * *}$ & $0.00801^{* * *}$ & $0.0113^{* * *}$ & $0.0127^{*}$ \\
\hline & & & & \\
\hline & $(0.00128)$ & $(0.000557)$ & $(0.000450)$ & $(0.00619)$ \\
\hline School District ID & $\mathrm{Y}$ & $\mathrm{Y}$ & $\mathrm{Y}$ & $\mathrm{Y}$ \\
\hline Time FE & $\mathrm{Y}$ & $\mathrm{Y}$ & $\mathrm{Y}$ & $\mathrm{Y}$ \\
\hline Observations & 28,817 & 199,730 & 274,265 & 3,354 \\
\hline$R^{2}$ & 0.740 & 0.720 & 0.660 & 0.730 \\
\hline Adjusted $R^{2}$ & 0.740 & 0.720 & 0.660 & 0.727 \\
\hline$A I C$ & -26948.5 & -50182.9 & -1860.0 & -3920.9 \\
\hline$B I C$ & -26609.5 & -49754.3 & -1418.0 & -3682.3 \\
\hline
\end{tabular}


Notes: Each model represents an estimate based on a different combination of variables used during coarsened exact matching. Transactions for Model (1) were matched on mean neighborhood housing characteristics and resident income and age. Transactions for Model (2) were matched only on mean neighborhood housing characteristics. Transactions for Model (3) were matched on individual parcel characteristics. Transactions for Model (4) were matched on mean neighborhood housing characteristics, individual parcel characteristics, as well as resident age and income. The variables NewCityArea and NewCityTime shown in the econometric model are suppressed. Standard errors in parentheses. ${ }^{*} p<0.05,{ }^{* *} p<0.01,{ }^{* * *} p<0.001$

\subsection{Conclusion and Comments}

Housing values can provide evidence of whether or not new municipalities, and the public services they become responsible for providing, are valued by residents. However, there is the potential that differences in regional policy, as well as differences in local sentiment, will generate varying results with respect to the impact of municipal incorporation on housing values. If, for example, a vote for municipal incorporation is particularly close, this may be a signal that heterogeneous preferences exist within the community, and that some portion of the population expects the level of public service provision post-incorporation to be lower than that of the status-quo.

Besides voter sentiment, other regionally specific policies may play a role in mitigating (or strengthening) the positive (or negative) effect of municipal incorporation. As noted earlier, Proposition 13 has placed strict limitations on property taxation in California. It has also placed strong downward pressure on housing turnover which has, inherently, made it more costly for residents to "vote with their feet." Thus, because residents cannot easily select into a municipality that more accurately reflects their preferred level of public service provision, residents opposed to municipal incorporation may simply find themselves one day living in a new municipality that does not reflect their preferences, and from which they cannot easily flee. Further, local control and greater community voice may not fully compensate residents for the increased costs associated with the sacrificing of economies of scale in public service provision.

With regard to the California cities of Jurupa Valley, Eastvale, Menifee, and Wildomar, we find no evidence of a positive effect of municipal incorporation on housing values. Indeed, we find consistently negative results across all of our model specifications. This suggests that residents did not value the municipal incorporation. This is in stark contrast to previous research with regard to 
municipal incorporation where a positive capitalization effect was found and where the majority of new municipalities were formed by voter approval exceeding $80 \%$, with a high of $93.7 \%$. In comparison, none of the municipal incorporations in our sample exceeded $65 \%$ of voter approval with the lowest exhibiting a slim majority vote of $54.5 \%$.

Our research, in addition to providing evidence of regional heterogeneity in the impact of new municipal formations, also contributes to the body of knowledge related to property tax limitation laws. If a resident in a newly incorporated city does not value the new level of public service provision, Proposition 13 makes it much less likely that this resident will "vote with their feet" due to the loss of tax limitation associated with a move. Thus, the longer a resident has lived in the same location, the more likely they are to stay as the benefit from having virtually frozen property tax rates in this particular area of California is likely enormous. This has the potential to distort, or otherwise mitigate, the potentially positive effects of municipal incorporation observed in regions lacking such strict property tax limitations.

Overall, our results suggest that not all new municipal incorporations are created equal and that new city formations may be valued differently depending on both regional policy and local sentiment. In this regard, our research strongly supports the idea of regional heterogeneity generating significantly different outcomes with respect to the impact of municipal incorporation on housing values.

\subsection{West Virginia Death Certificate Analysis; Coal Country and the Opioid Crisis: Introduction}

The Centers for Disease Control reports that West Virginia has the highest rate of drug overdose deaths in the nation at 57.8 deaths per 100,000 population in 2017 , followed by Ohio (46.3), Pennsylvania (44.3), the District of Columbia (44.0) and Kentucky (37.2). ${ }^{40}$ This represents a $100 \%$ increase in the overdose death rate in the state since 2010 and a $403 \%$ increase since 2001. At the national level drug overdose death rates increased by roughly $76 \%$ since 2010 and $320 \%$

${ }^{40}$ https://www.cdc.gov/drugoverdose/data/statedeaths.html 
since 2001. The disparity between national and state historical overdose death rate trends is highlighted in Figure 3.1. At the national level, opioids were the main driver of drug overdose deaths and were involved in nearly $70 \%$ of cases in 2017 , with synthetic opioids contributing to large increases in drug overdose death rates in several states (Scholl et al., 2019).

This alarming trend is neither uniformly distributed geographically across the state, nor borne evenly across gender, race or age groups. Figure 3.2 shows the annual opioid-related overdose deaths in the state of West Virginia from 2001 to 2016 by gender. Year over year, males consistently exhibit higher numbers of opioid-related overdose deaths, despite some research documenting higher rates of opioid prescriptions among women of certain age groups (Ailes et al., 2015), as well as research suggesting that women are more likely to utilize prescription opioids to treat problems not associated with physical pain, such as anxiety or depression (McHugh et al. 2013).

Males continue to exhibit higher rates of opioid overdose deaths across all age groups, by a wide margin, with the exception of opioid overdose deaths occurring after the age of 65 . However, as highlighted in Figure 3.3, the average age for opioid overdose deaths in the state of West Virginia is 40.3 for males and 41.9 for females, suggesting that making it to the $65+$ age group is a relatively rare occurrence. Figure 3.3 also highlights that overdose deaths are concentrated among individuals between the ages of 25 and 54, with the age group of 35-44 exhibiting the greatest number of opioid overdose deaths during the years 2001-2016.

Geographically, opioid-related overdose deaths are not uniformly distributed across the state of West Virginia. As illustrated in Figure 3.4 opioid overdose deaths are primarily concentrated in counties located in the southwestern portion of the state, with the most severely impacted being Kanawha, Cabell, Raleigh, Mercer, and Berkeley as the exception in the east. 


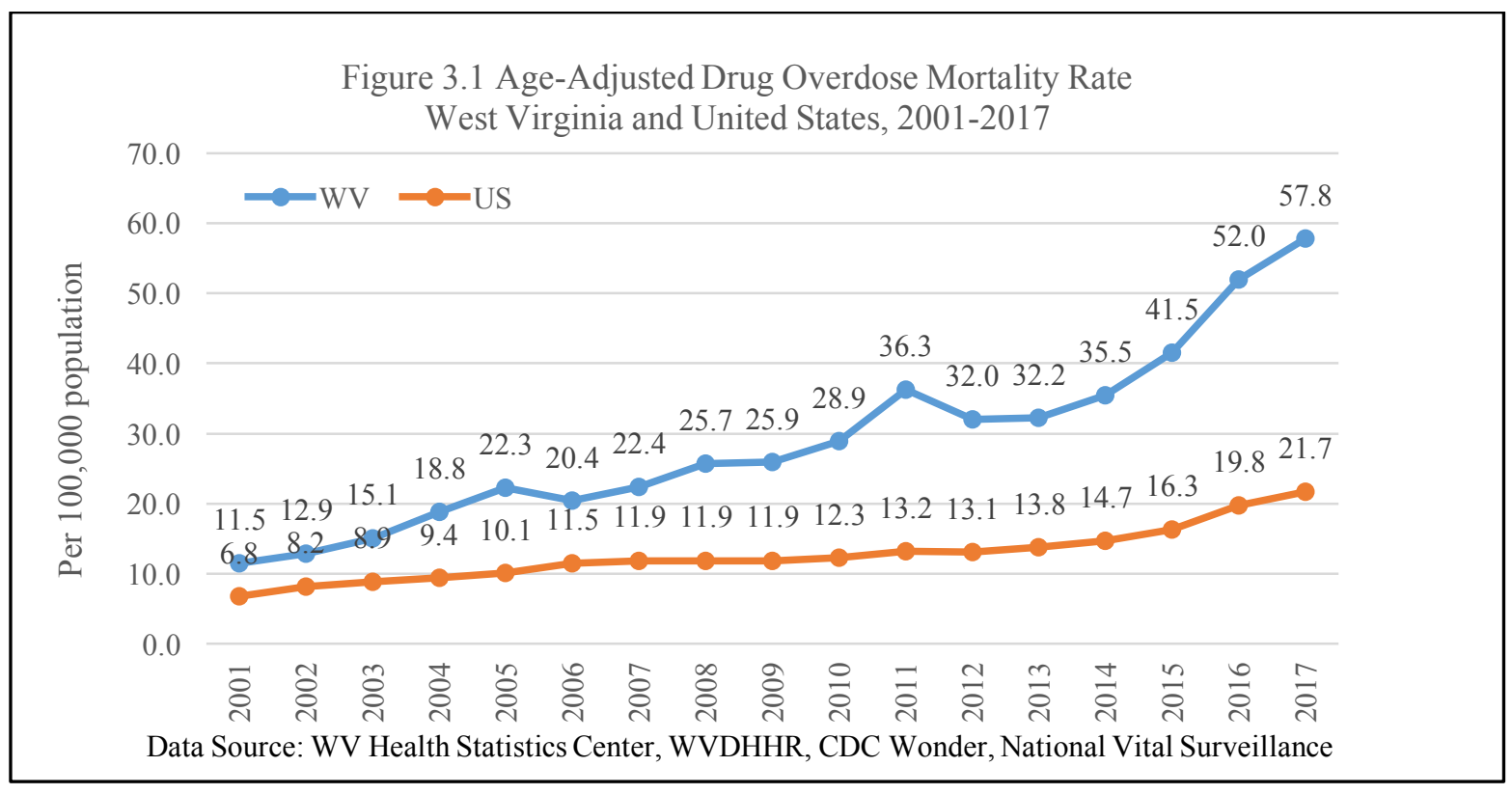

Figure 3.2 West Virginia Opioid-related Overdose Deaths by Year \& Gender 2001-2016 Occurrences $(\mathrm{N}=6,352)$

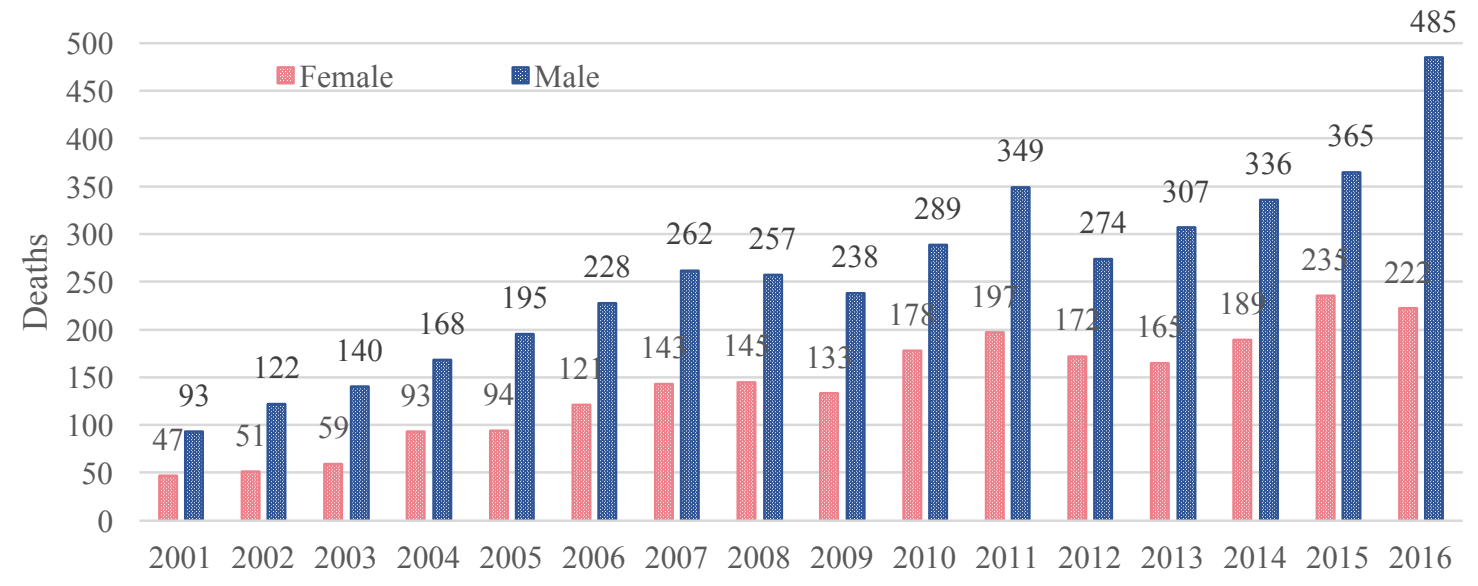




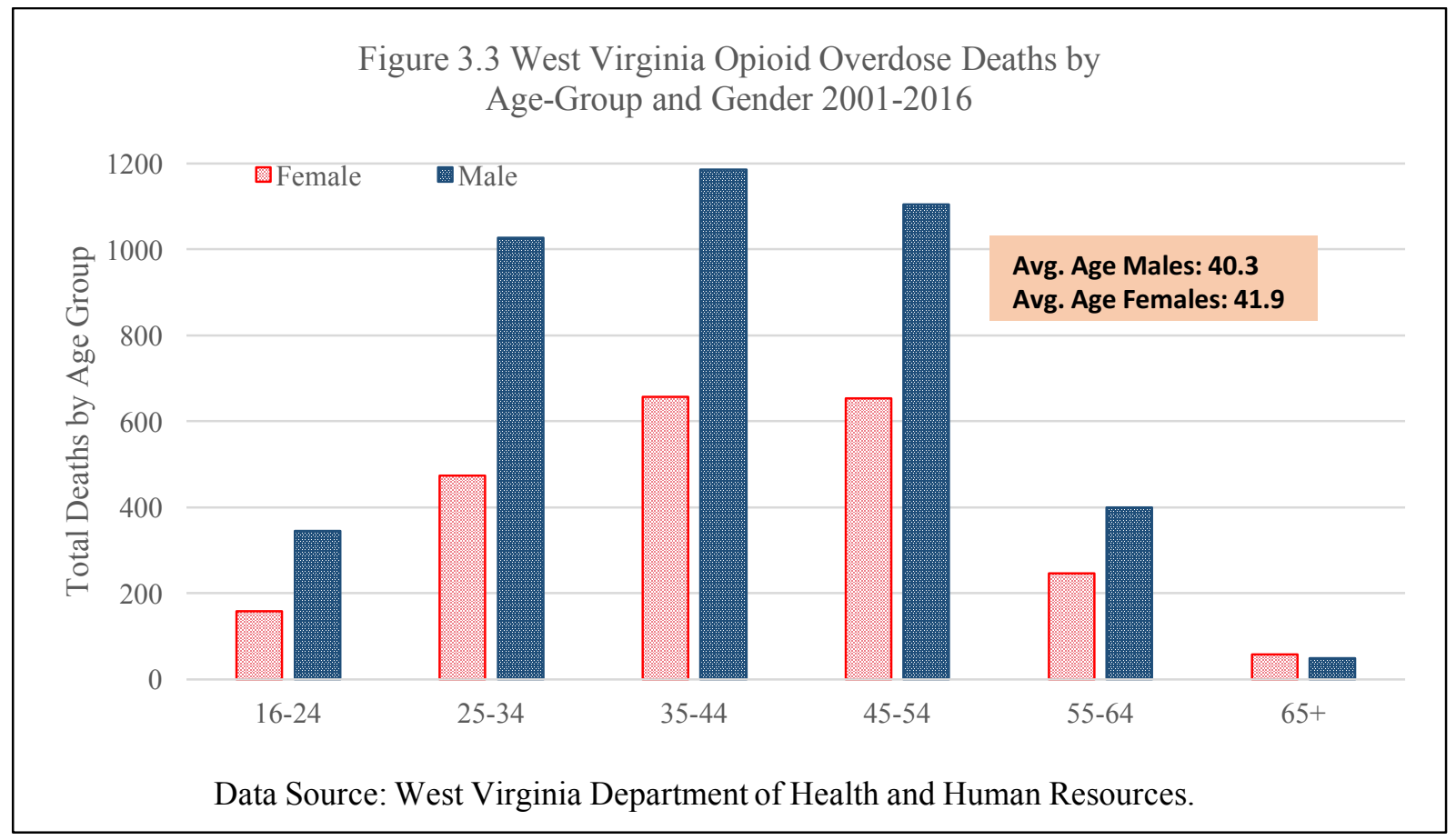

In addition to the social and economic impacts associated with drug overdose deaths, there are also related public health issues that arise due to opioid use and abuse. In 2015 West Virginia reported a rate of 14.7 cases of hepatitis B per 100,000 population, compared with the United States as a whole reporting $<1$ per 100,000 population, as well as a rate of hepatitis $\mathrm{C}$ infection 4 times that of the national trend. ${ }^{41}$ Even more alarming, in 2017 West Virginia reported an outbreak of HIV that affected 15 counties located primarily in the southern part of the state. Though not all of the cases of HIV were identified as having been transmitted via intravenous drug use, the outbreak's proximity to counties with high rates of illicit drug abuse is cause for concern (Evans et al, 2017). As was previously noted in Figure 3.4, these are also counties that exhibit higher numbers of opioid overdose deaths. Thus, the severity of this public health crisis cannot be overstated. Its concentration in the Appalachian Region, and West Virginia in particular, and the serious social and economic implications associated with it are particularly alarming.

\footnotetext{
${ }^{41}$ West Virginia Department of Health and Human Resources, West Virginia Drug Overdose Deaths Historical Review 2001-2015, August 2017.
} 


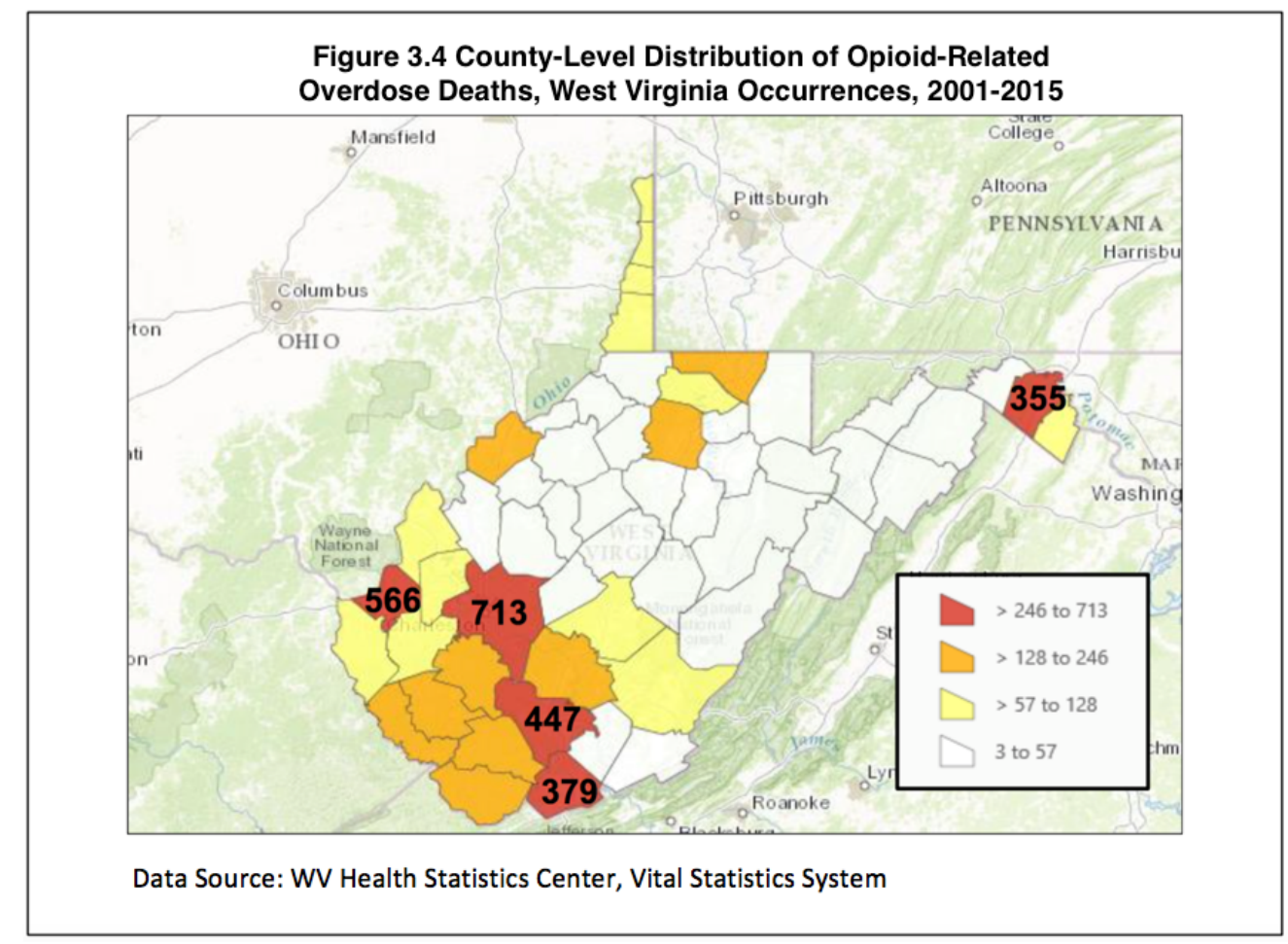

In this paper we utilize confidential death certificate data obtained from the state of West Virginia to analyze both the individual characteristics and local economic conditions associated with opioid overdose deaths across the state. Using this individual-level allows us to link each death to local socioeconomic and industry data across time, which enables us to gain some insight regarding the impact of regional economic growth (decline) — such as that observed in southern West Virginia's "coal country" — on opioid overdose deaths.

\subsection{Previous Research}

The literature associated with drug overdose deaths in the United States paints a complex, sometimes conflicting, picture. Not only do the effects of this public health crisis vary across demographic groups, they vary regionally, as well as across different types of drug user types. For example, Rigg and Monnat (2015) using data from the National Survey on Drug Use and Health, highlight variations in individual characteristics of drug users across different drug-use groups: heroin-only users (HO), prescription painkiller-only users (PPO) and individuals who use both heroin and prescription painkillers (HPP). While HO users were associated with socioeconomic disadvantage, older age, and interactions with the criminal justice system, PPO users were more 
economically stable, more connected to social institutions, and the least likely to have had criminal justice interactions. HPP users were more likely to be young, white males with poor physical/mental health as well as a history of drug use that began during adolescence. ${ }^{42}$

Rigg and Monnat (2014) also identify differences in the individual-level characteristics of those engaging in prescription opioid misuse (POM). Compared to non-users, POM's in their sample tended to be white, younger, low-income, low-education, urban residents, with children living in the household. Probability of POM was significantly lower among women, those who were married, and those with health insurance. However, Case and Deaton (2015) note that changes in all-cause mortality for whites ages 45-54, driven largely by drug and alcohol poisonings and suicides, are similar for both men and women.

Perhaps due to data limitations, previous research trying to examine the differences in drug overdose deaths across space, has utilized aggregated data, primarily at the county level. For example, Goetz et al. $(2015,2018)$ utilize county-level data to highlight the importance of including local industry employment data into analyses of drug overdose deaths. They find that places with more self-employment have a significant reduction in the average number of poor mental health days - which could contribute to drug use - despite individual stress related to uncertainty of wages and longer working hours. ${ }^{43}$ They also report important differences in drug overdoses in places with different industries, such as farming, manufacturing, and mining, which vary depending on the time period being examined. As will be discussed later in this paper, we build upon this work, by controlling for both an individual's industry of employment as well as local industry employment changes and how these characteristics impact the risk of an opioid overdose death over time.

Whether or not the problem of drug overdose deaths or POM is a rural or urban problem remains a somewhat contested subject in the literature. On one hand, some research finds that individuals in rural settings are more likely to engage in POM (Havens et al. 2007, Rosenblum et al. 2007) or

\footnotetext{
${ }^{42}$ We do not currently differentiate between drug-user types in this paper. However, this is an interesting avenue of research that we intend to explore further in the future.

${ }^{43}$ While the dataset we utilize in this analysis provides detailed information on the individual's industry of employment it, unfortunately, does not allow us to identify individuals who are selfemployed.
} 
begin using prescription opioids for nonmedical reasons and at earlier ages (Young et al 2012). Goetz and Davlasheridze (2018) also find that more rural areas, as measured by population density, are associated with higher overdose rates while Kuehn (2014) notes that, compared to previous generations of heroin users, newer users tend to be older, white, live in nonurban areas, and to have a history of prescription painkiller abuse. On the other hand, some research suggests either similar rates of POM in rural and urban areas (Wang et al. 2007) or that the distinction, with regards to population density, it not associated with POM (Spiller et al. 2009). While the state of West Virginia does not have a particularly high population density-it is ranked $29^{\text {th }}$ among U.S. states as of 2016 estimates - we nonetheless include population density and a measure of opioid overdose concentrations in our analysis. Betz and Jones (2018) find mixed results with regard to the urban/rural debate, and observe heterogeneous effects of employment growth on overdose rates across racial groups living in rural areas.

The trade-off between prescription drug access and illicit drug use has also been documented in the literature, especially as it pertains to the effectiveness of policy prescriptions. Although various federal, state, and local agencies have instituted policy prescriptions aimed at reducing overdose deaths - opioid related deaths in particular-these interventions have produced mixed results. While Dart et al. (2015) note a plateauing of prescription opioid abuse between 2011 and 2013, this has been accompanied by an increase in heroin use (Kuehn, 2014). A similar story with regards to heroin use has played out in West Virginia, with there being more heroin-involved overdose deaths in WV between 2012-2015 (523 deaths) than during the previous 11 years (296 deaths). ${ }^{44}$ We discuss opioid-specific overdose trends in some detail in a later section.

In general, though the issue of increasing rates of drug overdose deaths - opioid-related overdose deaths in particular-has received much attention in the literature, previous research has been limited in its ability to identify and control for the individual characteristics of each overdose death. This limitation is primarily due to the nature of publicly available death certificate data, which is typically aggregated up to a non-individual level. While most of the previous research has thus looked at the relationship between county-level factors and the aggregate number of overdose

${ }^{44}$ West Virginia Drug Overdose Deaths Historical Review, 2001-2015, WVDHHR. 
deaths, this paper represents the first analysis of opioid-related overdose deaths based on individual characteristics as well as more localized measures of economic activity.

\subsection{Econometric Approach \& Data}

We are interested in examining the individual and regional characteristics associated with opioid overdose deaths in the state of West Virginia. Thus our variable of interest is whether or not an individual has died due to an opioid-involved overdose death, and all results will be relative to

other types of deaths. ${ }^{4546} \mathrm{We}$ utilize a logit model to test what variables are important in regard to increased (decreased) likelihood of dying of an opioid overdose death. In our analysis we include a vector of individual-level characteristics, local characteristics and industry controls, as well as combinations of time and county fixed effects. Our base model specification is detailed below. A logit model is illustrated by equation (1), where $\mathrm{G}$ is the logistic function:

$$
\operatorname{Pr}\left(\mathrm{OOD}_{i c t}=1\right)=G(z)=\frac{e^{z}}{1+e^{z}}
$$

Where

$$
z_{i c t}=\beta_{0}+\beta_{1} X_{i t}+\beta_{2} \text { Community }_{c t}+\alpha_{c}+\varphi_{t}+\varepsilon
$$

In equation (1) the probability of an $\mathrm{OOD}$ for individual $i$, in county $c$, at time $t$, is modeled as a logistic function of various factors $\left(z_{i c t}\right)$. As shown in equation (2) this includes a vector of individual-level characteristics $X_{i t}$ such as age, sex, race, and education level, and a vector of timevarying community-level characteristics Community $_{c t}$ such as changes in industry-specific employment levels. We focus exclusively on opioid overdose deaths in this analysis as opioidinvolved deaths account for over $80 \%$ of all drug overdose deaths occurring in West Virginia during our sample period.

\footnotetext{
${ }^{45}$ We have made every effort to be consistent in our use of the term "opioid overdose death" rather than the more general "drug overdose death" throughout this paper. However, any accidental usage of the latter vs. the former should be understood to refer to opioid overdose deaths only.

${ }^{46}$ Ideally we would look at all opioid users, rather than just those that died from an opioid overdose. Utilizing death certificate data, therefore, is not without its limitations.
} 
Variations on the base model are primarily focused on isolating specific variables of interest for discussion. For example, we begin our analysis by focusing exclusively on the individual characteristics contained within our death certificate dataset. We then add controls such as county level population, density and overdose death controls, followed by the inclusion of further variables controlling for local employment, as well as industry-specific employment, trends at the zip code level. We also experiment with a number of different lagged variations of our employment variables. Finally, we investigate the potential for employment changes in one zip code to generate spillover effects that effect opioid overdose deaths in the surrounding area.

\subsection{Data}

The primary dataset utilized in our analysis consists of all death certificates for the state of West Virginia for individuals aged 16 years or older for the years 2001 through 2016. This dataset was obtained from the West Virginia Department of Health and Human Resources (WVDHHR). ${ }^{47}$ Over this time period the state of West Virginia averaged approximately 21,000 total deaths per year. However, due to the age restriction imposed on the data by the WVDHHR, we observe an average of approximately 19,000 deaths per year for a total of 309,156 individual deaths over our sample period.

Each death certificate contains the individual's age, race, years of education, marital status, address at time of death, industry and occupation codes describing the individual's type of employment ${ }^{48}$, state of birth and, of course, information regarding the cause of death. The cause(s) of death on each certificate is denoted by an International Classification of Disease (ICD-10) code. ${ }^{49}$ ICD codes typically utilized in previous analyses for the identification of drug overdose deaths include: X40-X44, X60-X64, X85, and Y10-Y14 (Goetz and Davlasheridze, 2018, Betz and Jones, 2018). Though the WVDHHR automatically denotes opioid-related overdose deaths, we utilized the ICD-

\footnotetext{
${ }^{47}$ Our research proposal and data request submitted to the WVDHHR accompanied a completed Institutional Review Board Protocol reviewed by the West Virginia University Office of Research Integrity and Compliance.

${ }^{48}$ Industry and Occupation codes on West Virginia death certificates are coded based on the Industry and Occupation Coding for Death Certificates, $8^{\text {th }}$ edition, U.S. Department of Health and Human Services.

${ }^{49}$ The ICD version 10 was adopted by the United States in 1999 and, thus, covers the entirety of our dataset.
} 
10 codes to verify each case and found no errors. We should note that our analysis differs slightly from previous overdose death analyses — such as Case and Deaton (2015) - in that we focus exclusively on overdose deaths related to opioids rather than all drug overdose deaths in general. The ICD-10 codes also allow for the differentiation of deaths caused by illicit drug use (such as heroin) versus those caused by prescription pharmaceuticals (such as oxycodone). Of the 309,156 death certificates in our sample we identified 6,352 cases where an individual died from an opioidrelated drug overdose.

\section{Supplementary Data}

We supplement our primary death certificate dataset with data from a variety of other sources. Micro-level industry data for the state of West Virginia were obtained from the National Establishment Time-Series (NETS) Database from 1996-2015. We aggregate these individual business data to create measures of 2-digit North American Industry Classification System (NAICS) employment codes at the zip code level. We then generate variables to control for both changes in overall employment across zip codes as well as changes in employment across individual industries within each zip code. We lag our employment variables by 1, 3 and 5 years. Finally, to investigate the possibility of spatial spillovers in the employment effects, we use an inverse distance weight matrix with a 50-mile cut-off to generate spatially-lagged employment variables.

We also obtained data from the Census' Longitudinal Employer-Household Dynamics Project (LEHD), which provide block group level information on residents' age and income levels. We aggregate this information up to the zip code level and create variables to control for local residents' age and income shares. As this data relates only to employed residents in any particular area, we include it in only an initial model specification for discussion purposes. Annual countylevel population data was also obtained from the Census.

To control for access to opioids, we obtained data from the Center for Disease Control (CDC) regarding annual retail opioid prescription rates (prescriptions dispensed per 100 persons) for the state of West Virginia at the county level. However, the data are available for only a limited time period (2006-2017) and so are only used in a separate, restricted, analysis discussed further in the results section. It is noteworthy, however, that between 2006 to 2017, when retail opioid 
prescriptions rates were documented, West Virginia averaged approximately 131 prescriptions per 100 population, while the national average was approximately 76 per 100 population.

\subsection{Summary Statistics}

Table 3.1 provides summary statistics for the basic characteristics of the individuals within our West Virginia death certificate dataset. As noted previously, the WVDHHR did not release death certificates to us for individuals under the age of 16. Thus, our sample does not capture minors who died due to an opioid overdose. ${ }^{50}$ Panel A of Table 3.1 provides summary statistics for all deaths in our death certificate dataset for individual between the ages of 16 and 65, while Panel B is restricted to opioid overdose deaths only. Approximately $7 \%$ of this age-restricted sample was recorded as having died due to an opioid overdose.

Restricting the sample of death certificates to individuals aged 16 to 65 allows us to make more meaningful, though general, comparisons of characteristics across individuals in our sample for two reasons. First, individuals who died from an opioid overdose death averaged approximately 41 years of age, well below both the average age at the time of death for our full sample of death certificates (73.2 years) as well as that of the most recent overall life expectancy of the United States reported by the CDC (78.6 years). ${ }^{51}$ Second, over $98 \%$ of individuals who died of an opioid overdose were under the age of 66. Thus, it makes more sense to compare the individual characteristics of opioid overdose deaths to those of a restricted age group as, unfortunately, few opioid users are likely to live to an advanced age. Additionally, after 65, people are more likely to die, in general, from a number of age-related causes.

Via Panel B of Table 3.1, we observe that males accounted for roughly two thirds of all opioid overdose deaths (OODs) and that the sample was overwhelmingly white. ${ }^{52}$ Individuals in our OOD sample were less likely to be married though about as likely to have graduated high school as

\footnotetext{
${ }^{50}$ A comparison between Table 3.1 of this paper and the WVDHHR's own publicly available summary of opioids recorded on death certificates suggests that the number of opioid overdose deaths observed among individuals less than 16 years of age was greater than zero.

${ }^{51} \mathrm{https} / /$ www.cdc.gov/nchs/fastats/life-expectancy.htm

${ }^{52}$ Given the makeup of West Virginia's racial demographics, this is not surprising. https://www.census.gov/quickfacts/WV
} 
individuals in our general sample. Though marriage has been cited as a protective factor against drug use (Heinz et al., 2009), it is unclear whether or not the lower rate of marriage observed among our West Virginia sample is a result of opioid user's ability (or inability) to attract a mate due to their drug use or, rather, is due to opioid user's behavior negatively impacting already established marriages that then eventually end in divorce. The structure of our dataset does not allow us to untangle the complexities of this particular relationship. College graduation rates were higher among the general death certificate sample than among our OOD sample, suggesting that education may reduce the likelihood that an individual uses and abuses opioid. Education has the potential to generate positive outcomes with respect to opioid overdose deaths either through reducing use via general knowledge of the negative health effects associated with opioid use or by increasing an individual's economic opportunities. Finally, approximately $70 \%$ of individuals in our opioid overdose sample were born in the state of West Virginia.

\begin{tabular}{|c|c|c|c|c|}
\hline \multicolumn{5}{|c|}{ Panel A - Restricted Sample, All Deaths, Age 16-65. } \\
\hline Variable & Mean & Std. Dev. & Min & $\operatorname{Max}$ \\
\hline Opioid OD Death & $7.3 \%$ & .2600701 & 0 & 1 \\
\hline Age & 52.0 & 11.41014 & 16 & 65 \\
\hline Male & $62.2 \%$ & .4849973 & 0 & 1 \\
\hline White & $95.6 \%$ & .2054709 & 0 & 1 \\
\hline Married & $45.7 \%$ & .4981309 & 0 & 1 \\
\hline HS Graduate & $74.1 \%$ & .4379947 & 0 & 1 \\
\hline College Graduate & $10.6 \%$ & .3075533 & 0 & 1 \\
\hline WV Born & $74.2 \%$ & .4375965 & 0 & 1 \\
\hline Observations & 85,898 & & & \\
\hline \multicolumn{5}{|c|}{ Panel B - Restricted Sample, Opioid Overdose Deaths, Age 16-65. } \\
\hline Variable & Mean & Std. Dev. & Min & Max \\
\hline Age & 40.5 & 10.87704 & 16 & 65 \\
\hline Male & $64.9 \%$ & .4771354 & 0 & 1 \\
\hline White & $97.1 \%$ & .1674867 & 0 & 1 \\
\hline Married & $30.3 \%$ & .4594617 & 0 & 1 \\
\hline HS Graduate & $74.3 \%$ & .4368705 & 0 & 1 \\
\hline College Graduate & $6.7 \%$ & .2503487 & 0 & 1 \\
\hline WV Born & $69.1 \%$ & .4620848 & 0 & 1 \\
\hline Observations & 6,267 & & & \\
\hline
\end{tabular}


Table A1 in the appendix provides summary statistics for opioid overdose deaths by gender. There are several disparities worth noting between male and female opioid overdose deaths. Females in our opioid overdose death samples lived, on average, slightly longer than their male counterparts ( 41.9 vs. 40.3 years) and exhibited much higher rates of marriage at their time of death $(36.3 \%$ vs. 26.9\%). Also, while both genders in this sample exhibit comparable rates of high school graduation, females in the opioid overdose sample were more likely to have graduated college than males (10.6\% vs. $6.8 \%)$. This particular observation is not necessarily surprising given that women have exhibited higher rates of college graduation than men for decades (Goldin et al., 2006).

That females in our opioid overdose sample lived slightly longer than their male counterparts is possibly due to differences in the specific opioids that each gender utilizes and/or encounters. For example, some of the most powerful opioids recorded in our death certificate dataset are carfentanil, fentanyl, buprenorphine and oxymorphone. Carfentanil is 10,000 times more potent than morphine (O'Donell, 2018), fentanyl is 50-100 times more potent, buprenorphine is $25-100$ times more potent ${ }^{53}$ and oxymorphone is 3-10 times more potent. ${ }^{54}$ Among our opioid overdose sample, males consistently exhibited higher rates of overdose deaths involving these four opioids. Though carfentanil-involved deaths were relatively rare in our dataset, the carfentanil-involved overdose death rate among males was over $50 \%$ higher than that of females. For fentanyl-involved deaths the overdose death rate among males was approximately $17 \%$ higher than females. For buprenorphine-involved and oxymorphone-involved deaths the overdose death rates were $23 \%$ and $9 \%$ higher, respectively. This suggests that, whether through preferences or intensity of opioid use, males are encountering stronger, more potent, opioids at higher rates than females in our sample, which may explain females' opioid users slightly longer life expectancy.

\subsection{Opioids Recorded on West Virginia Death Certificates}

Table 3.2 below provides a non-comprehensive list of opioids recorded on the West Virginia death certificates of individuals who died due to an opioid overdose. This table shows some interesting

\footnotetext{
${ }^{53}$ Buprenorphine is commonly known as Subutex and is used to treat opioid addiction. However, unlike methadone, which is also utilized to treat opioid addiction but is dispensed through clinics, buprenorphine can be prescribed and dispensed by a physician. This increases the potential for abuse and diversion.

${ }^{54}$ For further reference, heroin is approximately $2-5$ times more potent than morphine.
} 
trends in specific opioid use over time in the state of West Virginia. First, note that the top 5 opioids in terms of total number of deaths over time are oxycodone, hydrocodone, methadone, fentanyl and heroin. This is an interesting selection of opioids in that it includes two prescription opioids (oxycodone and hydrocodone), an opioid that is used to treat opioid addiction (methadone) ${ }^{55}$ and two primarily illicit opioids (fentanyl and heroin). ${ }^{56}$

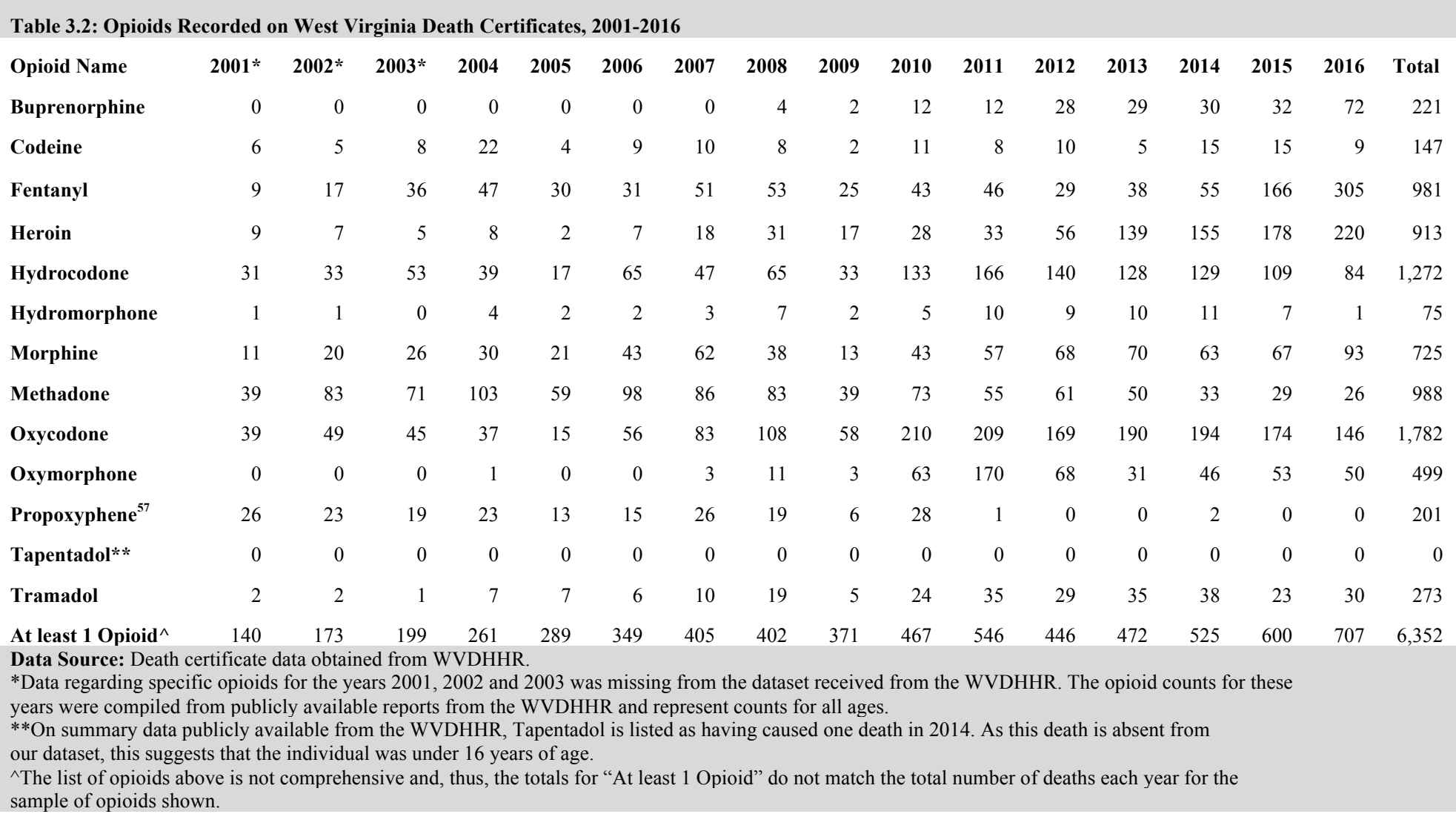

${ }^{55}$ Methadone prescription as a treatment for opioid addiction has decreased over time due to the advent of suboxone (which contains buprenorphine), a safer alternative for opioid addiction treatment in that it is more difficult, though by no means impossible, to overdose from. Figure A2 in the appendix highlights the decline of methadone-involved overdose deaths relative to those of buprenorphine.

56 Though fentanyl can be obtained legally via prescription, the increase in fentanyl-related opioid overdose deaths since 2013 has been associated with illicitly manufactured fentanyl (Gladden et al., 2016).

${ }^{57}$ Propoxyphene, commonly referred to as Darvocet, was banned by the FDA in 2010 due to its being linked with the development of serious heart problems. 
The relative trends for these opioids (excluding methadone) are shown in Figure 3.5. This graph highlights several interesting points. First, up until the year 2005, overdose deaths across these four opioids were relatively stable. Then, from 2006 until 2011 we observe rapid growth in opioid overdose deaths involving the prescription opioids hydrocodone and oxycodone. Finally, from 2012 until the latest year of our data we observe a decline in opioid overdose deaths involving these prescription opioids, while simultaneously observing a rapid increase in the number of opioid overdose deaths involving the illicit opioids fentanyl and heroin. This apparent trade-off between illicit and prescription opioid abuse has been documented in the literature and coincides with the implementation of various government policies that often involve supply-side remedies aimed at reducing the quantity of legal opioids prescribed (Dart et al., 2015 and Kuehn, 2014).

Given the points highlighted in Figure 3.5, it may be appropriate to think of the evolution of the opioid epidemic in West Virginia as being composed of three distinct time periods: the preprescription opioid period, the prescription opioid period and the illicit-opioid period. Indeed, it is becoming more common to hear researchers refer to the "pre-fentanyl" era, given how rapidly overdose deaths associated with it have grown in recent years. To highlight this point, we note that more people died in West Virginia from fentanyl-related overdoses during the most recent three years of our dataset (526), than did during the previous thirteen years (455).

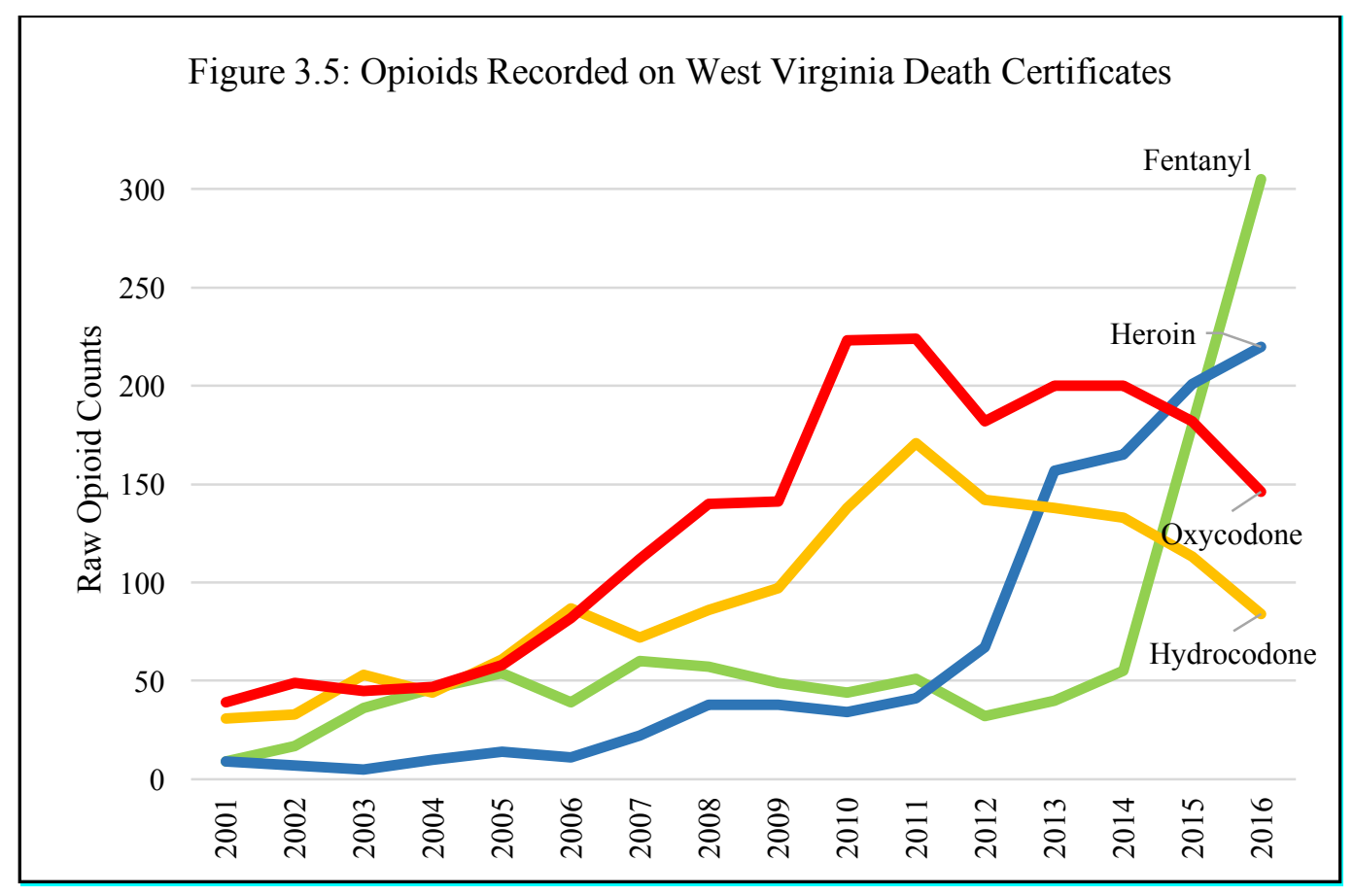




\subsection{Results - Basic Individual Characteristics and Opioid Deaths}

We begin with an analysis of the effect of basic individual characteristics on overdose deaths to motivate if restricting the age range of our dataset is likely to skew our results. As was hinted at during a review of the summary statistics, when attempting to identify the individual characteristics most associated with an increased (decreased) likelihood of dying from an opioid overdose it may be not be appropriate to include individuals who lived a relatively long life in a comparison group for individuals who died from an opioid overdose death. Put differently, because opioid users live, on average, far shorter lives than the average person, comparing them to individuals who die of late life age-related causes may not be appropriate. Thus, restricting our sample based on age may be warranted.

Table 3.3 presents the results of our initial regressions utilizing only the basic characteristics of the individuals in our death certificate sample. The dependent variable across this and all additional model specifications will remain the $0 / 1$ binary variable indicating whether or not the individual died of an opioid overdose. All tables present the marginal effects, rather than coefficients. For this basic analysis we control for age, age squared, sex, race, marriage, high school graduate, college graduate and whether or not the individual was born in the state of West Virginia. Table 3.3 presents the results for our full sample (Model 1) and samples restricted by age (65 years of age and below) and then by sex and race (Models 2-6).

The results are consistent across all sample groups tested. The marginal effect on years of age confirms that, with each additional year of age, an individual runs an increased risk of dying due to an opioid overdose. However, we observe via the negative coefficient of age squared that the effect decreases as individuals become older. This is likely due, again, to the fact that individuals who abuse opioids are unlikely to live long lives. Per Figure 3.3 the vast majority of individuals dying from an opioid overdose do so between the ages of 25 and 54. Figure 3.3 also shows that very few individuals who die from an opioid overdose make it into the 55-65+ age range. As previously noted, the average age of opioid overdose deaths was 40.3 for males and 41.9 for females. 
Despite making up a larger portion of the opioid overdose deaths in West Virginia, and after controlling for other individual characteristics, being male did not generate a statistically significant effect. However, whites were by far more likely to die of an overdose death, relative to all other races. Consistent with our earlier discussion, marriage is associated with a decreased likelihood of an opioid overdose death but this result is merely descriptive due to issues of reverse causality.

To the extent that education may generate positive health outcomes by decreasing the likelihood of opioid use, abuse and subsequent death, the benefits do not present as significant at the level of high school graduate. However, individuals who completed college were consistently less likely to die from an opioid overdose than individuals who did not, with the exception of Model 6, which was restricted to non-whites only. It should be noted that Model 6 only consisted of 3,794 individuals, as non-whites make up a very small percentage of all opioid overdose deaths in West Virginia.

Individuals who were born in West Virginia were consistently less likely to die from an opioid overdose than individuals who were born in a different state, despite making up nearly $70 \%$ of the sample of opioid overdose deaths. This raises an interesting question regarding the characteristics of individuals migrating to, or working in, the state relative to native born West Virginians and may warrant further examination in the future.

\begin{tabular}{|c|c|c|c|c|c|c|}
\hline & \multirow[t]{2}{*}{ Full Sample } & \multicolumn{5}{|c|}{ Restricted Sample: Ages 16 to 65} \\
\hline & & All & Male & Female & White & Non-White \\
\hline Variables & Model 1 & Model 2 & Model 3 & Model 4 & Model 5 & Model 6 \\
\hline Years of age & $\begin{array}{l}0.00415^{* * *} \\
(0.000127)\end{array}$ & $\begin{array}{l}0.0156^{* * *} \\
(0.000511)\end{array}$ & $\begin{array}{c}0.0167^{* * *} \\
(0.000661)\end{array}$ & $\begin{array}{c}0.0138^{* * *} \\
(0.000805)\end{array}$ & $\begin{array}{c}0.0161^{* * *} \\
(0.000528)\end{array}$ & $\begin{array}{l}0.00531^{* *} \\
(0.00181)\end{array}$ \\
\hline Age Squared & $\begin{array}{c}-0.0000659^{* * *} \\
(0.00000155)\end{array}$ & $\begin{array}{l}-0.000246^{* * *} \\
(0.00000634)\end{array}$ & $\begin{array}{l}-0.000260^{* * *} \\
(0.00000825)\end{array}$ & $\begin{array}{l}-0.000221^{* * *} \\
(0.00000990)\end{array}$ & $\begin{array}{l}-0.000253^{* * *} \\
(0.00000656)\end{array}$ & $\begin{array}{c}-0.0000976^{* * *} \\
(0.0000226)\end{array}$ \\
\hline Male & $\begin{array}{c}-0.000346 \\
(0.000495)\end{array}$ & $\begin{array}{r}-0.000736 \\
(0.00177)\end{array}$ & $\begin{array}{l}0 \\
\text { (.) }\end{array}$ & $\begin{array}{l}0 \\
(.)\end{array}$ & $\begin{array}{l}-0.00111 \\
(0.00182)\end{array}$ & $\begin{array}{c}0.00690 \\
(0.00749)\end{array}$ \\
\hline White & $\begin{array}{l}0.0112^{* * *} \\
(0.00137)\end{array}$ & $\begin{array}{l}0.0394^{* * *} \\
(0.00488)\end{array}$ & $\begin{array}{l}0.0368^{* * *} \\
(0.00603)\end{array}$ & $\begin{array}{l}0.0446^{* * *} \\
(0.00846)\end{array}$ & $\begin{array}{l}0 \\
\text { (.) }\end{array}$ & $\begin{array}{l}0 \\
(.)\end{array}$ \\
\hline Married & $\begin{array}{l}-0.00737^{* * *} \\
(0.000519)\end{array}$ & $\begin{array}{l}-0.0257^{* * *} \\
(0.00185)\end{array}$ & $\begin{array}{l}-0.0294^{* * *} \\
(0.00246)\end{array}$ & $\begin{array}{l}-0.0200^{* * *} \\
(0.00278)\end{array}$ & $\begin{array}{l}-0.0257^{* * *} \\
(0.00189)\end{array}$ & $\begin{array}{l}-0.0279^{* *} \\
(0.00932)\end{array}$ \\
\hline High School & $\begin{array}{l}-0.000296 \\
(0.000549)\end{array}$ & $\begin{array}{l}-0.00110 \\
(0.00196)\end{array}$ & $\begin{array}{l}0.000884 \\
(0.00253)\end{array}$ & $\begin{array}{l}-0.00446 \\
(0.00311)\end{array}$ & $\begin{array}{c}-0.000976 \\
(0.00201)\end{array}$ & $\begin{array}{l}-0.00243 \\
(0.00927)\end{array}$ \\
\hline
\end{tabular}




\begin{tabular}{|c|c|c|c|c|c|c|}
\hline College & $\begin{array}{l}-0.00619^{* * *} \\
(0.000929)\end{array}$ & $\begin{array}{l}-0.0228^{* * *} \\
(0.00333)\end{array}$ & $\begin{array}{l}-0.0254^{* * *} \\
(0.00450)\end{array}$ & $\begin{array}{l}-0.0187^{* * *} \\
(0.00486)\end{array}$ & $\begin{array}{c}-0.0229^{* * *} \\
(0.00344)\end{array}$ & $\begin{array}{l}-0.0190 \\
(0.0125)\end{array}$ \\
\hline WV Born & $\begin{array}{l}-0.00251^{* * *} \\
(0.000515)\end{array}$ & $\begin{array}{c}-0.00843^{* * *} \\
(0.00184)\end{array}$ & $\begin{array}{l}-0.00532^{*} \\
(0.00240)\end{array}$ & $\begin{array}{l}-0.0133^{* * *} \\
(0.00283)\end{array}$ & $\begin{array}{c}-0.00802^{* * *} \\
(0.00190)\end{array}$ & $\begin{array}{l}-0.0161^{*} \\
(0.00693)\end{array}$ \\
\hline Observations & 309,156 & 85,898 & 53,392 & 32,506 & 82,104 & 3,794 \\
\hline \multicolumn{7}{|c|}{$\begin{array}{l}\text { Notes: Regression results for the above models are based on the following sample restrictions: Model } 1 \text { represents the full, } \\
\text { unrestricted sample. Models } 2 \text { through } 6 \text { are restricted to individuals aged } 65 \text { or younger with additional restrictions applied } \\
\text { for models } 3-6 \text {. Model } 3 \text { is restricted to males only while model } 4 \text { is restricted to females only. Finally, model } 5 \text { is restricted to } \\
\text { whites only while model } 6 \text { is restricted to non-whites only. } \\
\text { Standard errors in parentheses. }{ }^{*} p<0.05,{ }^{* *} p<0.01,{ }^{* * *} p<0.001\end{array}$} \\
\hline
\end{tabular}

Because the results for our basic individual characteristic analysis are consistent across each model specification, we feel comfortable that restricting our sample to individuals aged 16-65 years old will not unduly skew our results. Thus, all future model specifications and results will be in reference to our death certificate dataset restricted to individuals aged 16-65.

\subsection{Local Characteristics and Opioid Deaths}

We now turn to examining the effect of local area characteristics (at the zip code level) on the likelihood of an individual opioid overdose death while also controlling for the individual characteristics described in the previous section. Table 3.4 presents the results for this initial analysis. Models 1 and 2 are identical except that Model 2 contains a control for county-level opioid prescription rates. County-level opioid prescription rates were only available for the years 2006-2017 and, thus, using them results in a reduced sample size. At the county level we also control for population density and opioid overdose deaths (OOD's) per 100,000 population. We exclude opioids overdose death per 100,000 population from Models 2 in order to isolate the effect of county-level opioid prescription rates on opioid overdose deaths. We utilize the Census' LEHD Origin-Destination Employment Statistics data to calculate local resident's age and income shares at the zip code level. As shown in Table 3.4, which again presents the calculated marginal effects, the results for our individual characteristics remain essentially unchanged with the addition of these county and zip code level variables. Thus, we will turn our attention to a discussion of local characteristics.

The marginal effects for population density are not statistically significant in either model. Our variable for the number of opioid overdose deaths per 100,000 population at the county level, 
however, is positive and statistically significant and, potentially capturing a number of elements related to the opioid epidemic. On one hand, this variable could be capturing peer or neighborhood effects at the county level, in the sense that individuals who are more likely to observe the use and abuse of opioids within their local community are more likely to engage in that same behavior. On the other hand, this could also be capturing an element of the supply side of the opioid epidemic in that areas with higher rates of OODs may simply be reflecting greater access and availability of opioids. With supply side issues in mind, Model 2 includes a control for the county level retail prescription opioid rates covering the years 2006-2016 of our sample. After excluding the countylevel opioid overdose death rates, the observed marginal effect of an increase in the county level retail prescription opioid rate is positive and statistically significant. Unsurprisingly, this indicates that, as the rate of prescription opioids increases in a county, the likelihood of an opioid overdose death increases.

Among our zip code level characteristics, we observe little consistency across model specifications. For our age group controls the omitted category is the percent of individuals aged 55 and above. For incomes shares the omitted category is the percent earning less than $\$ 1251$ per month. Also note, however, that these LODES variables relate only to employed residents in a particular area. Thus, the interpretation of these variables is slightly nuanced. For example, the interpretation of the observed marginal effect on 'percent of residents aged 29 or younger' suggests that, if a particular zip code has a larger share of younger residents that are employed, then the likelihood of an individual opioid overdose death is reduced in that area. This suggests that higher rates of unemployment among relatively younger age groups may contribute to increased rates of opioid overdose deaths over time.

\begin{tabular}{lcc}
\hline \multicolumn{2}{l}{ Table 3.4 - Opioid Overdose Deaths; County and Individual Characteristics - Marginal Effects } \\
\hline Variables & Model 1 & Model 2 \\
\hline Years of age & $0.0140^{* * *}$ & $0.0153^{* *}$ \\
& $(0.00327)$ & $(0.00554)$ \\
Age Squared & $-0.000226^{* * *}$ & $-0.000246^{* *}$ \\
& $(0.0000524)$ & $(0.0000888)$ \\
Male & -0.000842 & -0.00271 \\
& $(0.00185)$ & $(0.00246)$
\end{tabular}




\begin{tabular}{|c|c|c|}
\hline White & $\begin{array}{c}0.0477^{* * *} \\
(0.0122)\end{array}$ & $\begin{array}{l}0.0480^{* *} \\
(0.0184)\end{array}$ \\
\hline Married & $\begin{array}{l}-0.0198^{* * *} \\
(0.00495)\end{array}$ & $\begin{array}{l}-0.0244^{* *} \\
(0.00912)\end{array}$ \\
\hline High School & $\begin{array}{c}-0.00170 \\
(0.00209)\end{array}$ & $\begin{array}{l}-0.00278 \\
(0.00272)\end{array}$ \\
\hline College & $\begin{array}{l}-0.0171^{* *} \\
(0.00528)\end{array}$ & $\begin{array}{l}-0.0243^{*} \\
(0.00984)\end{array}$ \\
\hline WV Born & $\begin{array}{l}-0.00600^{*} \\
(0.00245)\end{array}$ & $\begin{array}{l}-0.00686^{*} \\
(0.00349)\end{array}$ \\
\hline \multicolumn{3}{|l|}{ County Level Characteristics } \\
\hline Population Density & $\begin{array}{c}-0.00000745 \\
(0.000164)\end{array}$ & $\begin{array}{c}0.000856 \\
(0.000615)\end{array}$ \\
\hline OOD per 100,000 & $\begin{array}{l}0.00147^{* * *} \\
(0.000349)\end{array}$ & \\
\hline Opioid RX Rates (2006-2017) & & $\begin{array}{l}0.000181^{*} \\
(0.0000816)\end{array}$ \\
\hline \multicolumn{3}{|l|}{ Zip Level Characteristics } \\
\hline Percent aged 29 or younger & $\begin{array}{c}-0.00230 \\
(0.00184)\end{array}$ & $\begin{array}{l}-0.00863^{*} \\
(0.00386)\end{array}$ \\
\hline Percent aged 30-54 & $\begin{array}{l}-0.000656 \\
(0.00169)\end{array}$ & $\begin{array}{c}-0.00542 \\
(0.00337)\end{array}$ \\
\hline Percent earning $\$ 1251$ to $\$ 3333$ per month & $\begin{array}{c}-0.00320^{* *} \\
(0.00102)\end{array}$ & $\begin{array}{l}0.000262 \\
(0.00174)\end{array}$ \\
\hline Percent earning greater than $\$ 3333 /$ month & $\begin{array}{c}-0.00172 \\
(0.000979)\end{array}$ & $\begin{array}{c}-0.00210 \\
(0.00156)\end{array}$ \\
\hline $\begin{array}{l}\text { Year FE's } \\
\text { County FE's }\end{array}$ & $\begin{array}{l}\mathrm{Y} \\
\mathrm{Y}\end{array}$ & $\begin{array}{l}\mathrm{Y} \\
\mathrm{Y}\end{array}$ \\
\hline Observations & 74906 & 55539 \\
\hline
\end{tabular}

\subsection{Industry of Employment and Opioid Deaths}

Utilizing the industry codes recorded on each West Virginia death certificate allows us to control for each individual's type of employment (or lack of employment) based on the definitions set forth in the Industry and Occupation Coding for Death Certificates (IOC), 8th edition, U.S. Department of Health and Human Services, which is utilized by the WVDHHR. Though we are 
able to control for the industry in which the individual was employed, we are unable to control for whether or not an individual is self-employed in that industry due to the structure of the WVDHHR coding system.

Industry groups were constructed based roughly on the divisions set forth in the IOC handbook with a few exceptions related to industries of particular economic significance to the State of West Virginia. Coal Mining and Natural Gas were previously combined together as one industry and were separated due to the fact that, during this time period, coal jobs were declining as natural gas was increasing. Natural Gas Distribution was separated out from general Utilities. Truck Transportation and Pipeline Transportation were separated out from general Transportation and Warehousing.

Industries under the general category of Healthcare and Social Assistance were mostly combined with the exception of Physician's Offices, Outpatient Care Centers, Home Healthcare Services, Hospitals and Nursing Care Facilities. These particular industries are of interest to our discussion due to increased access to medication and the potential for opioid diversion by healthcare professionals. $^{58}$

The following industries were combined into one large Industry Group: Information, Finance and Insurance, Real Estate, Professional/Technical Services, Management and Administrative Services. Industries falling under the category of Arts, Entertainment and Recreation were all combined, except for Restaurants and Food Services. All Public Administration industries were combined, except for the five branches of the Armed Forces. The category of non-military Public Administration serves as our omitted category.

Table 3.5 presents the results for regressions containing controls for the employment of the individual in the industry variables described above. Model 1 contains only the industry variables while Models 3 includes controls for county and individual characteristics. All results presented in Table 3.5 are marginal effects.

\footnotetext{
${ }^{58}$ A recent report from data firm Protenus finds that, of the cases of medication diversion analyzed in 2018 , doctors and nurses were responsible for $67 \%$ of incidents and $94 \%$ of incidents involved opioids. https://www.protenus.com/2019-drug-diversion-digest
} 
The results for some industries are more consistent between models than others. Oil and Gas Extraction, an important industry to the state of West Virginia, is significant when we do not control for individual and county characteristics but loses all significance otherwise. Coal Mining, possibly the industry most associated with the state, is consistently positive and strongly significant across both model specifications. This results suggests that individuals working (or who have worked) in the Coal Mining industry have a higher, statistically significant, likelihood of dying due to an opioid overdose death. Whether this observed effect is due to opioids being prescribed to treat pain as a result of injuries sustained while working in a high-risk industry or whether this is a "deaths of despair" response to declines in coal industry employment remains to be seen. Regardless, the results are consistent and suggests a strong relationship between employment in the Coal Mining industry and risk of opioid overdose death. All other mining activities (such as the mining of metallics) yielded positive and statistically significant results after controlling for county and individual level characteristics.

The Utilities industry generated positive results, suggesting that employment in this industry is also associated with an increased likelihood of dying from an opioid overdose death. This is an interesting result given that industries more directly related to the extraction of resources necessary for energy production - i.e. coal mining, oil and gas extraction, natural gas distribution-have already been controlled for. However, it is also possible that employment in this industry - which includes the transmission, distribution and maintenance of electrical power as well as sewage treatment facilities - is also associated with higher risk of injury relative to other, less physically demanding, industries.

The Construction industry is another industry that is both prone to job-related injuries as well as highly susceptible to economic shocks leading to large swings in employment over time. It is not surprising then that we observe consistently positive and statistically significant results for this industry. However, it is somewhat surprising that the magnitude of this effect is consistently larger than those observed for the coal industry, whose decline is typically more closely associated with the opioid epidemic in West Virginia.

The results for the Transportation and Warehousing industry are inconsistent across model specifications, losing significance after we include our individual and county controls. However, note that Pipeline Transportation and Truck Transportation have been isolated from this larger, 
more general, industry classification. Pipeline Transportation falls out of the regression entirely due to lack of variation - none of the individuals in our sample working in this sector died due to an opioid overdose-while Truck Transportation does not exhibit any statistically significant results.

The combined Health Care and Social Assistance industry controls failed to produce any significant results, lending support to our decision to separate out other major sources of medical services-Physician's Offices, Outpatient Care Centers, Home Healthcare Services, Hospitals and Nursing Care Facilities - from this broad category. Indeed, we observe some interesting results across these differentiated sources of medical care. While employment in Physician's Offices generated no significant results, the coefficients for Outpatient Care Centers suggest that employment in this industry increased the likelihood of an individual dying from an opioid overdose. The results for Home Health Care workers were similar, but lose significance when we control for individual and county characteristics. Employment in Hospitals was positive and statistically significant in Model 2. These results may be an indication of opioid diversion by medical personnel, as previous research has shown that, though diversion has been documented in all 50 states, it is highly concentrated in rural areas (Inciardi et al. 2007).

Illicit substance use and abuse has been well documented in the food services industry, with national surveys suggesting that restaurant workers have both the highest rates of past month substance abuse and past year substance use disorder ${ }^{59}$ among all industries in the United States (Bush \& Lipari, 2015). It is therefore unsurprising that we observe consistently positive and statistically significant coefficients for our Restaurant and Food Services industries. The combined industry group of Arts, Entertainment and Food Services-which contains employment in hospitality industries similar to restaurant and food services - exhibits, when significant, positive coefficients. Thus, employment in these industries follows national trends and suggests an increased likelihood of opioid use, abuse and subsequent death.

Our controls for the five branches of the armed forces generated no statistically significant results, with individuals serving in the Coast Guard falling out of the regression completely due to none having died from an opioid overdose during our sample period. This is noteworthy if for no other

${ }^{59}$ Substance use disorder is defined as "dependence on or abuse of alcohol or illicit drugs." 
reason than that previous research has documented that members of the armed forces report rates of chronic pain nearly double that of the general population as well as rates of regular opioid use nearly four times that of the general population (Jonas, 2014). Controls for individuals in the Reserves or National Guard were statistically significant only when we do not control for individual and county characteristics.

Unemployed and unpaid workers (such as homemakers) were consistently more likely to die from an opioid overdose. This lends support to the idea that decreased economic opportunities and economic distress in general are strong forces that drive the use and abuse of opioids.

Table 3.5 - Opioid OD Deaths, Employment, County and Individual Characteristics - Marginal Effects.

\begin{tabular}{|c|c|c|}
\hline Variables & Model 1 & Model 2 \\
\hline Agri., Forestry, Fishing, Hunting & $\begin{array}{c}0.0255^{*} \\
(0.0103)\end{array}$ & $\begin{array}{c}0.00944 \\
(0.00902)\end{array}$ \\
\hline Oil \& Gas Extraction & $\begin{array}{l}0.0431^{*} \\
(0.0171)\end{array}$ & $\begin{array}{c}0.0153 \\
(0.0149)\end{array}$ \\
\hline Coal Mining & $\begin{array}{c}0.0175^{* *} \\
(0.00661)\end{array}$ & $\begin{array}{l}0.0261^{* * *} \\
(0.00735)\end{array}$ \\
\hline All other mining & $\begin{array}{c}-0.00429 \\
(0.00919)\end{array}$ & $\begin{array}{c}0.0173^{*} \\
(0.00880)\end{array}$ \\
\hline Utilities & $\begin{array}{l}0.0416^{* * *} \\
(0.00897)\end{array}$ & $\begin{array}{l}0.0236^{* * *} \\
(0.00714)\end{array}$ \\
\hline Natural Gas Distribution & $\begin{array}{r}-0.00862 \\
(0.0182)\end{array}$ & $\begin{array}{l}0.00248 \\
(0.0167)\end{array}$ \\
\hline Construction & $\begin{array}{l}0.0521^{* * *} \\
(0.00929)\end{array}$ & $\begin{array}{l}0.0287^{* * *} \\
(0.00684)\end{array}$ \\
\hline Manufacturing & $\begin{array}{c}-0.00000 \\
(0.00558)\end{array}$ & $\begin{array}{c}0.00549 \\
(0.00526)\end{array}$ \\
\hline Wholesale Trade & $\begin{array}{c}0.0111 \\
(0.00839)\end{array}$ & $\begin{array}{c}0.0108 \\
(0.00777)\end{array}$ \\
\hline Retail Trade & $\begin{array}{l}0.0193^{* *} \\
(0.00653)\end{array}$ & $\begin{array}{c}0.00277 \\
(0.00550)\end{array}$ \\
\hline Transportation \& Warehousing & 0.0144 & $0.0159^{*}$ \\
\hline
\end{tabular}


Truck Transportation

$\begin{array}{cc}0.0102 & 0.0103 \\ (0.00838) & (0.00795)\end{array}$

Grouped Industries

0.00674

$-0.00325$

$(0.00606)$

$(0.00555)$

Landscaping Services

$0.0682^{* * *}$

0.0134

(0.0143)

(0.00972)

Waste Management Services

0.0303

0.0128

$(0.0191)$

$(0.0180)$

Educational Services

$-0.0397^{* * *}$

$-0.0111$

(0.0109)

(0.00873)

Health Care \& Social Assistance

0.00211

0.00105

$(0.00714)$

$(0.00654)$

Physician's Office

$-0.00893$

$-0.00406$

(0.0281)

(0.0254)

Outpatient Care Centers

$0.0345^{* * *}$

$0.0219^{*}$

(0.0103)

$(0.00928)$

Home Health Care

$0.0382^{* *}$

0.00593

$(0.0145)$

$(0.0126)$

Hospitals

0.0132

$0.0146^{*}$

$(0.00749)$

$(0.00727)$

Nursing Care Facilities

$-0.0194$

$-0.0315^{*}$

$(0.0161)$

$(0.0155)$

Arts, Entertainment \& Food Services

$0.0300^{* *}$

0.00798

(0.00992)

(0.00838)

Restaurants \& Food Services

$0.0632^{* * *}$

$0.0151^{*}$

(0.0113)

$(0.00633)$

Other Services

0.0136

$0.0148^{*}$

$(0.00776)$

$(0.00743)$

Automotive Repair \& Maintenance

$-0.00263$

$-0.0194^{*}$

$(0.00985)$

(0.00976)

Private Household Employment

$0.0199^{*}$

0.0121

(0.00908)

$(0.00842)$ 


\begin{tabular}{|c|c|c|}
\hline Vehicle Operation, General & $\begin{array}{c}0.0204^{* *} \\
(0.00681)\end{array}$ & $\begin{array}{c}0.00712 \\
(0.00561)\end{array}$ \\
\hline Military - Army & $\begin{array}{c}0.0239 \\
(0.0201)\end{array}$ & $\begin{array}{c}0.0204 \\
(0.0190)\end{array}$ \\
\hline Military - Air Force & $\begin{array}{c}0.0249 \\
(0.0315)\end{array}$ & $\begin{array}{c}0.0484 \\
(0.0306)\end{array}$ \\
\hline Military - Navy & $\begin{array}{l}-0.0473 \\
(0.0482)\end{array}$ & $\begin{array}{l}-0.0196 \\
(0.0430)\end{array}$ \\
\hline Military - Marines & $\begin{array}{c}0.0630 \\
(0.0339)\end{array}$ & $\begin{array}{c}0.0379 \\
(0.0329)\end{array}$ \\
\hline Military - Res. \& Nat. Guard & $\begin{array}{l}0.0781^{*} \\
(0.0346)\end{array}$ & $\begin{array}{c}0.0340 \\
(0.0311)\end{array}$ \\
\hline Unemployed & $\begin{array}{c}0.0756^{* * *} \\
(0.0151)\end{array}$ & $\begin{array}{l}0.0318^{* *} \\
(0.0109)\end{array}$ \\
\hline Unpaid Work & $\begin{array}{l}0.0400^{* * *} \\
(0.00773)\end{array}$ & $\begin{array}{c}0.0130^{*} \\
(0.00520)\end{array}$ \\
\hline Population Density & & $\begin{array}{c}0.000212 \\
(0.000127)\end{array}$ \\
\hline OOD per 100,000 & & $\begin{array}{l}0.00134^{* * *} \\
(0.000235)\end{array}$ \\
\hline Years of age & & $\begin{array}{l}0.0140^{* * *} \\
(0.00239)\end{array}$ \\
\hline Age Squared & & $\begin{array}{l}-0.000225^{* * *} \\
(0.0000381)\end{array}$ \\
\hline Male & & $\begin{array}{l}-0.00449^{*} \\
(0.00226)\end{array}$ \\
\hline White & & $\begin{array}{l}0.0434^{* * *} \\
(0.00872)\end{array}$ \\
\hline Married & & $\begin{array}{l}-0.0198^{* * *} \\
(0.00379)\end{array}$ \\
\hline High School & & $\begin{array}{l}0.000586 \\
(0.00198)\end{array}$ \\
\hline
\end{tabular}




\begin{tabular}{lcc}
\hline Year FE & Y & Y \\
County FE & Y & Y \\
\hline Observations & 85475 & 85475 \\
\hline Standard errors in parentheses. $^{*} p<0.05,{ }^{* *} p<0.01,{ }^{* * *} p<0.001$ & &
\end{tabular}

\subsection{Opioid Overdose Deaths and Employment Spillovers}

In this section we investigate the relationship between changes in local employment conditions and opioid overdose deaths. Specifically, we utilize NETS industry microdata to generate variables to control for changes in both overall employment, and industry-level employment changes at the zip code level. Industry-level employment changes are measured by aggregating individual business data up to the NAICS 2-digit industry code for each zip code in West Virginia and then calculating the percent change in total number of employees working in each industry from year to year. Annual changes in the total number of employees working in each zip code are also calculated. These variables are used to capture whether or not the overall number of employed persons in a zip code is increasing (decreasing) while simultaneously capturing which industries are experiencing growth or decline.

We also include a spatial component to our analysis due to the potential for changes in employment within an individual zip code to generate economic effects that impact individuals living in neighboring zip codes. Utilizing an inverse distance weight matrix (restricted to a 50-mile radius), we generate spatially weighted variations of all of our employment variables to capture the effect that a change in employment in one zip code has on the likelihood of dying from an opioid overdose death of individuals living within 50 miles of that zip code. Because we utilize an inverse weight matrix, individuals living closer to the zip code in question are assumed to be more strongly affected by employment changes than, say, individuals living right at the margin of the 50-mile range. 
Finally, we lag each of our employment variables by 1, 3 and 5 years to observe the effect that changes in employment have on the likelihood of individual opioid overdose deaths over time. The marginal effects for variables in each of the regressions containing our three lags are presented in Table 3.6. The results for variables capturing changes in total employment within a zip code are shown first, followed by the spatially weighted industry employment variables in Panel A and then the non-weighted industry employment variables in Panel B. Models 1-3 represent the results for 1, 3 and 5 year lags of the employment variables. All model specifications include our previously detailed controls for individual characteristics and individual industry of employment, though they are suppressed for readability. Variations of each of the lagged models were also run excluding the spatial spillover variables and individual industry variables but this did not significantly change our results.

Beginning with changes in total employment, we observe no statistically significant effect over the 1, 3 and 5 year lags of this variable, suggesting that employment growth (or decline) in a single zip code is not associated with increased risk of opioid overdose deaths. However, the spatially weighted variation suggests that, as total employment increases in one zip code, we observe an increased likelihood of opioid overdose deaths among the individuals living within 50 miles of the zip code experiencing employment growth. This result is interesting in that we typically expect decreases in employment to increase the likelihood of opioid overdose deaths. This effect appears to grow over time, with the coefficient on the 5 -year lag being much larger in magnitude relative to the 1 and 3-year lags. Though interesting, this result does not tell us much regarding what industries are potentially driving this increase in opioid overdose deaths. For that information we must turn to our industry-specific employment variables.

Turning now to Panel A, we observe that the effect of employment growth within each individual industry sector on the risk of opioid overdose deaths varies widely across industries. Notably Mining, an industry strongly associated with the opioid epidemic in West Virginia, is not observed to have a statistically significant spatial effect on opioid overdose deaths. One explanation for this potentially confusing result is that the mining industry in West Virginia has been in decline for quite some time. Thus, it is possible that the potentially negative effects of widespread decline in this industry had already occurred prior to the start of our sample period. However, recall from our earlier analysis of individual industry employment that individuals in our sample that were 
working in coal mining still exhibited an increased likelihood of an opioid overdose deaths, relative to individuals working in other industries.

Growth in Construction employment is also spatially associated with an increased risk of opioid overdose deaths, at least in the short run as the marginal effects for the 3 and 5-year lags lose their significance. This may highlight the fact that construction work is both seasonal and highly susceptible to employment shocks driven by the state of the national economy. This result is also in line with our findings for individuals who worked in the construction industry.

While no exact delineation exists between the NAICS Manufacturing sectors 31, 32 and 33, they can broadly be defined as (31) Food and Textiles Manufacturing, (32) Wood, Petroleum, Coal and Chemical Manufacturing and (33) Metal, Electronics and Transportation Equipment Manufacturing. Of these three sectors only growth in the Wood, Petroleum, Coal and Chemical Manufacturing sector exhibits a positive, statistically significant effect on opioid overdose deaths, albeit in the short run only. As this industry group contains manufacturing elements associated with the energy sector, this result is not surprising.

Differentiating between Transportation and Warehousing's industry codes 48 and 49 is more straightforward than the codes for the manufacturing sector. Code 48 almost exclusively contains transportation related services, while code 49 contains industries associated with the storage and delivery of goods (warehousing). For Transportation (48) we observe a decreased risk of opioid overdose death over all lag periods, suggesting that growth in this industry generates a beneficial effect with respect to opioid deaths. However, employment growth in Warehousing (49) is observed to generate the opposite effect, with an increased risk of opioid overdose deaths being observed over time. Speaking generally, it is possible that this result is driven by a difference in skill level and training across these two industry divisions. Industry 48 contains jobs requiring specialized training such as air, rail and water transportation while industry 49 contains jobs of relatively lower skill, such as local delivery, general warehousing and the Postal Service. Overall, the coefficients on these industries may suggests that areas experiencing growth in higher-skilled logistics and transportation jobs may observe a decreased risk of opioid overdose deaths relative to areas experiencing growth in lower-skilled jobs. 
Interestingly, growth in the Accommodation and Food Services sector is associated with a decreased risk of opioid overdose deaths, contradicting our previously analysis regarding individual industry employment. One possible explanation for this discrepancy is that growth in this industry may simply be reflecting growth in amenities meant to serve the demands of the local populace or, perhaps, an increasing number of tourists. In that respect, areas experiencing growth in hospitality-related industries may, on average, benefit from the increased economic activity, while individuals working in those industries remain at higher risk of opioid abuse.

\begin{tabular}{|c|c|c|c|}
\hline & $\begin{array}{c}\text { Model 1 } \\
1 \text {-year lags }\end{array}$ & $\begin{array}{c}\text { Model } 2 \\
\text { 3-year lags } \\
\end{array}$ & $\begin{array}{c}\text { Model } 3 \\
\text { 5-year lags }\end{array}$ \\
\hline$\%$ Change in Total Employment & $\begin{array}{c}-0.000113 \\
(0.0000800)\end{array}$ & $\begin{array}{c}0.0000315 \\
(0.0000536)\end{array}$ & $\begin{array}{r}0.0000236 \\
(0.0000911)\end{array}$ \\
\hline$\%$ Change in Total Employment - Spatial Inv. Distance & $\begin{array}{c}0.000190^{*} \\
(0.0000943)\end{array}$ & $\begin{array}{c}0.000181^{*} \\
(0.0000903)\end{array}$ & $\begin{array}{c}0.000711^{* * *} \\
(0.000117)\end{array}$ \\
\hline \multicolumn{4}{|c|}{ Panel A: Percent Change in Industry Employment - Inverse Distance Spatial Lags } \\
\hline Agri., Forest, Fishing, Hunting & $\begin{array}{c}-0.00105^{* * *} \\
(0.000239)\end{array}$ & $\begin{array}{l}-0.000844^{*} \\
(0.000353)\end{array}$ & $\begin{array}{l}-0.00143^{* * *} \\
(0.000408)\end{array}$ \\
\hline Oil \& Gas Extraction & $\begin{array}{c}0.000453 \\
(0.000444)\end{array}$ & $\begin{array}{c}-0.0000918 \\
(0.000435)\end{array}$ & $\begin{array}{c}0.000863 \\
(0.000604)\end{array}$ \\
\hline Mining & $\begin{array}{c}-0.00000346 \\
(0.0000973)\end{array}$ & $\begin{array}{c}0.0000128 \\
(0.0000835)\end{array}$ & $\begin{array}{c}0.0000732 \\
(0.0000730)\end{array}$ \\
\hline Support Activities for Mining & $\begin{array}{c}-0.000145 \\
(0.0000769)\end{array}$ & $\begin{array}{c}-0.0000504 \\
(0.0000737)\end{array}$ & $\begin{array}{r}0.0000224 \\
(0.0000628)\end{array}$ \\
\hline Utilities & $\begin{array}{l}-0.000637^{*} \\
(0.000281)\end{array}$ & $\begin{array}{c}-0.000201 \\
(0.000284)\end{array}$ & $\begin{array}{c}0.000141 \\
(0.000290)\end{array}$ \\
\hline Construction & $\begin{array}{c}0.000624^{* * *} \\
(0.000156)\end{array}$ & $\begin{array}{l}-0.000170 \\
(0.000184)\end{array}$ & $\begin{array}{c}-0.000196 \\
(0.000201)\end{array}$ \\
\hline Manufacturing - 31 & $\begin{array}{c}-0.00000352 \\
(0.000232)\end{array}$ & $\begin{array}{c}0.000193 \\
(0.000262)\end{array}$ & $\begin{array}{c}0.000187 \\
(0.000314)\end{array}$ \\
\hline Manufacturing -32 & $\begin{array}{c}0.000998^{* * *} \\
(0.000211)\end{array}$ & $\begin{array}{l}-0.000316^{*} \\
(0.000137)\end{array}$ & $\begin{array}{c}0.000105 \\
(0.000109)\end{array}$ \\
\hline Manufacturing -33 & $\begin{array}{l}-0.0000550 \\
(0.000112)\end{array}$ & $\begin{array}{l}-0.0000629 \\
(0.0000885)\end{array}$ & $\begin{array}{c}-0.000301^{* *} \\
(0.000116)\end{array}$ \\
\hline Wholesale Trade & $\begin{array}{c}0.0000984 \\
(0.0000713)\end{array}$ & $\begin{array}{c}0.000168^{* *} \\
(0.0000620)\end{array}$ & $\begin{array}{l}-0.000235 \\
(0.000186)\end{array}$ \\
\hline Retail Trade -44 & -0.000223 & 0.000198 & 0.000182 \\
\hline
\end{tabular}


Retail Trade -45

Transportation \& Warehousing - 48

Transportation \& Warehousing - 49

Information

Finance \& Insurance

Real Estate, Rental \& Leasing

Professional Technical Services

Management

Administrative and Support Services

Educational Services

Health Care and Social Assistance

Arts, Entertainment \& Recreation

Accommodation \& Food Services

Other Services (except Public Admin.)

\begin{tabular}{|c|c|c|}
\hline$(0.000147)$ & $(0.000105)$ & $(0.000118)$ \\
\hline $\begin{array}{l}0.0000765^{*} \\
(0.0000353)\end{array}$ & $\begin{array}{c}0.0000157 \\
(0.0000392)\end{array}$ & $\begin{array}{c}0.00000586 \\
(0.0000391)\end{array}$ \\
\hline $\begin{array}{c}-0.000357^{* *} \\
(0.000129)\end{array}$ & $\begin{array}{l}-0.000219^{*} \\
(0.000104)\end{array}$ & $\begin{array}{c}-0.000498^{* * *} \\
(0.000128)\end{array}$ \\
\hline $\begin{array}{c}0.000173^{*} \\
(0.0000826)\end{array}$ & $\begin{array}{c}0.000216^{* *} \\
(0.0000707)\end{array}$ & $\begin{array}{c}0.000226^{* *} \\
(0.0000752)\end{array}$ \\
\hline $\begin{array}{l}0.0000669 \\
(0.000117)\end{array}$ & $\begin{array}{c}0.000173 \\
(0.000110)\end{array}$ & $\begin{array}{l}-0.000165 \\
(0.000230)\end{array}$ \\
\hline $\begin{array}{l}0.0000891 \\
(0.000247)\end{array}$ & $\begin{array}{c}-0.00000690 \\
(0.000329)\end{array}$ & $\begin{array}{l}-0.000781^{*} \\
(0.000393)\end{array}$ \\
\hline $\begin{array}{l}-0.000529^{*} \\
(0.000211)\end{array}$ & $\begin{array}{r}-0.0000384 \\
(0.000131)\end{array}$ & $\begin{array}{r}-0.0000430 \\
(0.000146)\end{array}$ \\
\hline $\begin{array}{c}-0.000342^{* *} \\
(0.000122)\end{array}$ & $\begin{array}{c}0.000145 \\
(0.0000893)\end{array}$ & $\begin{array}{r}-0.0000681 \\
(0.000110)\end{array}$ \\
\hline $\begin{array}{c}0.000328 \\
(0.000493)\end{array}$ & $\begin{array}{l}0.00184^{* * *} \\
(0.000522)\end{array}$ & $\begin{array}{l}0.00288^{* * *} \\
(0.000681)\end{array}$ \\
\hline $\begin{array}{l}-0.000487^{* * *} \\
(0.0000824)\end{array}$ & $\begin{array}{l}-0.000250^{* *} \\
(0.0000790)\end{array}$ & $\begin{array}{l}-0.000252^{* *} \\
(0.0000835)\end{array}$ \\
\hline $\begin{array}{l}-0.000582 \\
(0.000310)\end{array}$ & $\begin{array}{c}-0.000920^{* *} \\
(0.000282)\end{array}$ & $\begin{array}{l}-0.000582^{*} \\
(0.000265)\end{array}$ \\
\hline $\begin{array}{l}0.0000662 \\
(0.000107)\end{array}$ & $\begin{array}{c}0.000128 \\
(0.0000898)\end{array}$ & $\begin{array}{c}0.000110 \\
(0.000153)\end{array}$ \\
\hline $\begin{array}{c}0.000252 \\
(0.000159)\end{array}$ & $\begin{array}{l}-0.000105 \\
(0.000124)\end{array}$ & $\begin{array}{l}-0.000111 \\
(0.000145)\end{array}$ \\
\hline $\begin{array}{l}-0.000579^{*} \\
(0.000238)\end{array}$ & $\begin{array}{c}-0.000802^{* *} \\
(0.000269)\end{array}$ & $\begin{array}{c}-0.000155 \\
(0.000286)\end{array}$ \\
\hline $\begin{array}{l}-0.0000733 \\
(0.0000467)\end{array}$ & $\begin{array}{c}0.0000292 \\
(0.0000375)\end{array}$ & $\begin{array}{c}-0.0000306 \\
(0.0000464)\end{array}$ \\
\hline \\
\hline $\begin{array}{l}-0.0000557 \\
(0.0000335)\end{array}$ & $\begin{array}{c}0.0000643^{*} \\
(0.0000312)\end{array}$ & $\begin{array}{c}0.0000547 \\
(0.0000399)\end{array}$ \\
\hline $\begin{array}{c}0.0000766 \\
(0.0000491)\end{array}$ & $\begin{array}{l}-0.0000595 \\
(0.0000535)\end{array}$ & $\begin{array}{c}-0.0000856 \\
(0.0000691)\end{array}$ \\
\hline $\begin{array}{c}0.0000327 \\
(0.0000263)\end{array}$ & $\begin{array}{l}-0.0000132 \\
(0.0000220)\end{array}$ & $\begin{array}{c}0.0000441 \\
(0.0000357)\end{array}$ \\
\hline $\begin{array}{c}-0.00000879 \\
(0.0000116)\end{array}$ & $\begin{array}{l}-0.0000224^{*} \\
(0.0000110)\end{array}$ & $\begin{array}{c}0.00000635 \\
(0.00000760)\end{array}$ \\
\hline
\end{tabular}

Panel B: Percent Change in Industry Employment Lags

Agri., Forest, Fishing, Hunting

Oil \& Gas Extraction

Mining

Support Activities for Mining 
Utilities

Construction

Manufacturing - 31

Manufacturing - 32

Manufacturing - 33

Wholesale Trade

Retail Trade -44

Retail Trade -45

Transportation \& Warehousing - 48

Transportation \& Warehousing - 49

Information

Finance \& Insurance

Real Estate, Rental \& Leasing

Professional Technical Services

Management

Administrative and Support Services

Educational Services

Health Care and Social Assistance

Arts, Entertainment \& Recreation

\begin{tabular}{|c|c|c|}
\hline $\begin{array}{l}-0.0000283 \\
(0.0000261)\end{array}$ & $\begin{array}{c}0.0000107 \\
(0.0000246)\end{array}$ & $\begin{array}{l}-0.0000343 \\
(0.0000296)\end{array}$ \\
\hline $\begin{array}{l}-0.0000321 \\
(0.0000459)\end{array}$ & $\begin{array}{c}0.0000586 \\
(0.0000373)\end{array}$ & $\begin{array}{c}0.00000394 \\
(0.0000377)\end{array}$ \\
\hline $\begin{array}{c}-0.00000339 \\
(0.0000122)\end{array}$ & $\begin{array}{c}0.0000199 \\
(0.0000125)\end{array}$ & $\begin{array}{l}-0.0000289 \\
(0.0000156)\end{array}$ \\
\hline $\begin{array}{c}0.0000359 \\
(0.0000233)\end{array}$ & $\begin{array}{c}0.0000177 \\
(0.0000110)\end{array}$ & $\begin{array}{c}0.0000118 \\
(0.0000143)\end{array}$ \\
\hline $\begin{array}{l}-0.0000142 \\
(0.0000130)\end{array}$ & $\begin{array}{c}0.000000803 \\
(0.00000986)\end{array}$ & $\begin{array}{r}-0.00000905 \\
(0.0000145)\end{array}$ \\
\hline $\begin{array}{l}-0.0000599 \\
(0.0000398)\end{array}$ & $\begin{array}{l}-0.0000519 \\
(0.0000367)\end{array}$ & $\begin{array}{c}0.0000259 \\
(0.0000330)\end{array}$ \\
\hline $\begin{array}{c}0.000000706 \\
(0.0000231)\end{array}$ & $\begin{array}{c}0.0000211 \\
(0.0000155)\end{array}$ & $\begin{array}{l}0.00000139 \\
(0.0000237)\end{array}$ \\
\hline $\begin{array}{c}-0.00000525 \\
(0.00000770)\end{array}$ & $\begin{array}{c}0.00000340 \\
(0.00000805)\end{array}$ & $\begin{array}{l}-0.0000278 \\
(0.0000245)\end{array}$ \\
\hline $\begin{array}{l}-0.0000183 \\
(0.0000149)\end{array}$ & $\begin{array}{c}-0.0000172 \\
(0.0000137)\end{array}$ & $\begin{array}{r}-0.00000761 \\
(0.0000131)\end{array}$ \\
\hline $\begin{array}{l}0.00000383 \\
(0.0000165)\end{array}$ & $\begin{array}{c}0.0000131 \\
(0.0000121)\end{array}$ & $\begin{array}{l}-0.0000110 \\
(0.0000216)\end{array}$ \\
\hline $\begin{array}{c}0.0000126 \\
(0.0000141)\end{array}$ & $\begin{array}{l}0.00000715 \\
(0.0000134)\end{array}$ & $\begin{array}{r}-0.00000719 \\
(0.0000262)\end{array}$ \\
\hline $\begin{array}{l}0.00000303 \\
(0.0000359)\end{array}$ & $\begin{array}{c}0.0000105 \\
(0.0000315)\end{array}$ & $\begin{array}{l}-0.0000199 \\
(0.0000613)\end{array}$ \\
\hline $\begin{array}{l}-0.0000718 \\
(0.0000461)\end{array}$ & $\begin{array}{r}-0.00000903 \\
(0.0000118)\end{array}$ & $\begin{array}{r}-0.00000963 \\
(0.0000140)\end{array}$ \\
\hline $\begin{array}{l}0.00000453 \\
(0.0000324)\end{array}$ & $\begin{array}{l}-0.0000451 \\
(0.0000324)\end{array}$ & $\begin{array}{c}0.0000213 \\
(0.0000146)\end{array}$ \\
\hline $\begin{array}{l}-0.0000435 \\
(0.0000340)\end{array}$ & $\begin{array}{c}0.0000359 \\
(0.0000348)\end{array}$ & $\begin{array}{c}0.0000578 \\
(0.0000364)\end{array}$ \\
\hline $\begin{array}{l}-0.0000219 \\
(0.0000275)\end{array}$ & $\begin{array}{l}-0.0000463 \\
(0.0000276)\end{array}$ & $\begin{array}{l}-0.0000286 \\
(0.0000275)\end{array}$ \\
\hline $\begin{array}{l}0.00000709 \\
(0.0000233)\end{array}$ & $\begin{array}{r}-0.00000986 \\
(0.0000258)\end{array}$ & $\begin{array}{l}-0.0000195 \\
(0.0000274)\end{array}$ \\
\hline $\begin{array}{c}0.0000496^{*} \\
(0.0000194)\end{array}$ & $\begin{array}{l}-0.000102^{* *} \\
(0.0000390)\end{array}$ & $\begin{array}{l}-0.0000531 \\
(0.0000346)\end{array}$ \\
\hline-0.0000130 & $-0.0000452^{*}$ & $-0.0000616^{* *}$ \\
\hline
\end{tabular}




\begin{tabular}{lc|c|c} 
& $(0.0000176)$ & $(0.0000198)$ & $(0.0000191)$ \\
Accommodation \& Food Services & & & \\
& 0.00000196 & -0.0000187 & 0.00000604 \\
& $(0.0000392)$ & $(0.0000360)$ & $(0.0000367)$ \\
Other Services (except Public Admin.) & -0.0000423 & 0.00000143 & 0.0000205 \\
& $(0.0000521)$ & $(0.0000414)$ & $(0.0000325)$ \\
\hline Observations & 44559 & 38592 & 33370 \\
\hline Individual Characteristics & $\mathrm{Y}$ & $\mathrm{Y}$ & $\mathrm{Y}$ \\
Industry of Employment & $\mathrm{Y}$ & $\mathrm{Y}$ & $\mathrm{Y}$ \\
Notes: The omitted industry is Public Administration. & & \\
Standard errors in parentheses. ${ }^{*} p<0.05,{ }^{* *} p<0.01,{ }^{* *} p<0.001$ & & \\
\hline
\end{tabular}

\subsection{Conclusion}

Much of the previous research associated with drug overdose deaths, and opioid overdose deaths in particular, has been conducted at the aggregate level, utilizing datasets such as the Compressed Mortality Files provided by the National Center for Health Statistics. The wide body of literature concerning this public health crisis has established the importance of identifying and examining the local and individual-level characteristics among those affected by this public health crisis. However, this paper represents the first analysis conducted utilizing non-aggregated, individuallevel death certificate data combined with more local area employment data to identify the individual and local factors contributing to opioid overdose deaths in the state of West Virginia.

As part of our analysis we provide a detailed examination of the industry employment characteristics for each individual in our sample. Our main findings suggest that employment in specific industries in West Virginia - such as coal mining, construction, and restaurant and food services - are associated with greater probability of dying from an opioid overdose. Further, we examine specific sectors of the medical industry-where the potential for opioid diversion is higher--and present results suggesting an increased risk of opioid overdose deaths for individuals working in outpatient care centers, home health care and hospitals.

Additionally, we examine the impact of changes in local employment trends--both in terms of overall employment and in industry-specific employment—on opioid overdose deaths across zip codes. We expand upon this employment analysis by including a spatial component to our analysis that allows us to identify whether or not local employment changes generate spillover effects that 
affect the surrounding areas. One interesting takeaway from this portion of our analysis is that employment growth in the mining, oil, and gas industry is not associated with an increased risk of opioid overdose deaths in the immediate locale or the larger surrounding area, contradicting the perception that opioids and the expansion (or contraction) of energy-related sectors in West Virginia are invariably linked.

Our analysis also highlights the apparent ease with which individuals are able to substitute away from legal prescription opioids towards illicit variations such as heroin and fentanyl, and the tragedy that occurs as a result. Policy makers, while working energetically to reduce the number of opioid related overdose deaths, should ensure that they consider this trade-off when they are crafting policy aimed at curtailing legal opioid prescriptions. ${ }^{60}$ In this respect, Prescription Drug Monitoring Programs may aid in reducing access to prescription opioids but, as a consequence, may drive individuals to more dangerous, illicit substances.

Sadly, there remains no magic pill capable of curing the opioid epidemic. A multipronged approach is necessary, one that includes strengthening partnerships between local, state and federal agencies. Education campaigns, perhaps targeting high-risk industries or occupations may be beneficial. Revising or reinforcing the policies governing the chain of custody of medications subject to high rates of diversion within the medical field may also be warranted. Whatever approach is pursued by policy makers, the collection and dissemination of timely, high-quality data will enable researchers to better understand the many different aspects of this ongoing public health crisis.

\footnotetext{
${ }^{60}$ That said, obvious cases of reckless prescription writing do exist. See Dr. Katherine Hoover of West Virginia who wrote more than 335,000 prescriptions from 2002 to 2010 , a rate of approximately 130 per day.
} 


\section{Appendix}

\begin{tabular}{|c|c|c|c|c|}
\hline \multicolumn{5}{|c|}{$\begin{array}{l}\text { Table A1: Summary Statistics - Basic Individu } \\
\text { Panel A - Male Opioid Overdose Deaths Only }\end{array}$} \\
\hline Variable & Mean & Std. Dev. & Min & Max \\
\hline Age & 40.3 & 11.26118 & 16 & 88 \\
\hline White & $96.8 \%$ & .1757259 & 0 & 1 \\
\hline Married & $26.9 \%$ & .4439933 & 0 & 1 \\
\hline HS Graduate & $74.2 \%$ & .4378745 & 0 & 1 \\
\hline College Graduate & $6.2 \%$ & .2408769 & 0 & 1 \\
\hline WV Born & $70.3 \%$ & .4568757 & 0 & 1 \\
\hline Observations & 4,108 & & & \\
\hline \multicolumn{5}{|c|}{ Panel B - Female Opioid Overdose Deaths Only } \\
\hline Variable & Mean & Std. Dev. & Min & Max \\
\hline Age & 41.9 & 11.54394 & 16 & 89 \\
\hline White & $97.7 \%$ & .1490659 & 0 & 1 \\
\hline Married & $36.3 \%$ & .4808993 & 0 & 1 \\
\hline HS Graduate & $74.3 \%$ & .4371492 & 0 & 1 \\
\hline College Graduate & $7.9 \%$ & .2709945 & 0 & 1 \\
\hline WV Born & $66.9 \%$ & .4703948 & 0 & 1 \\
\hline Observations & 2,244 & & & \\
\hline
\end{tabular}

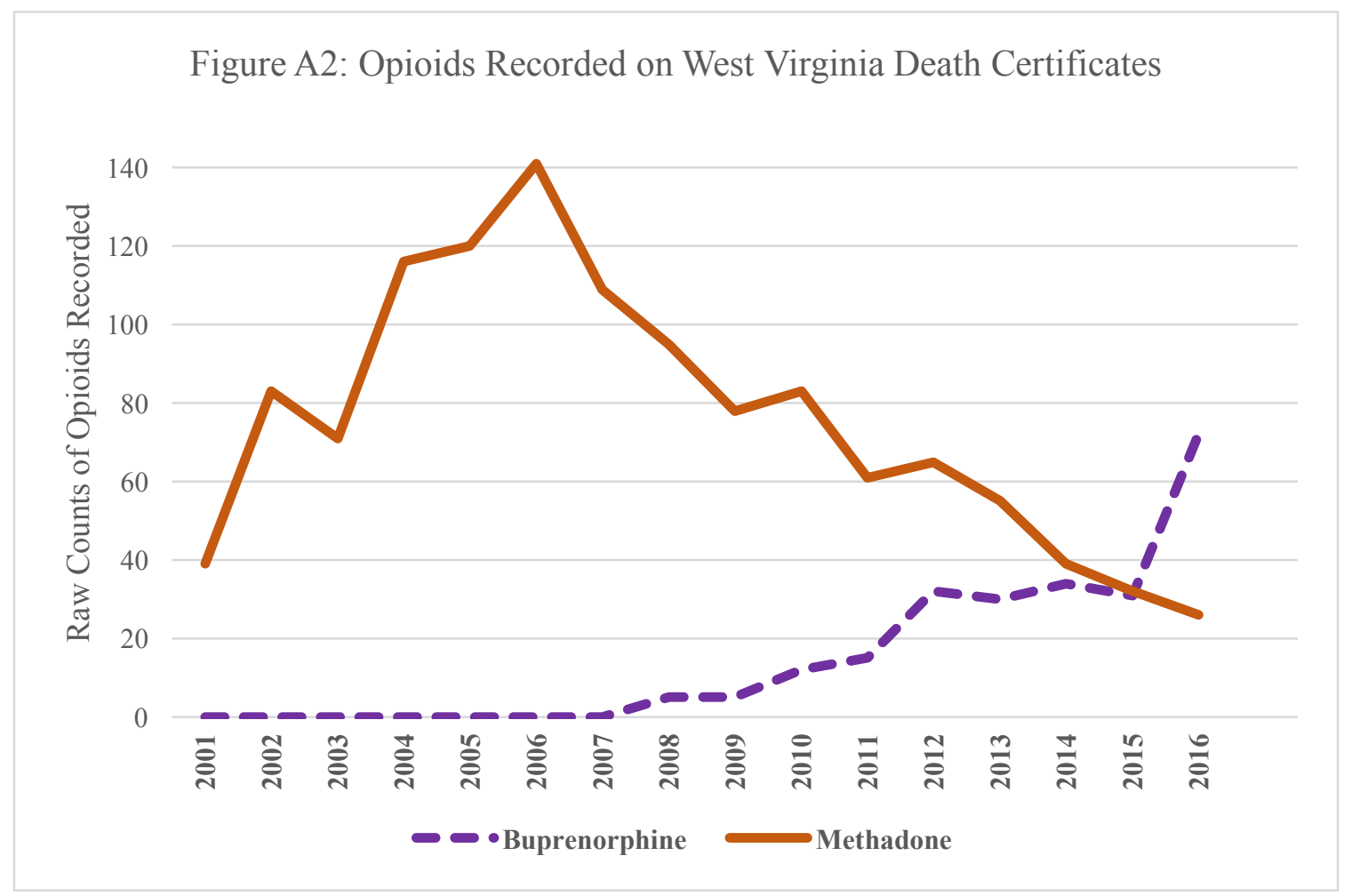




\section{References}

Ailes, E., Dawson, A. Lind, J., et al. 2015. Opioid prescription claims among women of reproductive age--United States, 2008-2012. Morb Mortal Wkly Rep. 64(2), 37-41.

Alesina, A., Baqir, R. and Hoxby, C. 2004. Political Jurisdictions in Heterogeneous Communities. Journal of Political Economy 112, 348-396.

Andreyeva T., Luedicke J., Wang YC. 2014. State-level estimates of obesity-attributable costs of absenteeism. Journal of Occupational and Environmental Medicine 56, 1120-7.

Asay, G. R. B., Roy, K., Lang, J. E., Payne, R. L., \& Howard, D. H. 2016. Absenteeism and Employer Costs Associated With Chronic Diseases and Health Risk Factors in the US Workforce. Preventing Chronic Disease, 13, 141.

Banzhaf, H. and Bhalla, G. 2012. Do Households Prefer Small School Districts? A Natural Experiment. Southern Economic Journal 78, 819-841.

Baum, C. L., Ruhm, C. J. 2009. Age, socioeconomic status and obesity growth. Journal of Health Economics, 28, 3, 635.

Betz, M., and Jones, L. 2018. Wage and Employment Growth in America's Drug Epidemic: Is All Growth Created Equal? Amer. J. Agr. Econ 100(5), 1357-1374.

Billings, S. and Thibodeau, T. 2011. Intrametropolitan Decentralization: Is Government Structure Capitalized in Residential Property Values? Journal of Real Estate Finance and Economics 42, 416-450.

Blackwell, M., Iacus, S., King, G., and Porro, G. 2009. Cem: Coarsened exact matching in Stata. The Stata Journal 9, 524-546. 
Blundell, R., and Dias, M. 2009. Alternative Approaches to Evaluation in Empirical Microeconomics. Journal of Human Resources 44, 565-640.

Brasington, D. 2001. Capitalization and Community Size. Journal of Urban Economics 50, 385-395.

Bush, D. and Lipari, N. 2015. Substance Use and Substance Use Disorder by Industry. Center for Behavioral Health Statistics and Quality, U.S. Department of Health and Human Services. April 16 Report.

Case, A., and Deaton, A. 2015. Rising Morbidity and Mortality in Midlife among White NonHispanic Americans in the 21st Century. Proceedings of the National Academy of Sciences 112 (49): 15078-83.

Case, A., Darren, L., \& Paxson, C. 2002. Economic status and health in childhood: the origin of the gradient. American Economic Review 92, 1308-1334.

Cavaco, S., Eiksson, T., \& Skalli, A. 2014 Life cycle development of obesity and its determinants in six European countries. Economics and Human Biology. Volume 14, 62-78.

Cawley J., Rizzo J.A., \& Haas, K. 2007. Occupation-specific absenteeism costs associated with obesity and morbid obesity. Journal of Occupational and Environmental Medicine, 49, 1317 24.

Cawley J., Rizzo J.A., \& Haas, K. 2008. The association of diabetes with job absenteeism costs among obese and morbidly obese workers. Journal of Occupational and Environmental Medicine, 50, 527-34.

Cawley, J., 2004. The Impact of Obesity on Wages. Journal of Human Resources, Vol. 39 Issue 2, 451-474. 
Currie, A., \& Shields, M. A. 2007. The child health/family income gradient: Evidence from England. Journal of Health Economics, 26, 2, 213.

Cutler, D., \& Lleras-Muney, A. 2010. Understanding differences in health behaviors by education. Journal of Health Economics 29, 1-28.

Cutler, D., Elmendorf, D. and Zeckhauser, R. 1999. Restraining the Leviathan: property tax limitation in Massachusetts. Journal of Public Economics, 71, 313-334.

Cutler, D., Glaeser, E., Shapiro, J. 2003. Why Have Americans Become More Obese? The Journal of Economic Perspectives, 17(3), 93-118.

Cutler, D., Lleras-Muney, A., \& Vogl, T. 2008. Socioeconomic Status and Health: Dimensions and Mechanisms. National Bureau of Economic Research Working Paper.

Dart, R., Surratt, H., Cicero, T., Parrino, M., Severtson, S., Bucher-Bartelson, B., and Green, J. 2015. Trends in opioid analgesic abuse and mortality in the United States. The New England Journal of Medicine 372 (3), 241-248.

Evans, M., Labuda, S., Hogan, V., et al. 2017. Notes from the Field: HIV Infection Investigation in a Rural Area - West Virginia. MMWR Morb Mortal Wkly Rep 2018. 67, $257-258$.

Ferreira, F. 2010. You Can Take It With You: Proposition 13 Tax Benefits, Residential Mobility, and Willingness to Pay for Housing Amenities. Journal of Public Economics 94, $661-73$.

Filer, J. and Kenny, L. 1980. Voter reaction to city-county consolidation referenda. Journal of Law and Economics 23, 179-190. 
Gladden, R.M., Martinez, P. and Seth P. 2016. Fentanyl Law Enforcement Submissions and Increases in Synthetic Opioid-Involved Overdose Deaths - 27 States, 2013-2014. MMWR Morb Mortal Wkly Rep. 65, 837-843. DOI: http://dx.doi.org/10.15585/mmwr.

Goettler, A., Grosse, A., \& Sonntag, D. 2017. Productivity loss due to overweight and obesity: a systematic review of indirect costs. BMJ Open 7.

Goetz, J. and Davlasheridze, M. 2018. Explaining Spatial Disparities in Drug Overdoses, 19702014. Working Paper presented at the 2018 ASSA Annual Meeting.

Goetz, J., Davlasheridze, M., and Han, Y. 2015. County-Level Determinants of Mental Health, 2002-2008. Social Indicators Research 124 (2), 657-670.

Goldin, C., Katz, L. and Kuziemko, I. 2006. The Homecoming of American College Women: The Reversal of the College Gender Gap. Journal of Economic Perspectives, 20 (4): 133-156.

Guettabi, M., \& Munasib, A. 2015. The Impact of Obesity on Consumer Bankruptcy. Economics and Human Biology. Volume 17, 208-224.

Havens, J., Oser, C., Leukefeld, C., Webster, J., Martin, S., O'Connell, D., et al. 2007. Differences in prevalence of prescription opiate misuse among rural and urban probationers. The American Journal of Drug and Alcohol Abuse 33(2), 309-317.

Heinz, A. J., Wu, J., Witkiewitz, K., Epstein, D. H., and Preston, K. L. 2009. Marriage and relationship closeness as predictors of cocaine and heroin use. Addictive Behaviors, 34(3), $258-263$.

Ho, D., Imai, K., King, G., and Stuart, E. 2007. Matching as nonparametric preprocessing for reducing model dependence in parametric causal inference. Political Analysis, 15, 199-236. 
Hoyt, W. 1999. Leviathan, local government expenditures, and capitalization. Regional Science and Urban Economics 29, 155-171.

Hughey, M., Kaczynski, A., Child, S., Moore, J., Porter, D., Hibbert, J. 2017. Green and lean: Is neighborhood park and playground availability associated with youth obesity? Variations by gender, socioeconomic status, and race/ethnicity. Preventive Medicine, Volume 95.

Iacus, S., King, G., and Porro, G. 2011. Multivariate matching methods that are monotonic imbalance bounding. Journal of the American Statistical Association 493, 345-361.

Iacus, S., King, G., and Porro, G. 2012. Causal Inference without Balance Checking: Coarsened Exact Matching. Political Analysis 20, 1-24.

Inciardi, J. A., Surratt, H. L., Lugo, Y., \& Cicero, T. J. 2007. The Diversion of Prescription Opioid Analgesics. Law Enforcement Executive Forum. 7(7),127-141.

Isserman, A. 2005. In the National Interest: Defining Rural and Urban Correctly in Research and Public Policy. International Regional Science Review, 25 (4), 465-499.

Jonas, W. and Schoomaker, E. 2014. Pain and Opioids in the Military: We Must Do Better. JAMA Intern Med. 2014, 174(8), 1402-1403. DOI: 10.1001/jamainternmed.2014.2114

Kenny, L. and Reinke, A. 2011. The role of income in the formation of new cities. Public Choice 149, 75-88.

Kinge, J., \& Morris, S. 2014. Variation in the relationship between BMI and survival by socioeconomic status in Great Britain. Economics \& Human Biology. Volume 12, 67-82.

Klaiber, H., and Phaneuf, D. 2010. Valuing open space in a residential sorting model of the twin cities. Journal of Environmental Economics and Management, 60, 57-77. 
Kneeshaw-Price, S., Saelens, B., Sallis, J. et al. 2015. Neighborhood Crime-Related Safety and Its Relation to Children's Physical Activity. Journal of Urban Health, Vol. 92, Issue 3, 472489.

Kuehn, B. 2014. Driven by prescription drug abuse, heroin use increases among suburban and rural whites. Journal of the American Medical Association 312 (2), 118-119.

Leon-Moreta, A. 2015. Municipal incorporation in the United States. Urban Studies 52, 31603180.

Ludwig, J., Sanbonmatsu, L., Gennetian, L., Adam, E., Duncan, G., Katz, L., Kessler, R., Kling, J., Lindau, S., Whitaker, R., \& McDade, T. 2011. Neighborhoods, Obesity, and Diabetes: A Randomized Social Experiment. New England Journal of Medicine 365, 15091519.

Marmot, M., Smith, G.D., Stansfeld, S., Patel, C., North, F., Head, J., White, I., Brunner, E., \& Feeny, A. 1991. Health inequalities among British civil servants: The Whitehall II Study. Lancet 337, 1387-1393.

McHugh, R., Devito, E., Dodd, D., et al. 2013. Gender differences in a clinical trial for prescription opioid dependence. J Subst Abuse Treat. 45(1): 38-43.

Meltzer, R. and Cheung, R. 2014. How are homeowner's associations capitalized into property values? Regional Science and Urban Economics 48, 93-102.

Meyer, O., Castro-Schilo, L., \& Aguilar-Gaxiola, S. 2014. Determinants of mental health and self-rated health: A model of socioeconomic status, neighborhood safety, and physical activity. American Journal of Public Health, 104(9), 1734-41.

Mokdad, A., Bowman, B., Ford, E., Vinicor, F., Marks, J., \& Koplan J. 2001. The Continuing Epidemics of Obesity and Diabetes in the United States. JAMA. 286(10), 1195-1200. 
Monnat, S. and Rigg, K. 2014. Urban vs. rural differences in prescription opioid misuse among adults in the United States: Informing region specific drug policies and interventions. International Journal of Drug Policy 26, 484-491.

Monnat, S. and Rigg, K. 2015. Comparing Characteristics of Prescription Painkiller Misusers and Heroin Users in the United States. Addictive Behaviors (51), 106-112.

Monnat, S. and Rigg, K. 2016. Examining Rural/Urban Differences in Prescription Opioid Misuse Among US Adolescents. The Journal of Rural Health 32 (2), 204-218.

Musso, J. 2001. The political economy of city formation in California: Limits to Tiebout sorting. Social Science Quarterly 82, 139-153.

O’Donnell, J., Gladden, R.M., Mattson, C.L. and Kariisa, M. 2018. Notes from the Field: Overdose Deaths with Carfentanil and Other Fentanyl Analogs Detected - 10 States, July 2016-June 2017. Morbidity and Mortality Weekly Report, 67 (27), 767-768.

O'Sullivan, A., Sexton, T. and Sheffrin, S. 1995. Property taxes and tax revolts: The legacy of Proposition 13. Cambridge University Press.

Ogden, Cynthia L., Lamb, Molly M., Carroll, Margaret D., \& Flegal, Katherine M. 2010. Obesity and Socioeconomic Status in Adults: United States, 2005-2008. National Center for Health Statistics Data Brief.

Patrick, C. and Mothorpe, C. 2017. Demand for new cities: Property value capitalization of municipal incorporation. Regional Science and Urban Economics 67, 78-89.

Powell-Wiley, T. M., Cooper-McCann, R., Ayers, C., Berrigan, D., Lian, M., Mc-Clurkin, M., Ballard-Barbash, R., Das, S. R., Hoehner, C. M., and Leonard, T. 2015. Change in 
Neighborhood Socioeconomic Status and Weight Gain: Dallas Heart Study. American Journal of Preventive Medicine. 49 (1): 72-79.

Rosen, K. 1982. The Impact of Proposition 13 on House Prices in Northern California: A Test of the Interjurisdictional Capitalization Hypothesis. Journal of Political Economy 90, 191-200.

Rosenblum, A., Parrino, M., Schnoll, S., Fong, C., Maxwell, C., Cleland, C., et al. 2007. Prescription opioid abuse among enrollees into methadone maintenance treatment. Drug and Alcohol Dependence 90 (1), 64-71.

Ruhm, C. 2016. Taking the Measure of a Fatal Drug Epidemic. NBER Working Paper No. 22504.

Scholl, L., Seth, P., Kariisa, M., Wilson, N. and Baldwin, G. 2019. Drug and Opioid-Involved Overdose Deaths — United States, 2013-2017. Morb Mortal Wkly Rep. 67, 1419-1427.

Simmonds, M., Llewellyn, A., Owen, C., and Woolacott, N. 2015. Predicting adult obesity from childhood obesity: a systematic review and meta-analysis. Obesity Reviews, 17(2), 95107.

Spiller, H., Lorenz, D, Bailey, E., and Dart, C. 2009. Epidemiological trends in abuse and misuse of prescription opioids. Journal of Addictive Diseases 28 (2), 130-136.

Tiebout, C. 1956. A Pure Theory of Local Expenditures. Journal of Political Economy 64, 416424.

Van den Berg, G., Lindeboom, M., \& Portrait, F. 2006. Economic Conditions Early in Life and Individual Mortality. The American Economic Review, 96(1), 290-302. 
Wang, K., Becker, W., and Fiellin, D. 2013. Prevalence and correlates for nonmedical use of prescription opioids among urban and rural residents. Drug and Alcohol Dependence 127(1), $156-162$.

Wasi, N., White, M., Sheffrin S. and Ferreira, F. 2005. Property Tax Limitations and Mobility: Lock-In Effect of California's Proposition 13. Brookings-Wharton Papers on Urban Affairs, $59-97$.

Whitaker, R.C., Wright, J.A., Pepe, M.S., Seidel, K.D., \& Dietz, W.H. 1997. Predicting obesity in young adulthood from childhood and parental obesity. New England Journal of Medicine $337,869-873$.

Young, A., Havens, J., and Leukefeld, C. 2012. A comparison of rural and urban nonmedical prescription opioid users' lifetime and recent drug use. The American Journal of Drug and Alcohol Abuse 38(3), 220-227. 